University of South Florida

DIGITAL COMMONS

Digital Commons @ University of

@ UNIVERSITY OF SOUTH FLORIDA

South Florida

4-8-2005

\title{
Biomechanical Evaluation of Injury Severity Associated with Patient Falls from Bed
}

Bonnie E. Bowers

University of South Florida

Follow this and additional works at: https://digitalcommons.usf.edu/etd

Part of the American Studies Commons

\section{Scholar Commons Citation}

Bowers, Bonnie E., "Biomechanical Evaluation of Injury Severity Associated with Patient Falls from Bed" (2005). USF Tampa Graduate Theses and Dissertations.

https://digitalcommons.usf.edu/etd/2788

This Thesis is brought to you for free and open access by the USF Graduate Theses and Dissertations at Digital Commons @ University of South Florida. It has been accepted for inclusion in USF Tampa Graduate Theses and Dissertations by an authorized administrator of Digital Commons @ University of South Florida. For more information, please contact digitalcommons@usf.edu. 
Biomechanical Evaluation of Injury Severity Associated with Patient Falls from Bed

by

Bonnie E. Bowers

A thesis submitted in partial fulfillment
Of the requirements for the degree of
Master of Science in Biomedical Engineering
Department of Chemical Engineering
College of Engineering
University of South Florida

Co-Major Professor: William Lee, Ph.D.

Co-Major Professor: John Lloyd, Ph.D.

Andrea Baptiste, MA

Gail Powell-Cope, Ph.D.

Date of Approval:

April 8, 2005

Keywords: height, floor mats, bedrails, elderly, acceleration

C Copyright 2005, Bonnie E. Bowers 


\section{Table of Contents}

List of Tables $\quad$ iii

List of Figures $\quad$ V

Abstract vii

Clinical Observations 1

Introduction 1

Mechanical behavior of physiological tissues 1

Incidence of falls and associated injuries in the elderly population 6

$\begin{array}{ll}\text { Incidence of falls from bed and associated injuries } & 7\end{array}$

Risk factors and biomechanical issues associated with falls 9

Intrinsic factors $\quad 9$

Extrinsic factors $\quad 15$

Environmental hazards 15

Impact surface $\quad 17$

$\begin{array}{ll}\text { Gaps in the research } & 18\end{array}$

Injury Prevention $\quad 20$

Introduction $\quad 20$

$\begin{array}{ll}\text { Bedrails and legal issues } & 20\end{array}$

$\begin{array}{ll}\text { Bedrails and adverse events } & 21\end{array}$

$\begin{array}{ll}\text { Bedrails and reduction programs } & 22\end{array}$

$\begin{array}{ll}\text { Bedrail alternatives } & 23\end{array}$

Height adjustable beds $\quad 24$

Gaps in the research $\quad 25$

Injury Assessment $\quad 26$

Introduction $\quad 26$

Head injury criteria $\quad 26$

Gaps in the research $\quad 29$

Significance of Current Research $\quad 30$

Introduction $\quad 30$

Quantifying the mechanics of falling from bed 30

Comparing injury prevention methods $\quad 31$

Assessing injury during a fall from bed $\quad 31$ 
Methodology $\quad 32$

Location $\quad 32$

Apparatus design and construction $\quad 32$

$\begin{array}{ll}\text { Protocol } & 38\end{array}$

Results $\quad 40$

Head first falls $\quad 40$

Acceleration measured at the head $\quad 40$

Acceleration measured at the thorax 45

Acceleration measured at the pelvis $\quad 49$

Feet first falls $\quad 53$

Acceleration measured at the head $\quad 54$

Acceleration measured at the thorax $\quad 58$

$\begin{array}{ll}\text { Acceleration measured at the pelvis } & 62\end{array}$

Discussion and Interpretation $\quad 70$

$\begin{array}{ll}\text { Introduction } & 70\end{array}$

$\begin{array}{ll}\text { Head first falls } & 70\end{array}$

Feet first falls $\quad 73$

$\begin{array}{ll}\text { General observations } & 76\end{array}$

$\begin{array}{ll}\text { Conclusions and Recommendations } & 77\end{array}$

$\begin{array}{lr}\text { References } & 80\end{array}$

Appendices $\quad 85$

Appendix A: MatLab Code $\quad 86$

Appendix B: Protocol $\quad 94$

Appendix C: SAS $^{\circledR}$ Code $\quad 95$ 


\section{List of Tables}

Table 1: $\quad$ Instrinsic factors associated with falling. $\quad 13$

$\begin{array}{lll}\text { Table 2: } & \text { Extrinsic factors associated with falling. } & 17\end{array}$

Table 3: $\quad$ HIC (15 msec) NHTSA standards. 29

Table 4: $\quad$ Head mean impact decelerations measured with and without a mat during head first falls and calculated values based on trend line equations.

Table 5: $\quad$ Mean HIC values calculated for head deceleration profiles measured during trials with and without a mat during head first falls.

Table 6: $\quad$ Impact forces calculated at the head for head first falls with and without a floor mat.

Table 7: $\quad$ Thoracic mean impact decelerations measured with and without a mat during head first falls and calculated values based on trend line equations.

Table 8: $\quad$ Mean TIC values calculated for thoracic deceleration profiles measured during trials with and without a mat during head first falls.

Table 9: $\quad$ Pelvic mean impact decelerations measured with and without a mat during head first falls and calculated values based on trend line equations.

Table 10: $\quad$ Mean PIC values calculated for pelvic deceleration profiles measured during trials with and without a mat during head first falls.

Table 11: Head mean impact decelerations measured with and without a mat during feet first falls and calculated values based on trend line equations.

Table 12: $\quad$ Mean HIC values calculated for head deceleration profiles measured during trials with and without a mat during feet first falls. 
Table 13: $\quad$ Thoracic mean impact decelerations measured with and without a mat during feet first falls and calculated values based on trend line equations.

Table 14: $\quad$ Mean TIC values calculated for thoracic deceleration profiles measured during trials with and without a mat during feet first falls.

Table 15: $\quad$ Pelvic mean impact decelerations measured with and without a mat during feet first falls and calculated values based on trend line equations.

Table 16: $\quad$ Mean PIC values calculated for pelvic deceleration profiles measured during trials with and without a mat during feet first falls.

Table 17: $\quad$ Impact forces calculated at the pelvis for feet first falls with and without a floor mat.

Table 18: $\quad$ Summary of measured mean maximum values and calculated injury criteria. 


\section{List of Figures}

Figure 1: $\quad$ Compact and spongy bone organization. 3

Figure 2: $\quad$ Compact (cortical) and spongy (trabecular) bone stress versus strain curves.

Figure 3: $\quad$ Viscoelastic response of compact bone. 6

Figure 4: $\quad$ Anisotropic response of compact bone. $\quad 6$

Figure 5: $\quad$ Bone mass association with age and gender. $\quad 10$

Figure 6: $\quad$ Wayne State Tolerance Curve. 27

Figure 7: $\quad$ Risk of life-threatening brain injury related to HIC values. 28

Figure 8: $\quad 50^{\text {th }}$ percentile male anthropomorphic test dummy with and without scrubs. 33

Figure 9: $\quad$ Carroll Healthcare ARRO Low Bed used to simulate common heights from which patients fall.

Figure 10: $\quad$ Posey floor mat used to simulate mats commonly used in the healthcare environment to cushion falls. 35

Figure 11: $\quad$ Sling designed to standardize the fall from bed event simulation. 36

Figure 12: Tri-axial accelerometer aluminum mounting blocks for the head, thorax, and pelvis.

Figure 13: Head mean impact decelerations plotted with an estimated trend line during head first falls.

Figure 14: $\quad$ HIC values plotted with an estimated trend line during head first falls. 44

Figure 15: Impact forces plotted with an estimated trend line during head first falls. 45

Figure 16: Thoracic mean impact decelerations plotted with an estimated trend line during head first falls. 
Figure 17: TIC values plotted with an estimated trend line during head first falls. 49

Figure 18: Pelvic mean impact decelerations plotted with an estimated trend line during head first falls.

Figure 19: $\quad$ PIC values plotted with an estimated trend line during head first falls. 53

Figure 20: Head mean impact decelerations plotted with an estimated trend line during feet first falls.

Figure 21: $\quad$ HIC values plotted with an estimated trend line during feet first falls. $\quad 58$

Figure 22: Thoracic mean impact decelerations plotted with an estimated trend line during feet first falls.

Figure 23: TIC values plotted with an estimated trend line during feet first falls. $\quad 62$

Figure 24: Pelvic mean impact decelerations plotted with an estimated trend line during feet first falls.

Figure 25: $\quad$ PIC values plotted with an estimated trend line during feet first falls. $\quad 66$

Figure 26: Impact forces plotted with an estimated trend line during feet first falls. 67 


\title{
Biomechanical Evaluation of Injury Severity Associated with Patient Falls from Bed
}

Bonnie Bowers

\begin{abstract}
The incidence of falls in the elderly population is a growing concern in the healthcare industry as associated morbidity is high, particularly morbidity associated with falls from bed. Bedrails were implemented as a device intended to reduce the incidence of falls from bed; however, recent evidence may indicate that bedrails contribute to adverse events including entrapment and entanglement. As such, efforts have been made to reduce the use of bedrails and implement alternatives including height adjustable beds and floor mats. An instrumented anthropomorphic test dummy was used in the current study to measure the deceleration profiles of the head, thorax, and pelvis upon impact onto a tile surface or floor mat. The height of the fall was varied by using a height adjustable bed, and the impact site was varied by head or feet first falls. The deceleration profiles were used to determine mean maximum values across repeated trials and to calculate injury criteria at the head (HIC), thorax (TIC), and pelvis (PIC). The mean maximum values were further used to estimate the effect of adding bedrails. Injury severity was then predicted from the injury criteria calculated for the head.
\end{abstract}

From this study, the mean maximum values were found to significantly increase with an increase in height regardless of fall direction. As such, the addition of bedrails consequently increased these values. Furthermore, the use of a floor mat significantly reduced the mean maximum values at the head and pelvis during head first falls and at vii 
the head and thorax during feet first falls. Injury criteria were also calculated for each body region and found to be significantly increased with an increase in height and decreased with the use of the floor mat. The HIC values were used to predict injury severity and resulted in nearly a 40 percent chance of sustaining a serious brain injury under any condition tested during this study. Based on these results, the recommendation was made to position hospital beds to the lowest available position, place floor mats by the bedside, and remove bedrails to decrease the risk of injury as a result of falling from bed. 


\section{Clinical Observations}

\section{Introduction}

The human body is a complex organism that responds with unique characteristics to applied forces. As such, the human body has certain limitations, and exceeding those limitations may result in injury. For example, as observed in the literature, injury may occurs as a result of over-exertion due to falling. As described by Tinetti, Speechley, and Ginter (1988), a fall occurs when a person "unintentionally [comes] to rest on the ground or at some other lower level, not as a result of a major intrinsic event or overwhelming hazard." Much research has focused on the elderly population to identify associated injuries and risk factors because falling is a common occurrence among this population. Lacerations, contusions, fractures, and head injuries are associated with falling, in general, and, specifically, falling from bed (Lyons and Oates, 1993; Macgregor, 2000). Risk factors associated with falling are categorized as intrinsic or extrinsic factors. Common intrinsic factors include age, medication use, and decreased mobility; while extrinsic factors include stairs, poor lighting, and slippery floors (Baum, Capezuti, and Driscoll, 2002). The characteristics of impact surface is an extrinsic factor that has only recently received attention; however, Simpson et al (2004) showed that concrete subfloors increase the risk of hip fractures. This observation may applicable to future designs of healthcare facilities.

\section{Mechanical behavior of physiological tissues}

The mechanical behavior of physiological tissues provides the basis of how the human body responds to applied loads. An injury results when the applied force exceeds the strength of the tissue whether hard or soft tissue, such as bone or muscle. When determining the strength of a physiological tissue, several factors must be considered including the basic anatomical organization of the tissue, and the rate and direction of the 
applied force. The composition, organization, and mechanical behavior of bone will be discussed as an example of these universal principles.

Bone is composed of organic and inorganic substances organized to maximize the forces the tissue is able to endure. Calcium and phosphate minerals embedded in collagen fibers provide rigidity to the bone tissue, while a ground substance interspersed throughout the mineralized collagen matrix provides flexibility and resilience. Water is also a key component in the composition of bone as it surrounds bone cells called osteocytes and binds to glycosaminoglycans found in the ground substance. Two distinct types of bone are present in the human body and are distinguished by their level of matrix organization (Marieb, 2001).

Spongy bone (Figure 1), found predominately in the skull, clavicle, ribs, sternum and the epiphyses of long bones, is characterized by small stints of bone or trabeculae. These trabeculae appear to be randomly arranged; however, they align themselves along lines of stress to provide the most support for the bone matrix. The trabeculae contain lamellae (literally "little plates") and osteocytes connected by canals called canaliculi, which provide nutrients to the bone matrix (Marieb ed, 2001). 


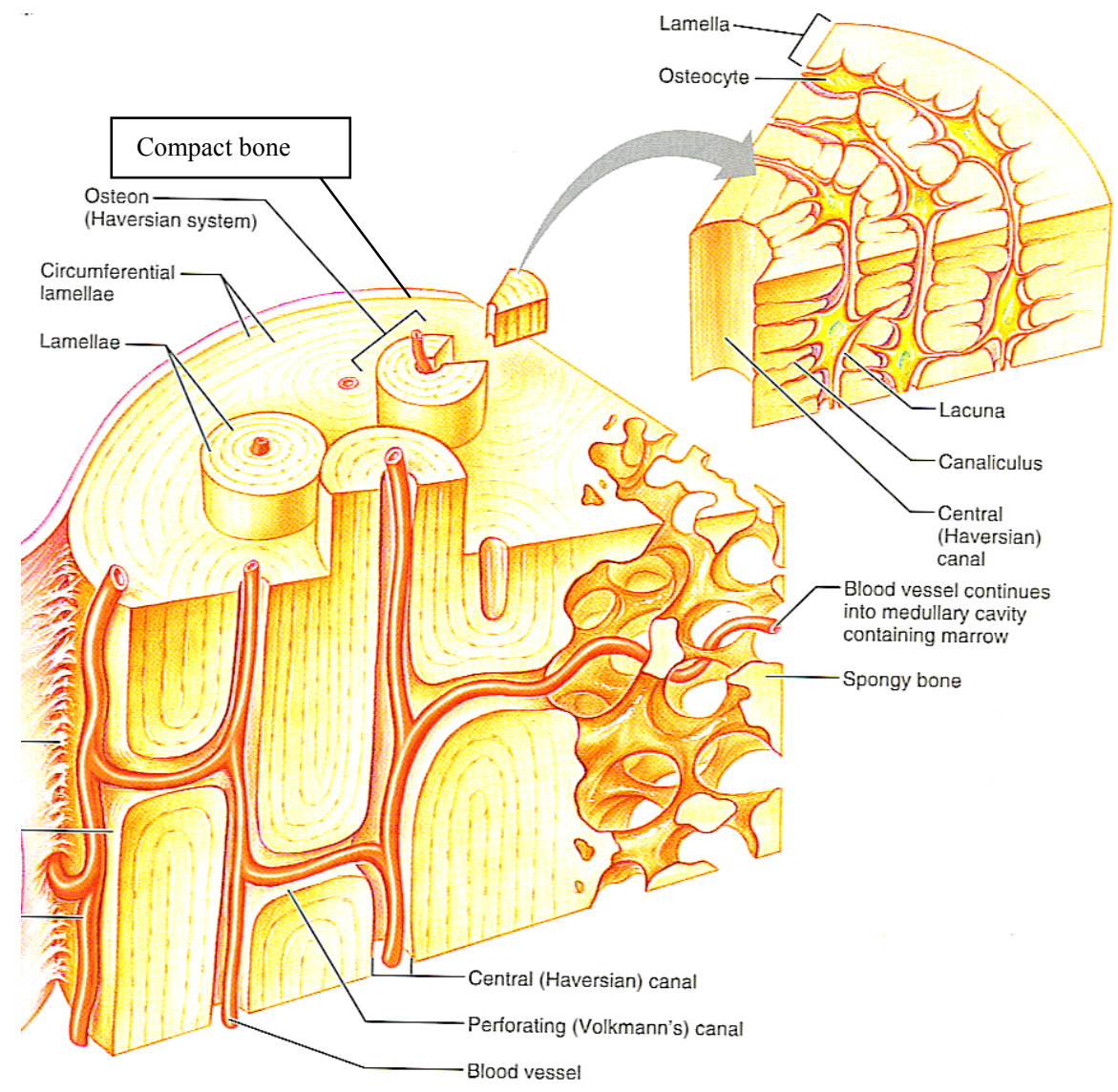

Figure 1: Compact and spongy bone organization. Source: Bone and Skeletal Tissues.

The structure of compact bone (Figure 1), found in vertebrae and long bones, shares some similarities with spongy bone in that they both contain lamellae and canaliculi, but the arrangement of these structures differentiates the two. Compact bone has a much more highly ordered system of structures. The basic structural unit of compact bone is the osteon, an elongated cylinder that is oriented parallel to the long axis of the bone. The lamellae of compact bones are organized into concentric layers to form the osteon; adjacent lamellae run in opposing directions to best withstand torsional stresses. Lamellae are also found between individual osteons and surrounding the entire bone shaft, just deep to the periosteum; these help fill gaps between forming osteons and resist torsion of the entire bone. Nutrients are supplied to compact bone through haversion canals located in the center of each osteon; these canals are connected to the periosteum by Volkmann's canals. The bone cells, osteocytes, are located in small 
cavities within the bone matrix called lacunae, which are connected by canaliculi in a manner similar to spongy bone. Although compact and spongy bone will predominate in various bones, a structurally intact bone cannot exist without each bone type, as both provide resistance to mechanical stresses. The epiphyses of long bones, for example, is composed primarily of spongy bone, but compact bone forms a thin outer shell to increase the overall strength of the bone. Likewise, spongy bone is found in the diaphyses of long bones, although compact bone is the primary tissue. Figure 1 shows this relationship between compact and spongy bone of the diaphysis of the femur. (Marieb, 2001).

Due to the difference in organization of the lamellae, compact and spongy bone display different biomechanical properties when tested under standardized conditions. Compact bone withstands much higher stress than spongy bone with values reported between 100 and $150 \mathrm{~N} / \mathrm{mm}^{2}$ for compact bone and between 8 and $50 \mathrm{~N} / \mathrm{mm}^{2}$ for spongy bone (Nordin and Frankel, 2001). Spongy bone, however, can withstand higher percent deformation than compact bone before failure; values range from 2 to 4 percent elongation for spongy bone as compared to 1 to 2 percent for compact bone (Nordin and Frankel, 2001). Physically, these properties mean that compact bone can support much higher forces per unit of area than spongy bone. On the other hand, spongy bone can store much more energy before fracture occurs. This behavior is due to the varying density of the two types of bone. Compact bone has a higher density than spongy bone; therefore, it has more material to support higher loads. Conversely, spongy bone dissipates more energy effectively through voids between trabeculae. This difference is shown graphically in Figure 2, where the area under the curve represents energy absorbed prior to failure (Nordin and Frankel, 2001). The occurrence of bone fracture can also be correlated to applied force. The force reported in the literature required to fracture a skull ranges from $4930 \mathrm{~N}$ to $5780 \mathrm{~N}$ (Nahum, Gatts, Gadd, and Danforth, 1968); Schneider and Nahum, 1972). Studies have also been conducted to determine the force required to fracture the hip. One such study reported a force of approximately $4340 \mathrm{~N}$ required to fracture a hip when the soft tissue is present (Etheridge, Beason, Lopez, Alonso, McGwin, and Eberhardt, 2005). 


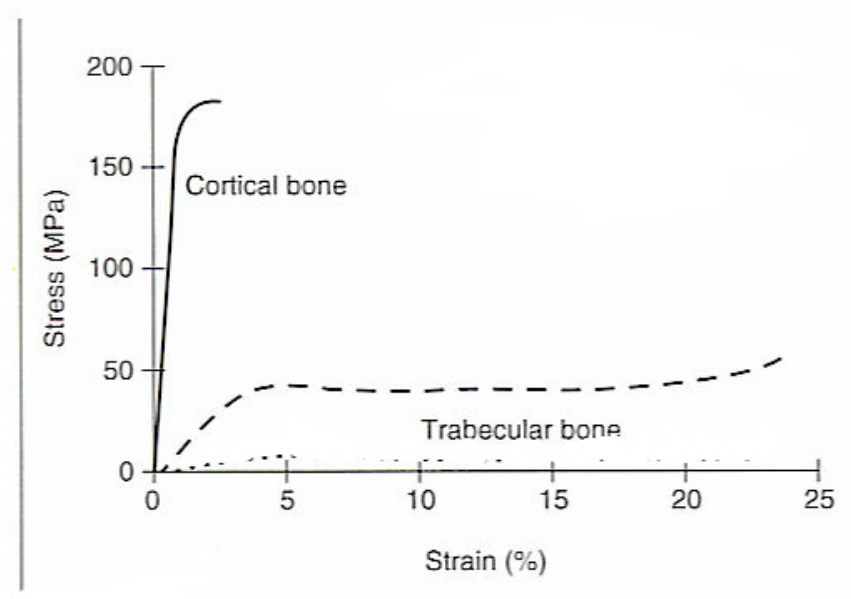

Figure 2: Compact (cortical) and spongy (trabecular) bone stress versus strain curves. Source: Nordin and Frankel, 2001.

These properties, however, are dependent not only on the bone structure but also on the rate and direction of loading as these tissues are viscoelastic and anisotropic, meaning they respond differently to forces applied at different rates and directions, respectively. For compact bone, the amount of stress the tissue is able to endure increases as the rate of impact increases; however, the amount of strain, or deformation per unit area, decreases. This means that compact bone can withstand high levels of stress at high loading rates but only for small amounts of time. Figure 3 graphically illustrates the viscoelastic characteristic of compact bone. The mechanical response of compact bone is also affected by the direction of loading as indicated in Figure 4. As the direction of loading rotates from parallel to perpendicular to the long axis, the amount of stress and strain compact bone can endure decreases. The anisotropic nature of compact bone correlates with the orientation of the osteons, as they are aligned parallel to the long axis of the bone. Likewise, the mechanical response of spongy bone displays a similar dependence upon rate and direction of loading. The viscoelastic and anisotropic characteristics of bone are important when exploring injury mechanisms of fall events (Nordin and Frankel, 2001). 


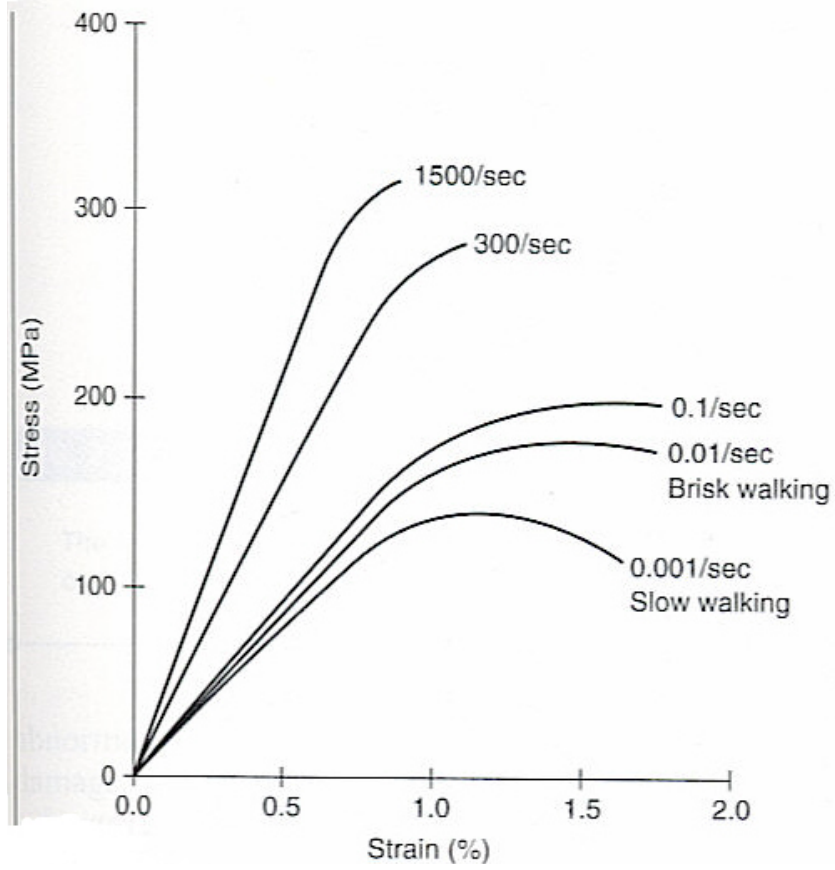

Figure 3: Viscoelastic response of compact bone. Source: Nordin \& Frankel, 2001.

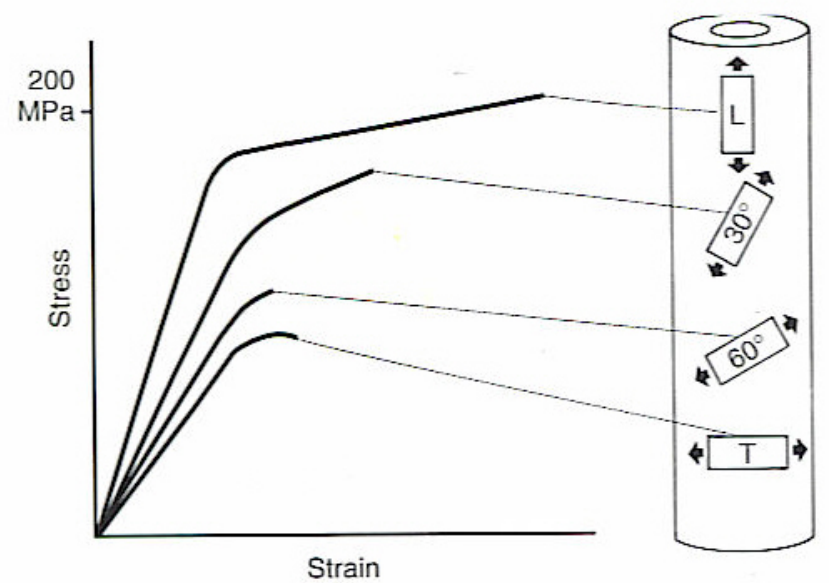

Figure 4: Anisotropic response of compact bone. Source: Nordin and Frankel, 2001.

Incidence of falls and associated injuries in the elderly population

Fall events affect all those living in a community whether directly as the one who falls or indirectly as a caregiver, family member, or friend. Studies of self-reported falls indicate that one in three persons over the age of 65 years living in the community will fall at least once annually (Tinetti, Speechley, and Ginter, 1988; O’Loughlin et al, 1993). Currently, the elderly population includes 12 percent of the total population; however, the 
U.S. Census Bureau (2004) projects this number to increase to 25 percent of the total population by the year 2030 .

Not only is the incidence rate high, but according to Champion et al (1989), falls account for a substantial portion of injuries in all age groups. However, for persons aged 65 years and older, falls account for 40 percent of trauma related injuries as compared to 11 percent in younger age groups. Furthermore, eleven percent of all trauma related injuries caused by falls result in death in those aged over 65 years (Champion et al, 1989). In a two year study conducted by Sattin et al (1990), incidence of injury and outcome were recorded for 2,994 injury events resulting from falls for a study population of 26,826 persons aged 65 years and older. Common fall-related injuries observed included open wounds, dislocations, sprains/strains, contusions, and fractures of the skull, spine, upper and lower limbs, and hips. Sattin et al also noted that women were 1.9-3.1 times more likely to sustain a fracture, other than one of the skull, as men, presumably due to higher rates of osteoporosis in women compared to men. Of these 2,994 injury events, forty-two percent resulted in hospitalization and 2.2 percent resulted in death prior to or during hospital admission. Sterling, O'Connor, and Bonadies (2001) further studied injury rates occurring in persons over 65 years of age as compared to those younger than 65 years and reported an injury rate seven times higher in the older age group. Interestingly, age was also associated with injury to particular anatomical locations. Those aged over 65 years were prone to injuries to the head/neck, chest, or pelvis/extremity regions, while those aged 65 years and younger were prone to abdomen and skin/soft tissue injuries. Sterling, O'Connor, and Bonadies further showed that injuries in the older study group were more severe than those of the younger study group.

\section{Incidence of falls from bed and associated injuries}

Falls from bed is a specific type of fall that became a focus of research as early as 1979, as reflected in a study conducted by Walshe and Rosen (1979). In this study, incidence and demographic data were collected from incidence reports for a one year period accounting for 86,000 patient bed days. During this time period, 53 reports were recorded. Eighty-three percent of those patients who fell from bed were identified as 
being over the age of 65 years, although elderly patients contributed only 22 percent of the total patient population receiving care. Innes and Turman (1983) further showed that 64 out of 270 falls that occurred over an 11-month period were identified as falls from bed. Twenty-four of these falls from bed resulted in injury including fractures, lacerations, and hematomas. In a similar review of incidence reports filed for long-term care facilities, Gurwitz et al (1994) found that 401 falls from bed occurred out of 2,032 total falls reported for the facility during a 12-month period.

Injury associated with falling from bed is not limited to the elderly population as several studies indicate that children also experience such injuries. Lacerations, contusions, fractures, and head trauma are mirrored in the pediatric population (Lyons and Oates, 1993; Macgregor, 2000). However, conflicting incidence of these injuries is reported in the literature with a range as low as 15 percent (Lyons and Oates, 1993) and as high as 52 percent (Macgregor 2000). This wide range of incidence of injury may simply be the result of varying fall environments or may indicate child abuse, as the majority of these falls are not witnessed by individuals other than the caregiver. In response to these conflicting results, Bertocci et al (2003) proceeded to observe the biomechanics of children falling from a bed or couch onto various flooring surfaces by using an instrumented Hybrid II pediatric anthropomorphic test dummy (ATD). Head injury criteria (HIC) for 36 milliseconds (msec) of acceleration was calculated to compare wood, linoleum, carpet, and playground foam flooring surfaces when a fall occurred from a height of 0.68 meters $(\mathrm{m})$. Axial tension, bending, and torsion were also measured in the femur and compared for each surface. Bertocci et al showed that playground foam resulted in 660 percent lower mean HIC values than those calculated for wood. Likewise, playground foam also resulted in the lowest axial tension values when compared to other flooring surfaces. However, Bertocci et al also showed that HIC values for all surfaces were not substantial enough to produce the higher incidence of injury as reported in the literature. 


\section{Risk factors and biomechanical issues associated with falls}

According to Baum, Capezuti, and Driscoll (2002), risk factors for falls are generally categorized into intrinsic and extrinsic factors. Intrinsic factors are based on the patient's medical condition such as impaired balance, poor physical functioning or medication interaction. On the other hand, extrinsic factors are those introduced by the environment with which the patient interacts, for example, uneven walking surfaces, poor lighting and stairs. Each may contribute to a patient's risk of falling and sustaining an injury. Furthermore, risk of injury increases linearly when multiple factors are present (Tinetti, Speechley, and Ginter, 1988).

\section{Intrinsic factors}

Several intrinsic factors have been identified by researchers that increase a person's risk of falling and sustaining an injury. These factors include various medical conditions, physical limitations due to age, and medication use. As with all mechanical systems, age of the components plays a key role in the performance of the overall system. The same holds true for biological tissues, as bones tend to become more brittle with age due to the natural aging process or clinical conditions such as osteoporosis. This change in mechanical properties can be correlated with the trend of decreasing bone mass with age, as shown in Figure 5. A difference in bone mass is also observed between genders

and will become clinically relevant with age. Bone mass density is calculated based upon bone mass per unit area, and its association with fracture incidence in falls among women aged 65 years and older was studied by Nevitt et al (1993). The researchers concluded that decreased bone mass density at the site of the fall impact significantly increased the risk of sustaining a fracture at the impact site. 


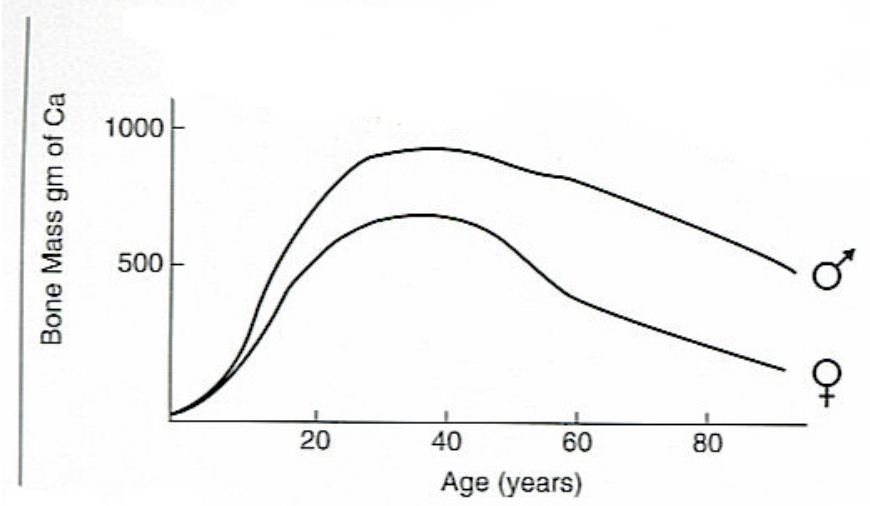

Figure 5: Bone mass association with age and gender. Source: Nordin \& Frankel, 2001.

As discussed previously, bone tissue exhibits viscoelastic and anisotropic properties. The importance of these characteristics becomes clinically apparent when fall direction and impact site is considered. Nevitt et al (1993) assessed the risk factors associated with fall outcomes among women aged 65 years and older. The incidence, circumstances, and outcomes of falls were prospectively studied for 891 women over a 4 year period. Of these, 130 women sustained hip fractures, 294 women sustained wrist fractures, and the balance sustained no fractures associated with falling. Nevitt et al concluded that women who sustained hip fractures were more likely to have fallen sideways or straight down than those who fell and did not sustain a hip fracture. On the other hand, women who sustained a wrist fracture were more likely to have fallen backwards than those who did not sustain a wrist fracture. These conclusions indicate that the direction of the fall significantly influenced the site of impact whether on the hip or on the outstretched hand. Also, the anatomy of the site of impact plays a crucial role in determining risk of fracture. For example, the soft tissue of the buttocks may protect the hip by absorbing energy upon impact of a backwards fall. However, the outstretched hand has little soft tissue to provide protection during the same backwards fall and direct impact to the extended wrist is imminent.

Janken, Reynolds, and Swiech (1988) conducted a retrospective study of clinical characteristics identifiable on patients' charts by comparing the charts of 631 patients over 60 years of age. By reviewing incident reports, 331 patients in the sample group were identified as "fallers," while 300 patients were "non-fallers." "General weakness, 
decreased mobility of the lower extremities, sleeplessness, incontinence, confusion, depression, and substance abuse" were characteristics observed to be significantly associated with those patients who fell (Janken, Reynolds, and Sweich, 1988). Tinetti, Speechley, and Ginter (1988) also studied factors associated with the risk of falling in persons aged 75 years and older. Balance and gait, and sensory tests were initially conducted, as well as, cognitive ability and medication use. The researchers observed a significant association with the use of specific medications including benzodiazepines, phenothiazines, and antidepressants to falling. Cognitive impairment, lower-extremity disability, and palmomental palp reflex were also determined to predispose a person aged 75 years and older to falling. These characteristics are related to the function of the nervous system and palmomental reflex, in particular, is the contraction of the muscles controlling the movements of the lips and cheeks when the palm of the hand is stroked. To a lesser extent, foot problems and gait and balance abnormalities were also noted to increase the risk of falling. Furthermore, Tinetti, Speechley, and Ginter showed the risk of falling to increase linearly with the number of risk factors present. In a study conducted by Lord, Clark, and Webster (1991), physiological conditions were measured for 95 residents of a hostel for the aged and analyzed for association with fall events. "Decreased sensation in the lower limbs, decreased visual contrast sensitivity, slow reaction times, muscle weakness, and decreased stability" were significantly associated with falling. Lord, Clark, and Webster also found "contrast sensitivity, proprioception in the lower limbs, ankle dorsiflexion strength, reaction time, and sway" to distinguish persons who fell multiple times from persons who fell only once during the 1 year study period. Gaebler (1993) confirmed the association of blindness or poor vision to persons who fall multiple times in a retrospective study of 50 multiple fallers matched to 50 single fallers.

Medication use and its association with falling was studied by Yip and Cumming (1994). Seventy-one patients aged 65 years and older who fell at least once during a one year period were compared to 55 patients aged 65 years and older who did not fall while residing in a nursing home. Medication use for each patient was recorded daily and analyzed for the 24 hours prior to a fall event. The researchers concluded that the use of 
antipsychotic medications increased the risk of falling in those aged 65 years and older. Yip and Cumming also noted that 40 percent of the 201 falls that occurred resulted in minor injuries including bruises, sprains, and lacerations. However, head injury and fractures were reported in 2 and 4 percent of the 201 falls, respectively. Mendelson (1996) also studied various medications and their association with falling in all age groups receiving services in an acute-care hospital. Medication dosage of 253 patients who fell while in the hospital were compared to that of patients, matched by age, sex, and service received, who did not fall. Mendelson identified a significant association between certain medications classified as antidepressants, minor tranquilizers or sedatives, and major tranquilizers and patients who fell. French et al (2004) further studied the association of benzodiazepine use and dosage to injury. Injury-coded healthcare encounters, totaling 3,139, were recorded in a veteran's hospital over a three year period; typical injuries included fractures of the skull and extremities, sprains and strains, and contusions. Benzodiazepine use and dosage was identified for each injury and association significance was established. French et al determined that a $1 \mathrm{U}$ or valium equivalent increase in dose increased the risk of experiencing an injury by six percent. Furthermore, increasing the exposure to benzodiazepines by one week increased the risk of injury by four percent. Although this study indicates an increased risk for injury when using benzodiazepines, the injury mechanisms could not be identified due to limitations in the administrative data. However, many of the injuries reported are commonly associated with falling; therefore, benzodiazepine use should be carefully considered before prescribing for individuals identified as at high risk for falls. A comprehensive list of intrinsic factors commonly associated with falls was compiled by Baum, Capezuti, and Driscoll (2002) and is presented in Table 1. 
Table 1: Instrinsic factors associated with falling. Source: Baum, Capezuti, \& Driscoll, 2002.

\begin{tabular}{|c|c|}
\hline Chronic Illnesses/Symptoms/Signs & Other neurological \\
\hline Functional & Cerebellar disorders \\
\hline Inability to move legs or arms & Shy-Drager syndrome \\
\hline independently Unilateral weakness & Multiple sclerosis \\
\hline Physical cognitive inability or lack of & Cervical spondylosis \\
\hline knowledge to use assistive device & $8^{\text {th }}$ cranial nerve tumor \\
\hline correctly & Neurosensory \\
\hline Cardiovascular & Impaired hearing \\
\hline Postural orthostatic hypotension & Impaired vision: cataracts, glaucoma, \\
\hline Aortic Stenosis & macular degeneration, and/or presbyopia \\
\hline Congestive heart failure & Pain, especially of joints \\
\hline Arrhythmias & Polyneuropathy secondary to diabetes, \\
\hline Anemia e.g. iron deficiency usually & peripheral vascular disease, or \\
\hline secondary to Gl blood loss, $\mathrm{B}_{12}$ & alcoholism \\
\hline deficiency, anemia of chronic disease & Psychiatric \\
\hline Musculoskeletal & Dementia \\
\hline Arthritis osteo, polymyalgia rheumatica & Depression \\
\hline Foot disorders & Post-stroke \\
\hline Osteoporosis & Acute Illnesses/Symptoms/Signs \\
\hline Disuse or deconditioning syndrome & Functional \\
\hline Osteomalacia & New-onset of weakness or incapacity in \\
\hline History of fracture & movement of extremities recent, rapid \\
\hline Post-amputation & decline in functional status (IADLs or \\
\hline Proximal muscle weakness & ADLs) \\
\hline Myopathy & Hypovolemia \\
\hline Neuromuscular & Low plasma volume \\
\hline Stroke & Anemia \\
\hline Parkinson's disease & Venous stasis \\
\hline \multirow[t]{2}{*}{ Huntingdon's disease } & Blood loss \\
\hline & Severe diarrhea \\
\hline
\end{tabular}


Table 1: Continued

\begin{tabular}{|c|c|}
\hline Acute Illnesses/Symptoms/Signs cont. & Psychiatric cont \\
\hline Autonomic neuropathies & Anxiety \\
\hline Diabetic & Hysterical fainting (conversion reaction) \\
\hline Uremic & Recent, post-stroke personality change \\
\hline Toxic & Musculoskeletal \\
\hline Amyloidosis & Fracture (hip, vertebral compression) \\
\hline Neurological & Sprain \\
\hline Transient ischemic attacks/recent stroke & Respiratory \\
\hline Seizures & Tussive syncope (syncope related to \\
\hline Vestibular dysfunction & unrelenting cough) \\
\hline Glossopharyngeal neuralgia & Pneumonia \\
\hline Cardiovascular & Massive pulmonary embolism \\
\hline Postural orthostatic hypotension & Pulmonary tamponade \\
\hline Vasovagal response & Hypocanpia due to hyperventilation \\
\hline Carotid sinus syncope & Hypoxia \\
\hline Vasodepressor syncope (fatigue, hunger, & Defecation syncope \\
\hline heat) & Acute abdomen cholecystitis, \\
\hline Acute heart failure & pancreatitis, appendicitis, diverticulitis \\
\hline New-onset arrhythmias & Diarrhea \\
\hline Acute myocardial infarction & Vomiting \\
\hline Aortic stenosis hypertrophic & Blood loss \\
\hline cardiomyopathy & Hypo/hyperthyroidism \\
\hline Carotid artery compression & Hypogycemia \\
\hline Genitourinary & Anemia \\
\hline Post-micturition syncope & Hypokalemia \\
\hline Urinary tract infection & Dehydration \\
\hline New-onset incontinence & Hyponatremia \\
\hline Psychiatric & Acidosis \\
\hline $\begin{array}{l}\text { Delirium (often indicative of underlying } \\
\text { acute physical illness) }\end{array}$ & Hypocapnia (hyperventilation) \\
\hline
\end{tabular}


Table 1: Continued

\begin{tabular}{|l|c|}
\hline Behavioral Symptoms & Cancer chemotherapeutic drugs \\
Poor judgment regarding personal safety & Quinine drugs \\
Cautiousness due to fear of falling & Central nervous system drugs \\
Risk-taking or impulsivity (may be & Ototoxic drugs (aspirin) \\
secondary to stroke or impaired & Psychotropics \\
cognition) & Hypnotics/sedatives \\
Tendency to stand quickly, especially & Antidepressants \\
from bed or immediately after a meal & Dopamine agonists \\
Effort to remove physical restraint & Circulatory drugs \\
Propensity to climb over or around side & Diuretics \\
rails & Antihypertensives \\
Disinterest or inability to use & Vasodilators (nitrates) \\
recommended assistive devices & Alpha blockers \\
Vestibulotoxic drugs & Beta blockers \\
Aminoglycoside antibiotics & Antiarrhythmics \\
\hline
\end{tabular}

\section{Extrinsic factors}

\section{Environmental hazards}

According to an article written by Arlene Jech (1992), certain environmental conditions present tripping hazards around the home. These hazards, seemingly obvious, are often overlooked due to their temporary nature or habitual use. For instance, an extension cord temporarily obstructing a walkway may not be viewed as a hazard by elderly persons due to years of experience of maneuvering to avoid such circumstances. However, decreased reaction time common to persons aged 65 years and older increases the likelihood of failed balance recovery once a fall is initiated. Other conditions around the home may contribute to falls due to the changing physicality of elderly persons without a corresponding change in behavior. Decreased visual acuity requires more adequate lighting in the home, particularly in hallways and around stairs. However, persons habitually using the stairs may feel their surroundings are memorized, and 
changes to the environment are not necessary. Connell and Wolfe (1997) further studied environmental hazards often present in the home and the resident's interaction with his environment on a situational basis. The researchers postulated that while certain environmental geometries are not hazardous per se, hazard potential is introduced when combined with decreasing physical ability or inattention to surroundings. During the study, eighteen fall or near-fall incidences were recreated to surmise the cause of the loss of balance. The researchers concluded that "collisions in the dark, failing to avoid temporary hazards, preoccupation with temporary conditions, frictional variations in foot contact, excessive environmental demands, habitual environmental use, [and] inappropriate environmental use" were common initiators of falls. Connell and Wolfe emphasized the interaction between the resident and the environment at the time of the fall. They observed that, though a particular action may be habitual, misjudgment of spatial orientation or preoccupation with temporary circumstances often lead to a discrepancy in body movements. For instance, a person rising from bed to walk to the bathroom without a light may misjudge proximity of an obstacle and trip rather than successfully maneuvering around it. Also, a person carrying a box along a familiar path may be preoccupied with the awkward load rather than paying attention to an obstacle, temporary or permanent. It is these unique situations that initiate falls rather than the object itself. However, the presence of the object presents a potential for hazardous conditions when subjected to the aforementioned circumstances. As such, Baum, Capezuti, and Driscoll (2002) compiled a list of common environmental conditions that are potentially hazardous and should be assessed for fall prevention; a reprint of this list is presented in Table 2 . 
Table 2: Extrinsic factors associated with falling. Source: Baum, Capezuti, \& Driscoll, 2002.

\begin{tabular}{|l|l|}
\hline In General & Bedroom \\
Poor lighting & High bed \\
Slippery floors & No hand rail or other transfer enabler \\
Low seating & Stairs \\
Unstable furniture & No hand rails \\
Shiny floors & Worn treads \\
Thick pile carpeting & Stairs not visibly different than \\
High shelving & adjoining floor \\
Bathroom & Stair edge not clearly defined \\
No grab bars & \\
Low toilet seats & \\
\hline
\end{tabular}

\section{Impact surface}

The characteristics of the impact surface greatly influence the fall outcome by contributing to the forces involved during the fall event. Researchers have only recently begun to study this association of impact surface and fall outcome. Nevitt et al (1993), as discussed previously, compared circumstances surrounding the incidence of falls resulting in no hip fractures and falls that resulted in hip fractures among women. Nevitt et al found that women who fell on hard surfaces, defined as "asphalt, concrete, stone, tile, linoleum, hardwood floors, and unpadded carpets," were more likely to sustain a hip fracture than those who fell on soft surfaces, defined as "grass, loose dirt, and padded carpets." Casalena et al (1998) developed a novel flooring material, known as the Penn State Safety Floor (PSSF), which minimizes the deflection under normal walking conditions while allowing a maximum deflection under impact conditions, thereby creating a material with viscoelastic properties. Initial testing of the PSSF indicated that the design achieved the goal of decreasing the peak impact force experienced by a hip when measured with an anthropomorphic mechanical device.

Simpson et al (2004) further considered the correlation between flooring surface and the number of hip fractures resulting from falls in 35 nursing homes that reported a total of 6,641 falls over a two year period. Using a transducer developed to model an 
elderly patient's hip, Simpson et al measured the impact force produced on carpeted and uncarpeted wooden and concrete sub-floors used in the study environments. Wooden sub-floors resulted in lower impact forces than those associated with concrete sub-floors. These measurements were also correlated to the number of hip fractures per 100 falls recorded throughout the study period. Consequently, wooden sub-floors resulted in significantly fewer hip fractures per 100 falls when compared to concrete sub-floors. However, carpeted floors resulted in 88 percent of the total number of falls recorded during the study period, regardless of wooden or concrete sub-floor. This result may indicate a trip hazard associated with carpet or may simply indicate a higher exposure to carpeted areas in the healthcare facilities.

\section{Gaps in the research}

Most research focuses on the incidence of falls in those aged 65 years and older because age is a key factor in determining risk for falls. However, risk factors are not limited to the elderly population. For instance, Tsai, Witte, and Radunzel (1998) showed that "history of falling [within the] past six months, generalized weakness, observed difficulty in mobility of lower extremities or walking, confusion/disorientation, [and] elimination problems (nocturia, incontinence)" were risk factors common to the elderly population and to patients receiving care in a psychiatric unit. The researchers also showed an increased risk of falling with an increase in body temperature and a positive association of falling with certain medications, including sedatives/hypnotics and antidepressants. Similar activities surrounding fall events in the elderly population and patients in the psychiatric unit were also noted to include getting out of bed, moving from a sitting to a standing position, and walking to the bathroom. Despite the incidence of falls presented by Tsai, Witte, and Radunzel, few other studies address the issue of falls in the psychiatric population. Furthermore, although much attention has been given to fall patterns, few studies have been conducted to quantify the injury mechanisms of falling from bed. Bertocci et al conducted a study to quantify the impact deceleration of children falling from a bed or couch onto various flooring surfaces, but the researchers did not address the issue of adults falling under similar circumstances. A basic 
understanding of injury mechanisms must be obtained before prevention efforts can be effectively employed. Also, knowledge of the fall environment, specifically impact surfaces, is lacking as researchers have only just begun to correlate incidence of injury and characteristics of the impact surface. Although Casalena et al have developed a new flooring system that may reduce the number of injuries associated with falling, the feasibility of implementing this system into the healthcare environment has not been addressed. 


\section{Injury Prevention}

\section{Introduction}

Due to the high incidence of injuries associated with falls, researchers and healthcare providers have developed and implemented several devices that patients may utilize to prevent injuries if a fall occurs. Falling from bed is a specific circumstance of falling that healthcare providers are striving to prevent by first implementing bedrails. However, studies have shown serious adverse events associated with the use of bedrails. As such, world wide efforts are directed towards reducing the usage of bedrails by careful patient evaluation and implementation of height adjustable beds, bedside floor mats, and other alternatives. Nevertheless, legal issues and perceptions of bedrail usage have proven to be a stumbling block to these efforts. Despite these complications, reduction programs have been successful in reducing the usage of bedrails without increasing the number of injuries associated with falling from bed.

\section{Bedrails and legal issues}

Bedrails were introduced in healthcare institutions as a device intended to prevent falls from bed. However, the introduction of bedrails into the healthcare environment raises questions of legal liability as discussed by Barbee in 1957. Ironically, nurses could be liable for injuries sustained by a patient when a fall out of bed occurred whether the bedrails were up or down. Barbee explained that negligence can be argued on the part of the nurse if a hospital or doctor's order was not followed by raising the bedrails and if a nurse failed to professionally judge the requirement of raised bedrails if a standing order was not given. Consequently, Rubenstein et al (1983) assert that the use of bedrails stems from consensus rather than scientific evidence as legal liability and malpractice issues became entangled with the healthcare industry. According to the authors, higher settlements are awarded in cases in which the hospital or nursing staff fail to produce 
evidence of actively attempting to prevent injury. Since bedrail position can be easily documented, raising the bedrails became standard practice not only to prevent patient falls but also to prevent claims of negligence on the part of the hospital or nursing staff. Recently, liability issues became further complicated with the inclusion of bedrails in the April, 1992 revision of hospital restraint devices posted by the Health Care Financing Administration (HCFA) (Braun \& Capezuti, 2000). Bedrails can be classified as restraint devices if a doctor's order specifically states the device's purpose as a mobility restraint; as such, bedrails used as a restraint must be accompanied by a doctor's order to be legal. Otherwise, bedrails that aid a patient transferring into and out of bed or repositioning while in bed are classified as assistive devices; therefore, they do not require a doctor's order to be implemented (Donius \& Rader, 1994).

\section{Bedrails and adverse events}

The decision-making process to use bedrails for a patient must consider these legal issues and the effect this device will have on the patient as bedrails reportedly contribute to serious adverse events. Parker and Miles (1997) found 74 incidences of patient deaths that were associated with bedrails as reported to the US Product Safety Commission between 1993 and 1996. These deaths were classified into one of three subgroups by identifying the type of entrapment involving bedrails. The majority of the reported incidences ( 70 percent) were caused by the patient being trapped between the mattress and bedrail. Bedrail compression of the patient's neck also resulted in 18 percent of the incidences reported, while 12 percent were caused by the patient becoming trapped between the bedrail and floor after partially falling or sliding off the bed. Furthermore, 111 cases of bedrail entrapment were identified by Todd, Ruhl, and Gross (1997) in a review of adverse events reported to the Food and Drug Administration (FDA) for the years 1985 through 1995. Of these 111 entrapments, 72 resulted in death with "asphyxiation, strangulation, suffocation, cardiac arrest, cardiac arrhythmias, or pneumonia" cited as the cause of death. "Fractures, sprains, soft tissue injuries, and respiratory or circulatory compromise" were also reported in 26 of these entrapments. Due to staff intervention, 13 of these entrapments had no associated injury. Accordingly, 
alerts have been posted by the FDA (FDA, CDRH, 1995) and the Joint Commission on Accreditation of Healthcare Organizations (JCAHO) (JCAHO, 2002) regarding the potential safety risk involved when using bedrails. The FDA has also sponsored the organization of the Hospital Bed Safety Workgroup, which is currently striving to establish bedrail and hospital bed standards that will reduce the injury risk posed by these systems.

Not only do these events affect the patient physically, but they also produce an economic impact as shown by Bradham et al (2003). Incidence and comparison groups were analyzed for acute medical/surgical care units and nursing home units within a regional Veterans Health Administration (VHA) network. Over a one year period, 207 medical/surgical admissions, accounting for 236 adverse incidences, was compared to 732 admissions without injury. Likewise, 191 nursing home admissions, accounting for 194 adverse incidences, were compared to 194 admissions without injury. By comparing the total number of bed days, procedures, and surgeries, Bradham et al estimated a potential total of $\$ 1,858,620$ to be saved annually in direct costs if bed-related adverse events were avoided in acute and extended care facilities.

\section{Bedrails and reduction programs}

In response to these reported adverse events, studies have been conducted to determine if bedrails can be safely removed without increasing the number of injuries associated with falling from bed. Accordingly, Feinsod et al (1997) replaced full-length bedrails with half-length bedrails, eliminated them completely, or utilized low beds as an alternative to full-length bedrails in a long-term care facility. Consequently, the injury rate recorded for 118 patients prior to full-length bedrail replacement did not differ significantly after the aforementioned bedrail alternatives were implemented for 128 patients, nor did any injury requiring hospitalization occur after the full-length bedrails were replaced. These findings are mirrored in a study involving a short-term rehabilitation unit. Si et al (1999) individually assessed patients and incrementally removed split rails from beds in a 25-bed unit over a one year period accounting for 143 
admissions. Incidence of fall did not differ significantly from the study period as compared to the previous year before bedrail usage was reduced.

The reduction of bedrail usage has drawn world-wide attention as Hanger et al (1999) conducted a similar study in a New Zealand hospital. Potential hazards of bedrails and available alternatives were presented in an educational program in an effort to reduce the use of bedrails throughout the 135 bed hospital. Six months after implementing the program, the mean number of beds with bedrails was reduced from 40 beds to 18.5 beds. The incidence of falls and associated injuries was also collected and analyzed six months before and after the program intervention. The number of falls did not differ significantly nor did the incidence of injury; however, the morbidity of falls decreased as fewer serious injuries occurred. Fractures, head trauma, joint dislocations, lacerations requiring sutures or plastic surgical intervention, or hip pain that immobilized the patient were all classified as serious injuries. Likewise, Hoffman et al (2003) implemented a program called BedSAFE to reduce the use of bedrails in three Veterans Health Administration nursing homes. After patient assessment, bedrail alternatives were implemented including floor mats, mattress perimeter borders, height adjustable beds, or environmental changes. Overall, a 27 percent reduction in bedrail use was made over the one year study period of the 60-bed long-term care units. The number of falls from bed also decreased by 11 percent; however, the number of injuries did not differ significantly pre- and post-BedSAFE.

\section{Bedrail alternatives}

During the bedrail reduction program BedSAFE (Hoffman et al, 2003), nursing staff used bedside floor mats to prevent injuries associated with falling from bed. The researchers noted that 89 percent of 126 post-BedSAFE injuries occurred when the floor mats were not in place. This suggests that the floor mats did indeed contribute a protective effect against injuries resulting from falls out of bed; however, the significance of this result was not analyzed with respect to injury rate. Also, the impact force was not measured during this study, thus, the level of protectiveness of the floor mats could only be inferred. Thus far, clinicians must rely upon manufacturer's advertisements of impact 
reductions associated with the use of floor cushions. For instance, the Posey floor cushion is advertised to provide an 85 percent reduction in impact force, measured in meters per second squared $(\mathrm{g})$, as compared to the impact generated by a baseball bat striking a baseball. Despite rigorous testing standards developed by the United States government, consumers may be misled by subjective interpretations of test results.

\section{Height adjustable beds}

Low-beds or height adjustable beds are a commonly recommended alternative to bedrails; however, increasing the prevalence of low-back injuries in nursing staff is a concern if patients receive care while the bed is in the low position. DeLooze et al (1994) conducted a study to measure the effect of individually chosen bed heights on peak and time integrated compressive and shear forces on the L5-S1 vertebral joint. Fourteen female and eight male nurses were asked to complete a set of patient handling tasks at a standard bed height of $0.715 \mathrm{~m}$ and again at a bed height of subject preference. Reflective markers placed on anatomical landmarks were tracked by a motion capture system and used, in conjunction with force plate and anthropomorphic data, to calculate joint reaction forces at the L5-S1 joint experienced during the various tasks. The researchers reported a significant decrease in peak shear forces and time integrated compressive and shear forces when the subject adjusted the bed to a comfortable working height; therefore, implementation of height adjustable beds was not excluded as a possible alternative to bedrails.

Caboor et al (2000) conducted a similar study to measure the effects that individually chosen bed height has on spinal motion, associated muscular activity, and the level of exertion perceived by the nurses during patient handling tasks. The series of tasks, completed by ten female and eight male nurses, included repositioning a patient in bed and patient transfers between a bed and wheelchair or toilet at a standard bed height of $0.515 \mathrm{~m}$ and an individually chosen bed height. Spinal motion was measured by electrogoniometers, while surface electromyography (EMG) measured the activity of major muscle groups associated with spinal motion. The subjects also rated the exertion level required to complete each task according to a 15 point rating scale ranging from 
extremely light to extremely heavy. Caboor et al showed that, while the range of spinal motion did not change significantly, the time spent in the neutral position or safe working zone of the spine was significantly increased with the individually chosen bed height. The authors also showed that according to the EMG data, individual bed height preference did not significantly affect the muscle activity compared to that associated with the standard bed height. Similarly, no significant difference was perceived by the subjects with respect to exertion level required at each bed height.

\section{Gaps in the research}

From these studies one may conclude that implementing height adjustable beds is an appropriate alternative to bedrails based on the effect to the nursing staff; however, research has not addressed the effect height adjustable beds will have on patients. Healthcare providers have implemented this alternative without conducting the research to prove any benefit of the device for patients. For example, the effect of falling from various bed heights has not been studied and only assumed that falling from bed at a lower height will give a protective effect from injury. Likewise, the question of aiding patient mobility by lowering the bed height has also not been addressed. Floor mats is another form of bedrail alternative intended to protect a patient from injuries if a fall from bed occurs. These mats have been implemented into the healthcare environment without proof of their protective effect. The performance of these devices should be compared in objective tests that quantify their impact dampening capabilities. Also, because these mats must be incorporated into the whole environment, other issues must be addressed including tripping hazards, ease of use by nursing staff, and sanitation methods. 


\section{Injury Assessment}

\section{Introduction}

In the medical community, various injury assessment scales are used to communicate injury severity. However, many of these scales are subject to caregiver interpretation and are not appropriate for industrial use when developing new products. As a result, the head injury criteria (HIC) was developed as a method of quantifying the mechanical response of the human head to various impact situations. This value has, therefore, been used to establish standards in the automotive industry in an effort to promote safety of automobiles. Consequently, the HIC value is widely used in the automotive industry but has seen limited application in other areas.

\section{Head injury criteria}

Thus far, in the healthcare industry, assessing injury severity is subject to caregiver interpretation and categorical scales. One such scale is the Abbreviated Injury Scale (AIS) developed by clinicians to assess the injury severity of a patient. This scale is a categorical scale from 0 to 6 that allows clinicians to assess and communicate a patient's probability of survival. The categories are as follows:

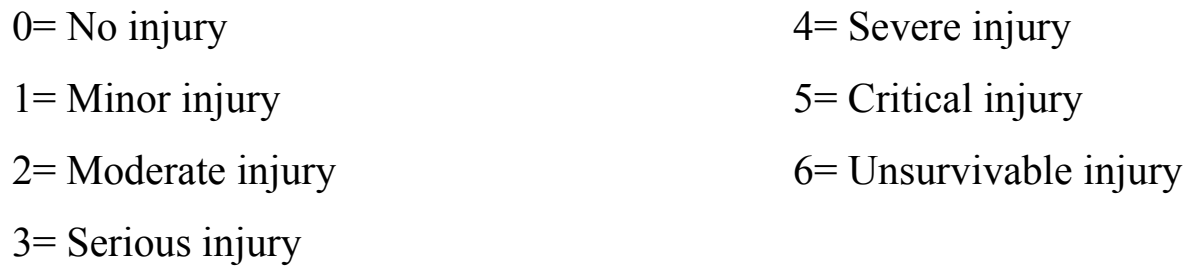

Categories 0 to 3 are generally associated with head and neck pain and mild concussion, while categories 5 and 6 are classified as unsurvivable injuries (Trauma.org, n.d.). Researchers have begun to bridge the gap between clinical observation and experimental data. This process began with Lissner (1960) and the introduction of the Wayne State Tolerance Curve (WSTC) which characterizes the mechanical response of 
cadaver heads upon impact. This curve was used to correlate rate and duration of impact with skull fracture and is shown in Figure 6. The curve represents the tolerance level of the human head to acceleration and duration of impact; however, this curve does not indicate injury severity. The WSTC was further used by Versace (1971) to develop a mathematical predictor of head injury. The Head Injury Criteria (HIC) (Equation 1) is an integral calculated for impact acceleration up to a $15 \mathrm{~ms}$ time period $\left(\mathrm{HIC}_{15}\right)($ Mertz, 1994). The maximum value of this integral is reported as the HIC value for a given impact event and is indirectly correlated with the AIS used by clinicians by predicting the risk of life-threatening brain injury as shown in Figure 7.

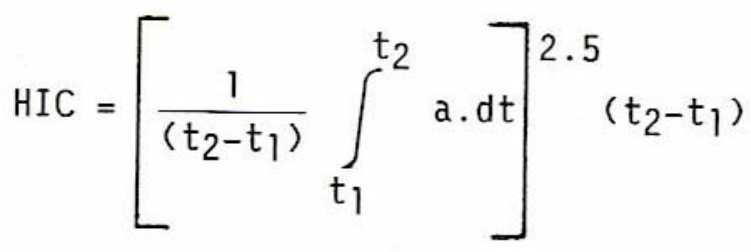

\section{Equation 1}

where $\mathrm{t}=$ time $(\mathrm{ms})$

$\mathrm{a}=$ acceleration $(\mathrm{g})$

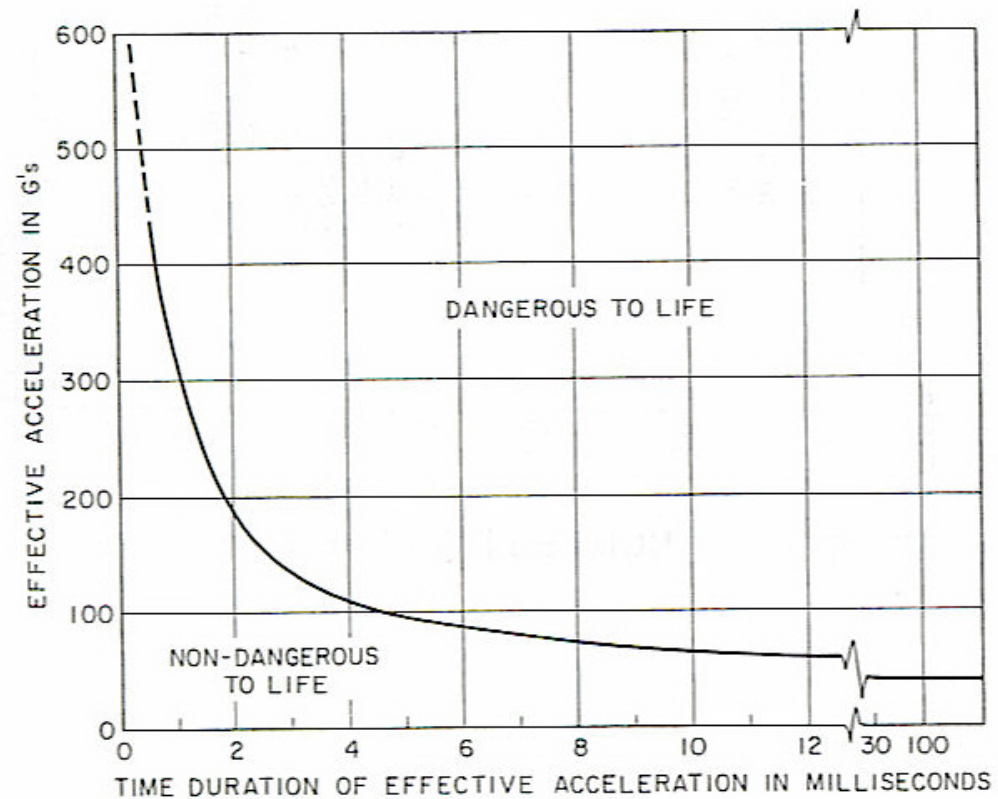

Figure 6: Wayne State Tolerance Curve. Source: Versace, 1972. 


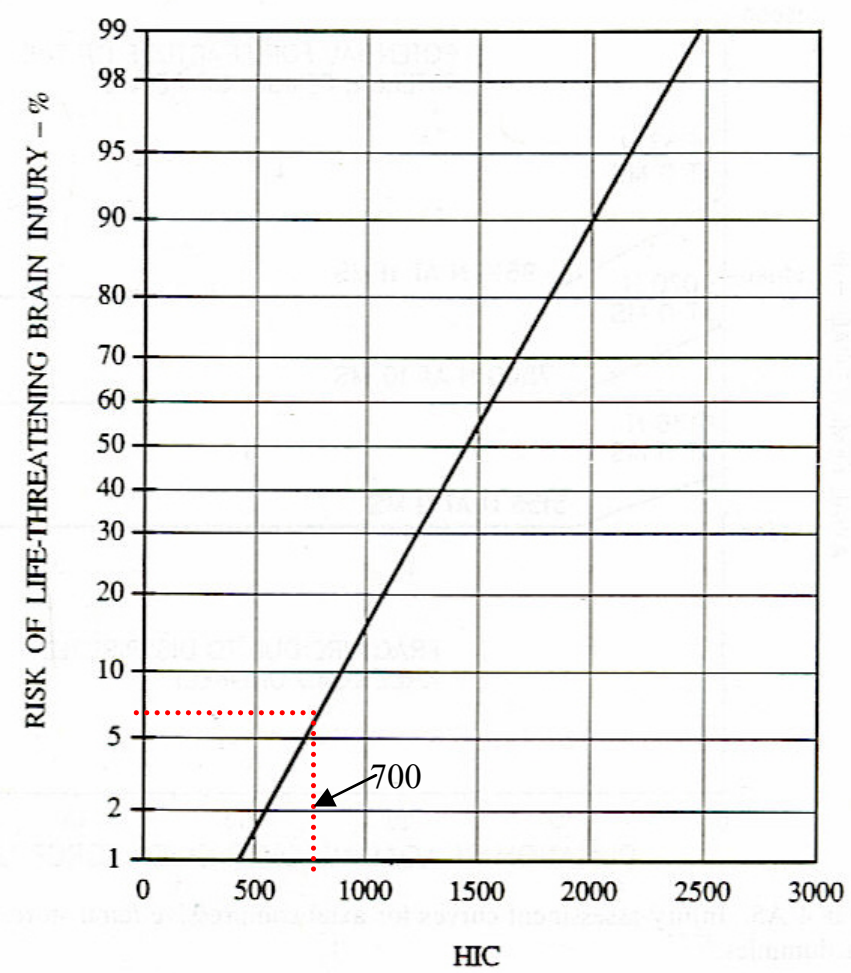

Figure 7: Risk of life-threatening brain injury related to HIC values. Source: Mertz, 1994.

The automobile industry has incorporated calculating the HIC value as a method of predicting injury by using instrumented dummies during crashworthiness testing of automobiles. Currently, the Hybrid III anthropomorphic test dummy is the most commonly used mannequin. The U.S. Department of Transportation has established safety standards based on $\mathrm{HIC}_{15}$ values calculated for various models of the Hybrid III dummy. The most current standards were established in 2002 and are presented in Table 3. Ongoing research to establish injury criteria for the thorax is being conducted, and the current NHTSA standards are also presented in Table 3. 
Table 3: HIC (15 msec) NHTSA standards. Source: Eppinger, Sun, Kuppa, and Saul, 2000.

\begin{tabular}{|lcc|}
\hline & Head Criteria $\left(\mathrm{HIC}_{15}\right)$ & Chest Acceleration $(\mathrm{g})$ \\
$95^{\text {th }}$ Percentile Male & 700 & 55 \\
$50^{\text {th }}$ Percentile Male & 700 & 60 \\
$5^{\text {th }}$ Percentile Female & 700 & 60 \\
6 year old Child & 700 & 60 \\
3 year old Child & 570 & 55 \\
1 year old Infant & 390 & 50 \\
\hline
\end{tabular}

Gaps in the research

Although widely used in automobile development, the HIC value has limited application to areas outside this industry. Bertocci et al, as discussed previously, used this value to predict head injury associated with falling from bed in children; however, this study is exceptional in that application. At the time of this writing, no other studies utilize the HIC value for this application neither for children nor adults. The HIC value has great potential for allowing researchers to objectively assess the effect any given situation will have on the human head. Thus far, this assessment tool has remained virtually untapped with regard to areas outside the automobile industry. Furthermore, similar assessment values are being developed for other anatomical locations, such as the thorax. However, these values are not well established in any industry, much less the medical research community. That is not to say that the automobile industry does not measure basic values, such as acceleration and force, for other parts of the body, but these areas of the body have received much less attention than the head. Therefore, industry standards are not as rigorously established for the thorax or pelvis as those of the head. As such, researchers must rely only on these basic values to communicate the response of the human body under certain conditions. For instance, falling from bed produces an impact not only to the head but also to the thorax and pelvis; yet, researchers can only infer injury based on acceleration measurements. 


\section{Significance of Current Research}

\section{Introduction}

As discussed previously, information regarding the biomechanics of falling from bed is by no means complete. Currently, most research studies are based on subjective evidence of the protective effects of bedrails and bedrail alternatives, including height adjustable beds and floor mats. These devices were implemented into the healthcare environment with the intention of preventing injuries caused by falling out of bed; however, few studies have been conducted to investigate patient-device interactions objectively. Furthermore, the subjective nature of these studies does not allow effective communication between healthcare providers and the manufactures of healthcare devices. The current study proposes to address some of these issues by first, providing a quantitative measure to describe the mechanics of falling from bed, second, quantitatively comparing height adjustable beds and floor mats, and third, applying an injury assessment criteria to the specific situation of falling from bed.

\section{Quantifying the mechanics of falling from bed}

The current knowledge base does not provide any measure of what happens when a patient falls from bed. There is, however, considerable evidence supporting the incidence of falling from bed and associated injury. Much research has also been conducted to identify risk factors including those specific to a patient and those found in the environment. Unfortunately, these studies do not communicate effectively the mechanics of a fall from bed event. As such, the current study proposes to objectively measure the impact deceleration during a fall from bed event. Not only will this measure provide an unbiased description of the moment of injury during a fall event but also provide a baseline with which to compare future studies involving the assessment of prevention methods. 


\section{Comparing injury prevention methods}

There exists a trend in the healthcare community that involves implementing devices intended to prevent injuries without properly assessing their effectiveness at achieving that underlying goal. This trend is evidenced with the implementation of bedrails and bedrail alternatives including height adjustable beds and floor mats. The current study, however, will provide a measure to objectively compare the effectiveness of height adjustable beds and floor mats by measuring the impact deceleration during a fall event when these devices are in use. Furthermore, the performance of these devices will be assessed during a clinically relevant environmental arrangement. Consequently, the presence of any physical benefit that may exist will be established; therefore, it will allow healthcare providers to make a more informed decision about utilizing these devices.

\section{Assessing injury during a fall from bed}

Injury criteria exist that are used to correlate injury severity with a physical measurement; however, these criteria, thus far, have not been applied to clinical situations. The Head Injury Criteria (HIC) is an assessment value that correlates acceleration with injury severity; however, this criteria has only been applied to the automotive industry. The current study proposed to apply HIC to the specific circumstance of falling from bed. As such, HIC will provide a correlation between impact deceleration and injury severity. Therefore, clinicians will be more informed about the potentially hazardous situation of falling from bed. The equation used to calculate HIC values was also applied to thoracic and pelvic acceleration profiles; therefore, injury severity may be inferred once research becomes available regarding the physical limits of the thorax and pelvis. 


\section{Methodology}

\section{Location}

The current study was conducted at the Biomechanics Laboratory of the James A. Hailey Veterans Administration Patient Safety Center.

\section{Apparatus design and construction}

To represent the patient population, a Hybrid III anthropomorphic test dummy (ATD) (manufactured by Denton ATD) was used during this study (See Figure 8). Numerous studies have been conducted to develop this ATD with physical characteristics similar to those of living persons including anthropomorphic dimensions, joint range of

motion, and response to applied forces (Backaitis and Mertz, 1994). For this study, a $50^{\text {th }}$ percentile male dummy was used, which means 50 percent of the total population would have anthropomorphic dimensions no larger than those of the ATD. As such, the ATD is designed to weigh $76.3 \mathrm{~kg}$ and measure $170.3 \mathrm{~cm}$ when standing erect. Since the ATD is not automated, it represents a fully dependent male patient, a common patient receiving care in the VA healthcare network. To further enhance the patient simulation, the ATD was clothed in hospital scrubs. Although the ATD is designed to meet population data with regard to dimension and response, the ATD skin does not mimic that of human skin with respect to friction coefficients. The ATD skin is composed of vinyl which produces a much higher coefficient of friction than does human skin. The inclusion of scrubs on the ATD decreased the likelihood of skewed data from differing friction coefficients as hospital patients are clothed in scrubs or gowns of similar material (See Figure 8). 

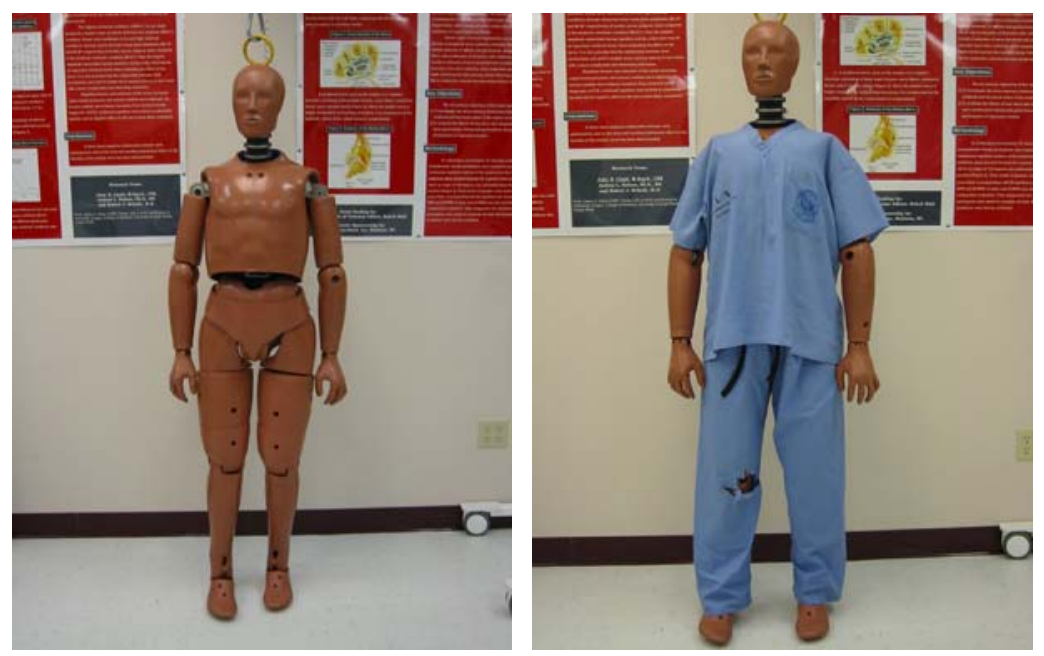

Figure 8: $50^{\text {th }}$ percentile male anthropomorphic test dummy with and without scrubs.

A Carroll Healthcare ARRO Low Bed was used to simulate the height from which patients frequently fall (See Figure 9). This bed provided an adjustable height range between 33.5 and $97.5 \mathrm{~cm}$, measured from the floor to the top of the uncompressed mattress. Due to the wide variety of beds used in hospitals, the height range from could which patients fall varies greatly. Using the ARRO Low Bed allowed data collection at the widest height range to encompass as many clinical situations as possible without compromising the data by changing beds to accommodate various bed heights. Bedrails were not physically implemented in this study because forcing the ATD over the bedrails would introduce additional acceleration that would otherwise not be present during a gravity driven or passive fall from bed event. Since bedrails increase the height from which patients fall, the effect of adding bedrails will be extrapolated from data collected at various heights provided by the ARRO Low Bed. 


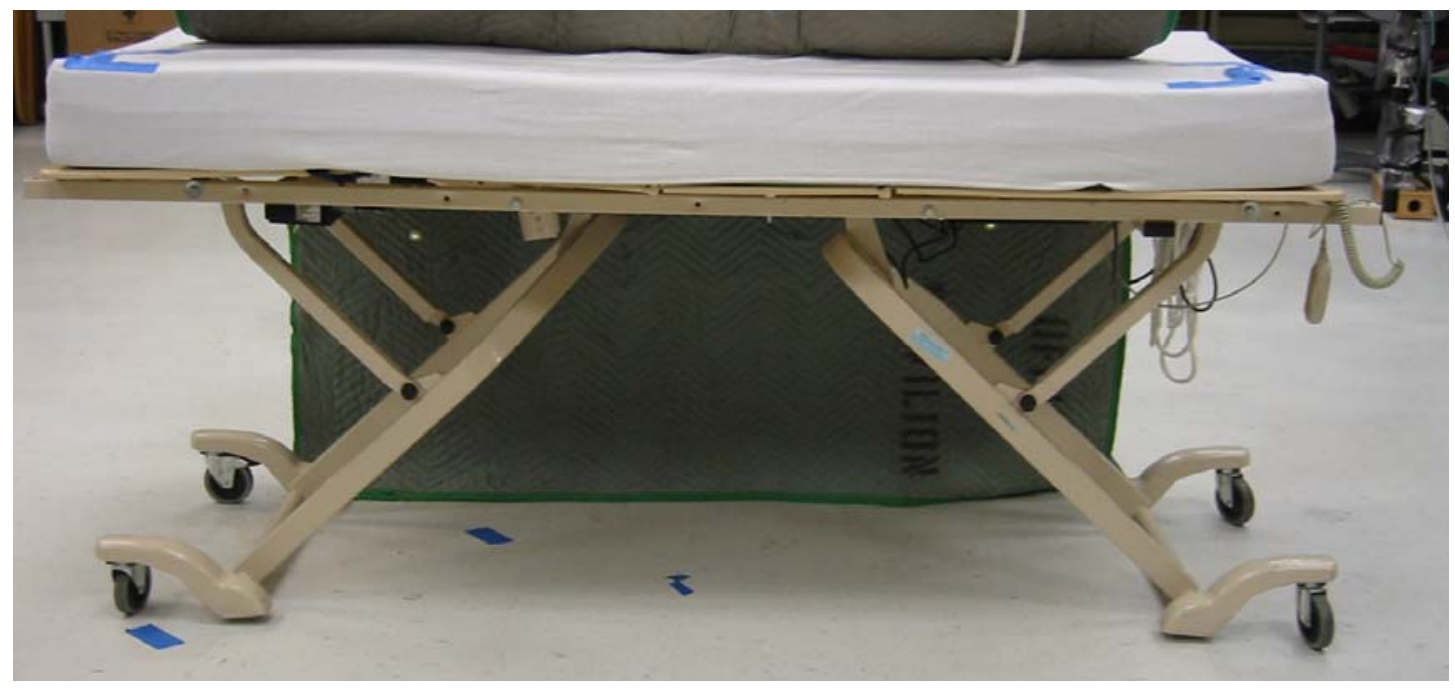

Figure 9: Carroll Healthcare ARRO Low Bed used to simulate common heights from which patients fall.

A Posey Beveled Floor Cushion, referred to as floor mat or mat for convenience in this paper, was used to represent devices intended to cushion a patient if a fall occurs (See Figure 10). The floor mat measured approximately $183 \mathrm{~cm}$ in length, $96.5 \mathrm{~cm}$ in width, and $2.54 \mathrm{~cm}$ in thickness. The core of the mat was composed of ethylene vinyl acetate (EVA) foam to absorb impact energy, and a vinyl cover was used to provide an easily sterilized surface. This floor mat included a tri-fold design and carrying handle for easy storage and portability. As shown in Figure 10, the edges of the floor mat were beveled to aid wheelchair accessibility to the bedside when the mat was in use and to decrease the risk of tripping. 


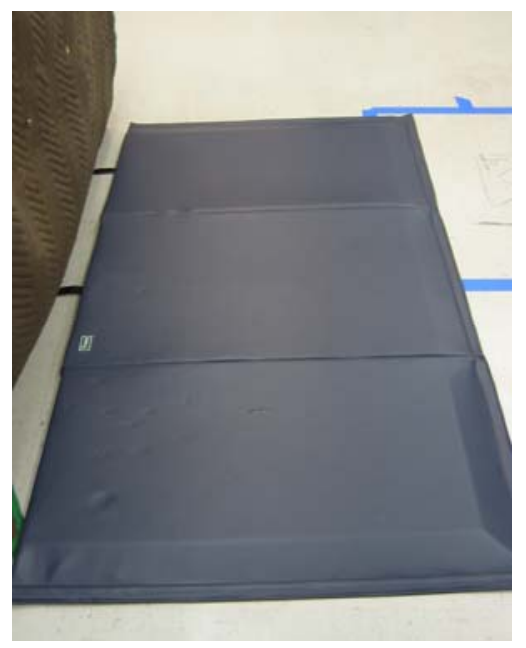

Figure 10: Posey floor mat used to simulate mats commonly used in the healthcare environment to cushion falls.

To simulate a patient falling from bed, the ATD was raised out of bed using a sling designed for this study (See Figure 11). The sling was attached to a ceiling lift that raised the ATD until gravity caused the ATD to slide out of bed. This provided a passive method of simulating a fall from bed, which represents a patient falling from bed as a result of position in bed whether from misjudgment or loss of balance while attempting to get out of bed. Using the sling not only standardized the falling process, but it also did not increase the level of acceleration by allowing gravity to initiate the fall. The positions of the ATD on the sling and the sling on the mattress were marked to standardize ATD placement, which was used to control the direction of the fall. The ATD was allowed to fall head first or feet first to simulate a more clinically relevant fall event, as researchers postulate these to be the more common types of falls experienced by patients. 


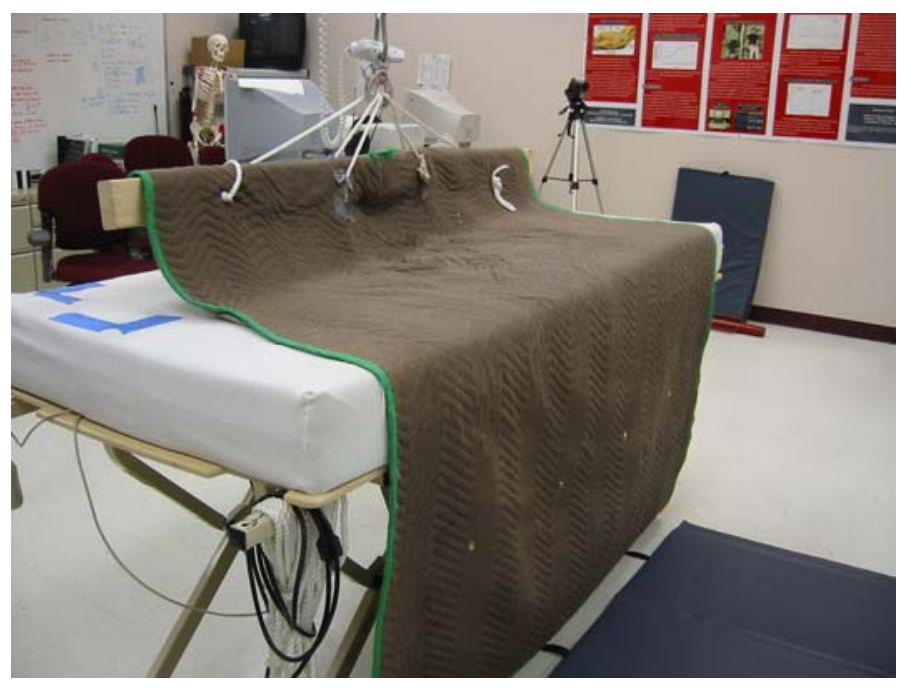

Figure 11: Sling designed to standardize the fall from bed event simulation.

Three 356A02 PCB accelerometers, as shown in Figure 12, were used to measure deceleration during an impact event caused from a fall from bed. These accelerometers were designed to measure $\pm 500 \mathrm{~g}$ with an output of $10 \mathrm{mV} / \mathrm{g}$ within a frequency range of 1 to $5000 \mathrm{~Hz}$. The manufacturer calibrated each accelerometer individually and certified this calibration. However, because these instruments were interfaced with the data collection software LabVIEW, the calibration needed to be verified. This was accomplished using a PCB handheld shaker. The shaker excited each axis of the accelerometer individually at $\pm 1 \mathrm{~g}$, and the output was captured using LabVIEW. The output ratio of $\mathrm{mV} / \mathrm{g}$ controlled by LabVIEW was set to manufacturer calibration values. Each axis of the accelerometer was again excited $\pm 1 \mathrm{~g}$, and axis calibration was verified. LabVIEW was also used to center the accelerometer output about $0 \mathrm{~g}$ and verified using the handheld shaker. Other methods of accelerometer calibration also exist and were attempted during the current study; however, the shaker method was ultimately used.

Accelerometers were placed in the head, thorax, and pelvis to measure the deceleration at the most critical areas of the body. As shown in the literature, incidence of injury to these areas is high and often severe. By collecting data at these critical locations, any benefit provided by the floor mat or height adjustable bed will be appropriately assessed. Each accelerometer was bolted to an aluminum mounting block that fit inside one of the three cavities (See Figure 12). The use of a mounting stud was 
the most appropriate method for securing the accelerometer to the mounting block; however, this method did allow mechanical vibration to be introduced into the data. To isolate the true data signal from the mechanical noise introduced through interactions at the bolt locations of the accelerometer and mounting block, a digital filter was designed using MatLAB. The data signal with the mechanical noise was analyzed using a Fast Fourier Transform (FFT), which breaks the signal down into signal frequencies and magnitude. Based on this analysis, the true data was found below frequencies of 100 Hertz (Hz). This information was then used to build a $4^{\text {th }}$ order Butterworth low pass filter with a cutoff frequency of $150 \mathrm{~Hz}$. The MatLAB code used to analyze the data using the FFT and digital filter is available in Appendix A.

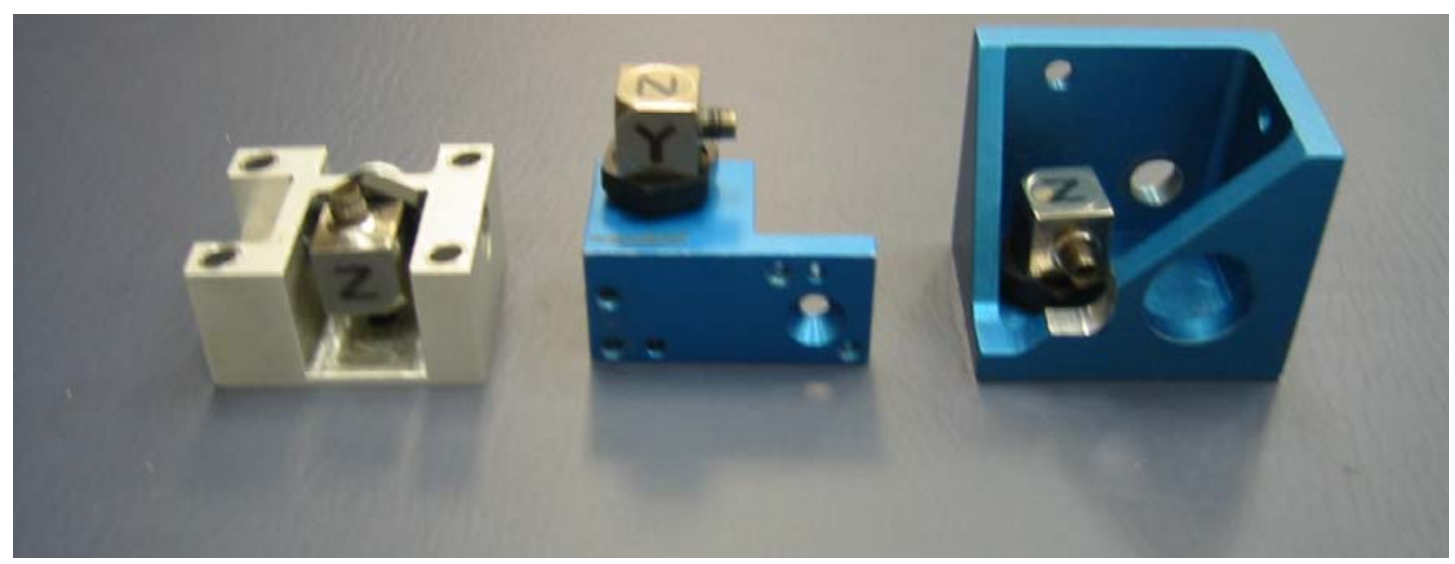

Figure 12: Tri-axial accelerometer aluminum mounting blocks for the head, thorax, and pelvis.

All trials were also recorded using a video camera. The recordings provided a visual verification of fall direction as well as a basis for describing the process of falling from bed. Reviewing the recordings also provided possible explanations for quantitative measurements and statistical analysis. This will be instrumental in furthering clinical understanding of fall from bed events, as few falls are actually observed by caregivers. 


\section{Protocol}

To standardize the data collection process, a data collection protocol was established and displayed at the experimenter's workstation. The data collection protocol is presented in Appendix B.

The impact deceleration was measured at six different bed heights $(33.5,48,62.5$, $77,91.5$, and $97.5 \mathrm{~cm}$ ) with and without the floor mat beside the bed. These twelve different configurations were tested with the ATD falling from bed head first and feet first. A power analysis was conducted with $\alpha=.05$ and $\beta=.80$; the number of trials needed to determine statistical significance was 2. During the data collection process the number of trials was increased to 6 to increase the reliability of the measures as a wide standard deviation was observed.

The data collection process began with arranging the bed, floor mat, and fall direction according to one of the above stated configurations. Once all factors were set to the appropriate conditions, the video camera was set to record the fall event beginning with recording the trial number. The ATD was then raised from the bed via the sling, controlled manually by the ceiling lift activated by the experimenter. The data collection software LabVIEW was activated just prior to the ATD falling from the bed. Once a fall event was complete, the impact deceleration was isolated and exported to a comma delimited file for further analysis. All factors were then returned to initial positions and prepared for further trials.

After all trials were complete, the data files were converted to Microsoft Excel ${ }^{\circledR}$ files and analyzed using the MatLAB code previously discussed. The peak deceleration of each trial for the head, thorax, and pelvis was reported and used to calculate mean maximum values and standard deviations for each test configuration, where mean maximum value equals the mean of the peak deceleration values across similar test conditions. The mean maximum values were also used to calculat impact force for the head during head first falls and for the pelvis during feet first falls according to Equation 2. A two-way ANOVA was performed by the statistical software package $\operatorname{SAS}^{\circledR}$ using the mean and standard deviation calculations for each test configuration. The acceleration profile of the head acceleration for each trial was further analyzed to 
calculate the HIC value according to the formula previously discussed in Injury assessment. The equation used to calculated HIC values was further applied to acceleration profiles measured for the thorax and pelvis; therefore, thoracic injury criteria (TIC) and pelvic injury criteria (PIC) were computed. A two-way ANOVA was also performed on these values using $\mathrm{SAS}^{\circledR}$. The $\mathrm{SAS}^{\circledR}$ code used to analyze the data in this study can be viewed in Appendix C.

$$
\text { Force }=\text { mass } * \text { acceleration } \quad \text { Equation } 2
$$




\section{Results}

\section{Head first falls}

A head first fall event generally began with the arm swinging free of the bedside. As the arm was now no longer in the same plane as the torso, a rotation about the longitudinal axis began. The head and upper torso then began to slide from the bed. The events that followed occurred very quickly and almost simultaneously as the video recording revealed. Depending on the height and amount of rotation that had occurred, the head impacted the ground laterally or anteriorly. The shoulder then impacted the floor, followed closely by the thorax impact. Because the ATD is still rotating throughout the fall event, the shoulder opposite the bedside where the fall initiated was the shoulder that often impacted first; this was true of heights above $48 \mathrm{~cm}$. The pelvis and lower limbs then impacted the floor to complete the fall event. At the completion of the fall event, the ATD landed in a prone position due to the 180 degrees of rotation that occurred about the longitudinal axis.

\section{Acceleration measured at the head}

According to the data collection protocol, 72 trials were conducted and analyzed for head first falls. Of these falls, the mean peak impact decelerations measured in the head ranged from $18.60 \pm 10.89 \mathrm{~g}$ to $70.36 \pm 16.52 \mathrm{~g}$ when the various heights were measured without a mat and from $6.90 \pm 1.41 \mathrm{~g}$ to $21.51 \pm 7.10 \mathrm{~g}$ when measured with a mat. Mean values and standard deviations for each test configuration for head first falls may be viewed in Table 4. As shown in Figure 13, the extreme measurements of the mean decelerations did not always correspond to the extreme test configuration. For instance, the highest deceleration measured when a mat was not in use did not correspond to the extreme height of $97.5 \mathrm{~cm}$ rather to $91.5 \mathrm{~cm}$. However, the ANOVA showed a significant increase in the mean impact decelerations with an increase in height $(\mathrm{p}<$ 
.0001). Likewise, the mean impact decelerations measured when a mat was in use were found to be significantly lower than those measured without a mat $(\mathrm{p}<.0001)$.

Furthermore, the ANOVA showed a significant interaction effect between the mat and an increase in height $(\mathrm{p}=.0006)$. In other words, the mat was more effective at lowering mean impact decelerations measured at the head as height increased.

Table 4: Head mean impact decelerations measured with and without a mat during head first falls and calculated values based on trend line equations.

\begin{tabular}{|l|c|c|}
\hline \multicolumn{1}{|c|}{ Height cm } & $\begin{array}{c}\text { Head g: No Mat } \\
\text { (Mean } \pm \text { SD) }\end{array}$ & $\begin{array}{c}\text { Head g: Mat } \\
\text { (Mean } \pm \text { SD) }\end{array}$ \\
\hline 33.5 & $34.50 \pm 15.42$ & $9.22 \pm 5.56$ \\
\hline 48.0 & $47.69 \pm 25.65$ & $12.69 \pm 12.74$ \\
\hline 62.5 & $18.60 \pm 10.89$ & $6.90 \pm 1.41$ \\
\hline 77.0 & $44.19 \pm 15.80$ & $10.70 \pm 2.94$ \\
\hline 91.5 & $70.36 \pm 16.52$ & $12.26 \pm 4.19$ \\
\hline 97.5 & $64.02 \pm 25.33$ & $21.51 \pm 7.10$ \\
\hline 112.5 & $69.19^{*}$ & $17.63^{* *}$ \\
\hline 115.0 & $70.47^{*}$ & $17.94^{* *}$ \\
\hline 117.5 & $71.75^{*}$ & $18.24^{* *}$ \\
\hline 120.0 & $73.03^{*}$ & $18.55^{* *}$ \\
\hline 122.5 & $74.31^{*}$ & $18.86^{* *}$ \\
\hline
\end{tabular}

*These values are calculated values based on the trend line equation Acceleration $=0.512 *($ Height $)+11.543$.

$* *$ These values are calculated values based on the trend line equation Acceleration $=0.123 *($ Height $)+3.792$. 


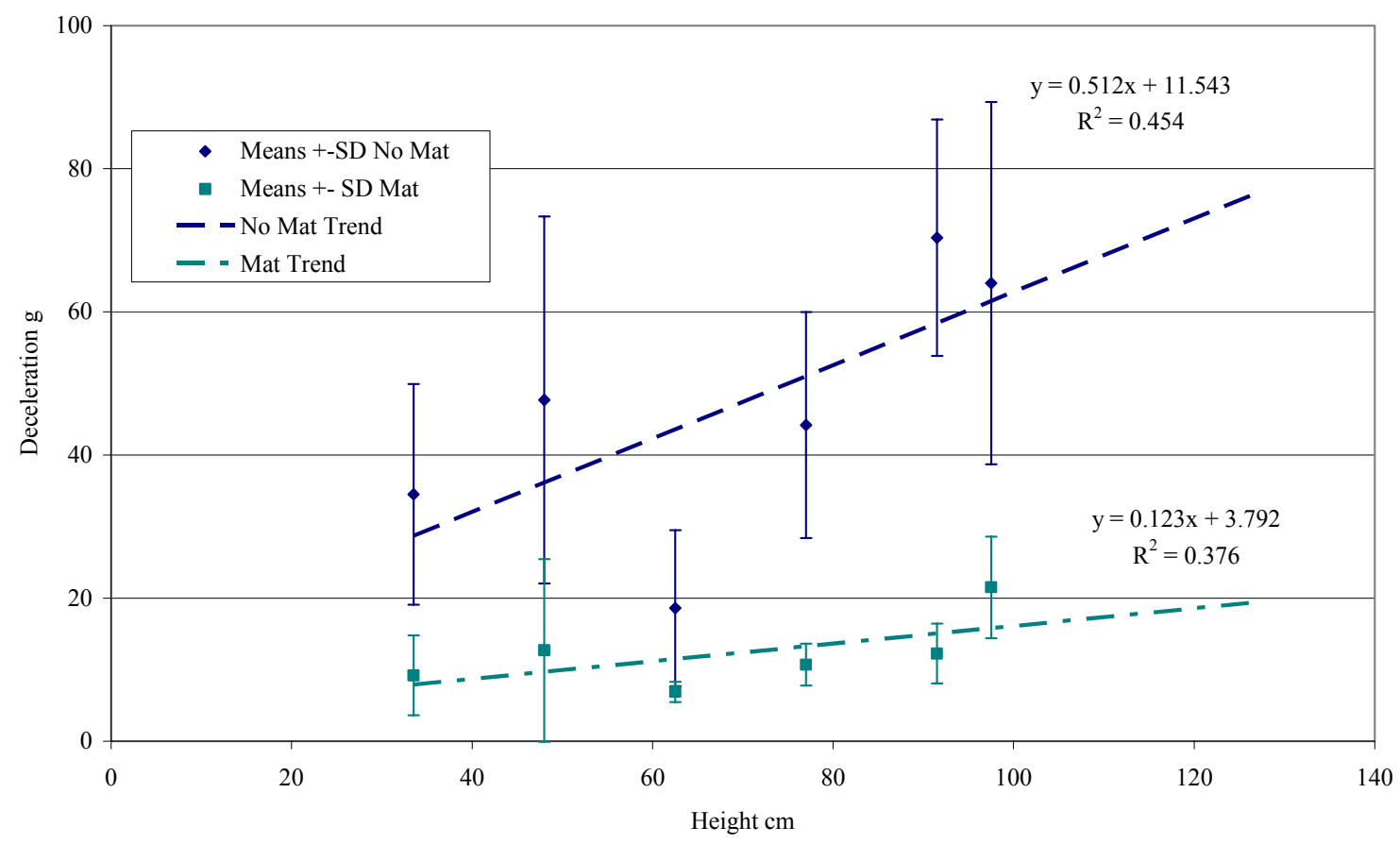

Figure 13: Head mean impact decelerations plotted with an estimated trend line during head first falls.

Head injury criteria (HIC) were also calculated for impact decelerations during head first falls measured with and without a mat. Similar to the mean impact decelerations, the extreme HIC values calculated for head first falls did not always correspond to the extreme test configurations. As such the HIC value calculated for head first falls measured with no mat ranged from $13.41 \pm 19.44$ to $282.68 \pm 103.97$.

Furthermore, the mat appeared to provide some protective effect as the HIC values were generally lower when calculated for trials conducted with a mat, as evidenced in the range of values calculated $1.33 \pm 0.48$ to $10.01 \pm 7.83$. ANOVA was also used to analyze the significance of the protective effect of the various heights and floor mat by comparing the HIC values calculated at the different test conditions. There was a significant effect of height on the HIC values. As the height increased, the HIC value significantly increased $(\mathrm{p}=.0017)$. Likewise, the mat significantly lowered the HIC value calculated for the same height $(\mathrm{p}<.0001)$. The mat was also shown to be more effective as height 
increased $(\mathrm{p}=.0026)$. The trend line equations used to estimate HIC values for heights added by bedrails resulted in a maximum value of 325.05 for falls onto the tile surface and 6.81 for falls onto the floor mat. The HIC values calculated for all test configurations are shown below in Table 5 and graphically illustrated in Figure 14.

Table 5: Mean HIC values calculated for head acceleration profiles measured during trials with and without a mat during head first falls.

\begin{tabular}{|l|c|c|}
\hline \multicolumn{1}{|c|}{ Height cm } & $\begin{array}{c}\text { HIC: No Mat } \\
(\text { Mean } \pm \text { SD) }\end{array}$ & $\begin{array}{c}\text { HIC: Mat } \\
\text { (Mean } \pm \text { SD) }\end{array}$ \\
\hline 33.5 & $38.70 \pm 30.61$ & $3.35 \pm 4.11$ \\
\hline 48.0 & $116.59 \pm 141.19$ & $9.36 \pm 16.16$ \\
\hline 62.5 & $13.41 \pm 19.44$ & $1.33 \pm 0.48$ \\
\hline 77.0 & $84.92 \pm 76.48$ & $3.21 \pm 1.74$ \\
\hline 91.5 & $282.68 \pm 103.97$ & $3.82 \pm 2.08$ \\
\hline 97.5 & $260.49 \pm 264.30$ & $10.01 \pm 7.83$ \\
\hline 112.5 & $289.56^{*}$ & $6.51^{* *}$ \\
\hline 115.0 & $298.43^{*}$ & $6.58^{* *}$ \\
\hline 117.5 & $307.30^{*}$ & $6.66^{* *}$ \\
\hline 120.0 & $316.17^{*}$ & $6.73^{* *}$ \\
\hline 122.5 & $325.05^{*}$ & $6.81^{* *}$ \\
\hline
\end{tabular}

*These values are calculated values based on the trend line equation $\mathrm{HIC}=3.549^{*}$ (Height) -109.728 .

$* *$ These values are calculated values based on the trend line equation $\mathrm{HIC}=0.030 *$ (Height $)+3.133$ 


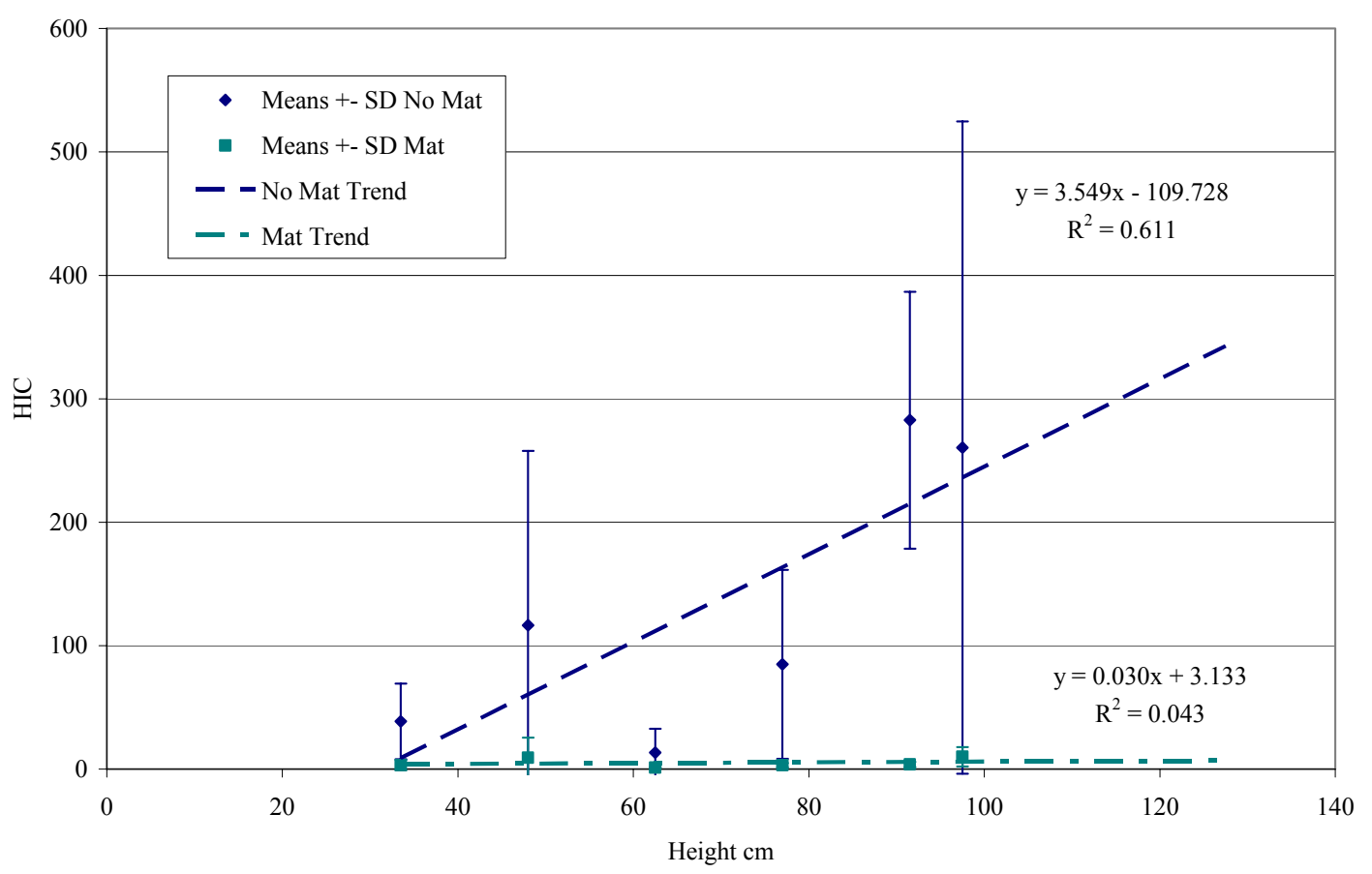

Figure 14: HIC values plotted with an estimated trend line during head first falls.

Force calculations were also performed for the first impact during head first falls. The head impacted the surface first and momentarily supported all the body weight of $76.3 \mathrm{~kg}$. As such the force calculations were based on this weight. The force reached a maximum value $5368.16 \mathrm{~N}$ at a height of $91.5 \mathrm{~cm}$ when impact occurred onto the tile floor. When the floor mat was used, the maximum value was $1641.12 \mathrm{~N}$ as shown in Table 6. These values were derived from Equation 2; therefore, no statistical analysis was performed. The forces calculated for head first falls with and without a floor mat are graphically represented in Figure 15. 
Table 6: Impact forces calculated at the head for head first falls with and without a floor mat.

\begin{tabular}{|c|c|c|}
\hline Height cm & Force N: No Mat & Force N: Mat \\
\hline 33.5 & 2631.99 & 703.13 \\
\hline 48.0 & 3638.53 & 968.02 \\
\hline 62.5 & 1419.24 & 526.79 \\
\hline 77.0 & 3371.51 & 816.68 \\
\hline 91.5 & 5368.16 & 935.67 \\
\hline 97.5 & 4884.87 & 1641.12 \\
\hline
\end{tabular}

Calculated Impact Force for Head First Falls

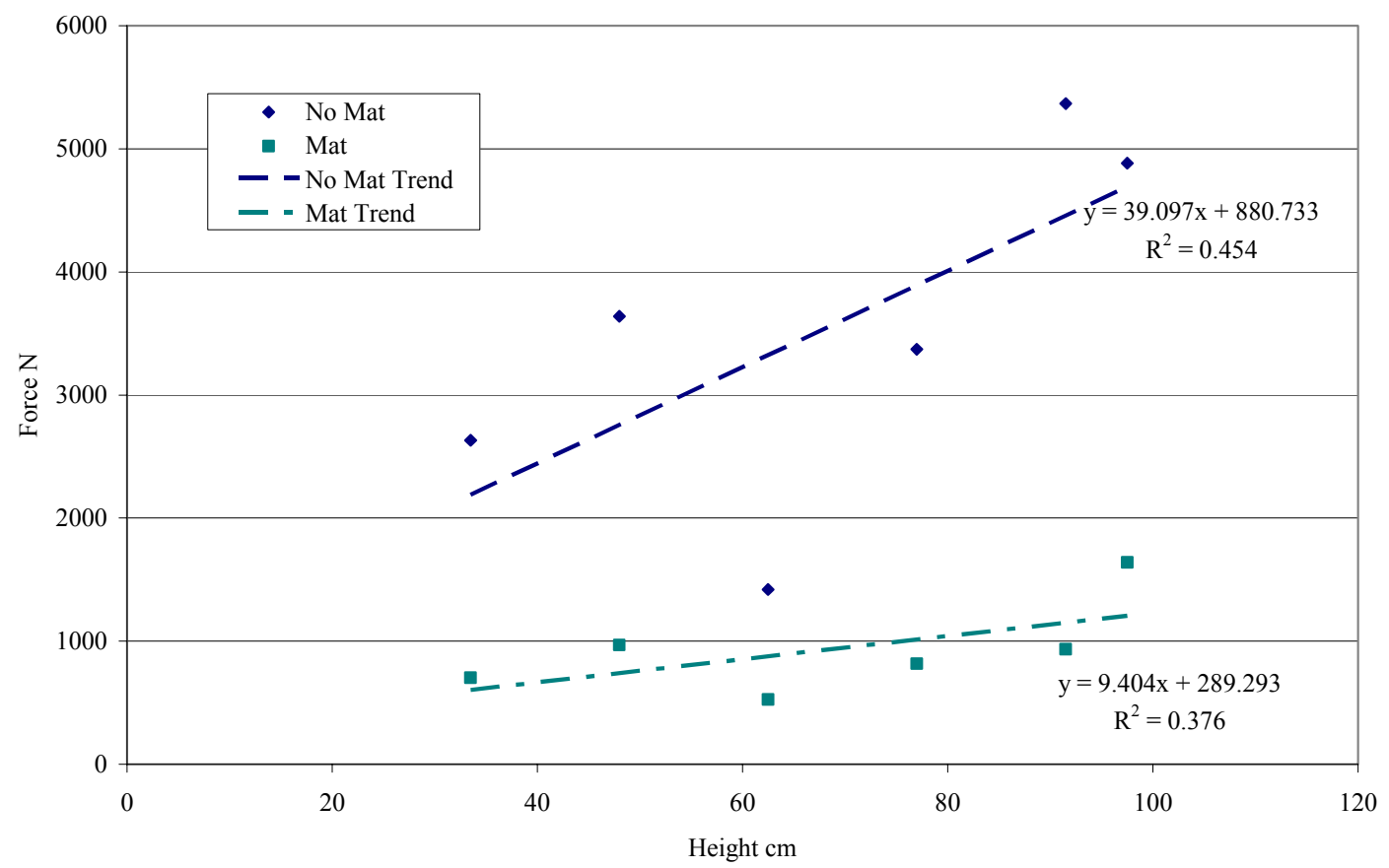

Figure 15: Impact forces plotted with an estimated trend line during head first falls.

\section{Acceleration measured at the thorax}

Impact deceleration was also measured at the thorax during the 72 head first falls. The mean peak impact decelerations measured in the thorax without a mat ranged from $16.85 \pm 6.97 \mathrm{~g}$ to $48.50 \pm 25.54 \mathrm{~g}$; the thoracic impact deceleration measured with a mat ranged from $6.61 \pm 3.98 \mathrm{~g}$ to $46.67 \pm 47.78 \mathrm{~g}$. Mean values and standard deviations for 
each test configuration for head first falls may be viewed in Table 7. The impact decelerations measured with a mat were lower than those measured without a mat for all heights except $77 \mathrm{~cm}$, as shown in Figure 16. As a result, the presence of the mat was found to have no significant effect upon the impact decelerations $(\mathrm{p}=.1639)$. However, the impact decelerations were found to increase significantly with an increase in height $(\mathrm{p}=.0052)$.

Table 7: Thoracic mean impact decelerations measured with and without a mat during head first falls and calculated values based on trend line equations.

\begin{tabular}{|l|c|c|}
\hline \multicolumn{1}{|c|}{ Height cm } & $\begin{array}{c}\text { Thorax g: No Mat } \\
(\text { Mean } \pm \text { SD })\end{array}$ & $\begin{array}{c}\text { Thorax g: Mat } \\
(\text { Mean } \pm \text { SD })\end{array}$ \\
\hline 33.5 & $16.85 \pm 6.97$ & $6.61 \pm 3.98$ \\
\hline 48.0 & $28.55 \pm 15.79$ & $20.79 \pm 19.09$ \\
\hline 62.5 & $29.48 \pm 20.15$ & $13.48 \pm 3.94$ \\
\hline 77.0 & $30.82 \pm 8.63$ & $46.67 \pm 47.78$ \\
\hline 91.5 & $36.14 \pm 9.55$ & $13.87 \pm 2.80$ \\
\hline 97.5 & $48.50 \pm 25.54$ & $43.11 \pm 41.31$ \\
\hline 112.5 & $47.11^{*}$ & $39.33^{* *}$ \\
\hline 115.0 & $47.93^{*}$ & $40.44^{* *}$ \\
\hline 117.5 & $48.75^{*}$ & $41.55^{* *}$ \\
\hline 120.0 & $49.56^{*}$ & $42.67^{* *}$ \\
\hline 122.5 & $50.37^{*}$ & $43.80^{* *}$ \\
\hline
\end{tabular}

*These values are calculated values based on the trend line equation Acceleration $=1.148 *\left(\right.$ Height $\left.^{0.787}\right)$.

**These values are calculated values based on the trend line equation Acceleration $=0.100 *\left(\right.$ Height $\left.{ }^{1.265}\right)$. 
Thorax Deceleration during Head First Falls

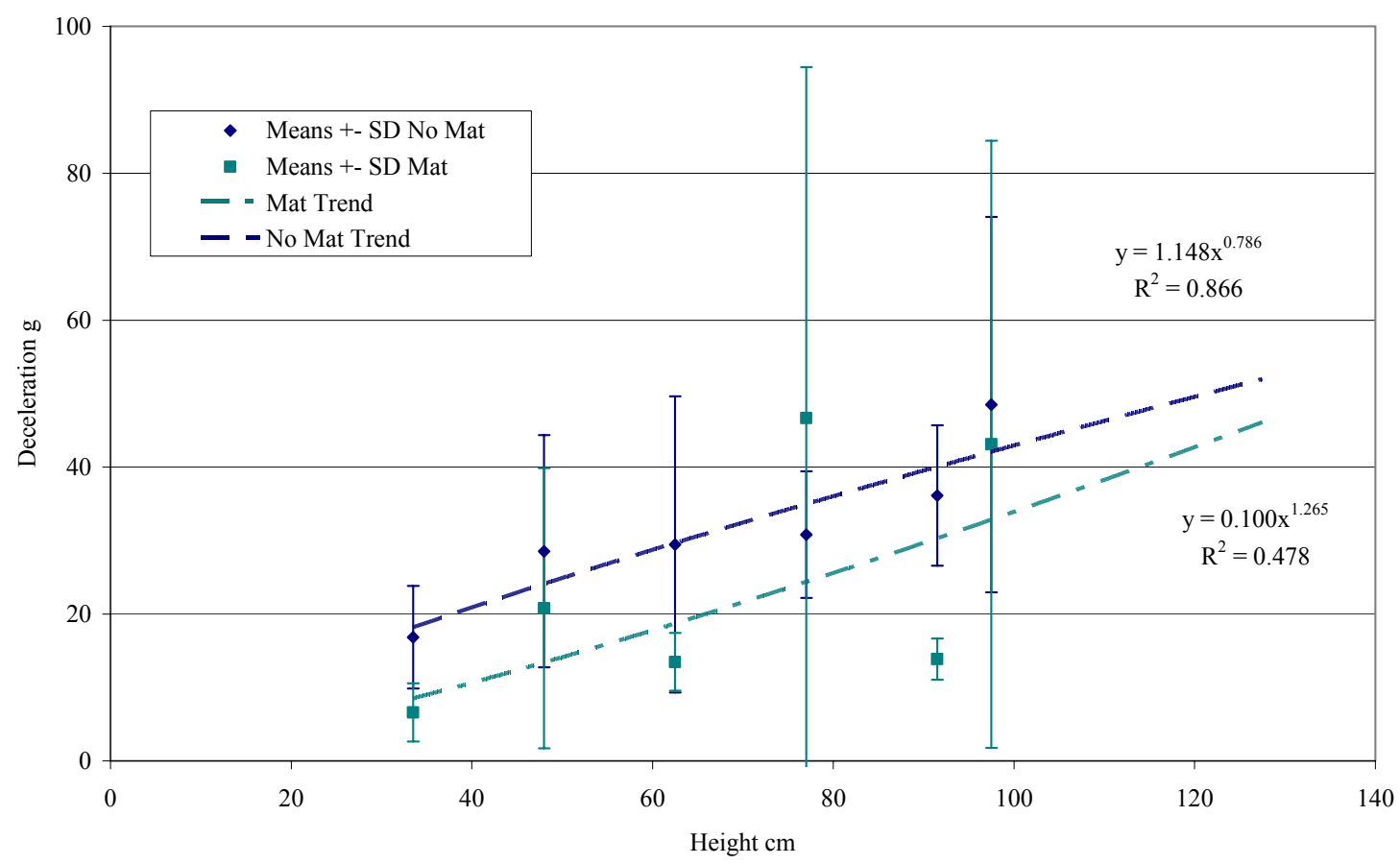

Figure 16: Thoracic mean impact decelerations plotted with an estimated trend line during head first falls.

Injury criteria were also calculated for impact decelerations measured at the thorax during head first falls. The thoracic injury criteria (TIC) ranged from $23.45 \pm$ 31.61 to $220.85 \pm 274.74$ when calculated for impacts onto the tile surface. The TIC calculated for impacts onto the floor mat ranged from $1.58 \pm 2.04$ to $525.12 \pm 824.83$. Interestingly, the extreme TIC values calculated for impacts onto the tile surface corresponded to the extreme bed heights; however, the TIC values calculated for impacts onto the floor mat did not follow a similar pattern. Impacts occurring from a height of 77 $\mathrm{cm}$ onto a floor mat resulted in the highest TIC values, whereas impacts occurring from a height of $33.5 \mathrm{~cm}$ onto a floor mat resulted in the lowest TIC values. As shown in Table 8 , the TIC values did not consistently decrease with the use of the floor mat, as expected, nor was there a consistent increase due to height. As such, the TIC values were not significantly increased with an increase in height $(\mathrm{p}=.1180)$ or significantly decreased with the use of the floor mat $(\mathrm{p}=.4286)$. Trend line equations were used to estimate TIC values for heights added by bedrails and resulted in a maximum value of 259.83 for 
falls onto the tile surface and 236.45 for falls onto the floor mat. Figure 17 illustrates these values graphically.

Table 8: Mean TIC values calculated for thoracic acceleration profiles measured during trials with and without a mat during head first falls.

\begin{tabular}{|l|c|c|}
\hline \multicolumn{1}{|c|}{ Height cm } & $\begin{array}{c}\text { TIC: No Mat } \\
(\text { Mean } \pm \text { SD) }\end{array}$ & $\begin{array}{c}\text { TIC: Mat } \\
\text { (Mean } \pm \text { SD) }\end{array}$ \\
\hline 33.5 & $23.45 \pm 31.61$ & $1.58 \pm 2.04$ \\
\hline 48.0 & $60.24 \pm 58.58$ & $68.51 \pm 139.95$ \\
\hline 62.5 & $89.89 \pm 152.01$ & $6.37 \pm 5.92$ \\
\hline 77.0 & $37.49 \pm 5.26$ & $525.12 \pm 824.83$ \\
\hline 91.5 & $102.09 \pm 32.50$ & $8.23 \pm 4.26$ \\
\hline 97.5 & $220.85 \pm 274.74$ & $247.28 \pm 350.52$ \\
\hline 112.5 & $203.37^{*}$ & $301.14^{* *}$ \\
\hline 115.0 & $216.22^{*}$ & $322.79^{* *}$ \\
\hline 117.5 & $229.87^{*}$ & $345.48^{* *}$ \\
\hline 120.0 & $244.39^{*}$ & $369.23^{* *}$ \\
\hline 122.5 & $259.83^{*}$ & $394.08^{* *}$ \\
\hline
\end{tabular}

*These values are calculated values based on the trend line equation $\mathrm{TIC}=12.920 * \mathrm{e}\left({ }^{0.0245^{*} \text { Height }}\right)$.

**These values are calculated values based on the trend line equation $\mathrm{TIC}=0.0001^{*}\left(\right.$ Height $\left.^{3.1586}\right)$. 


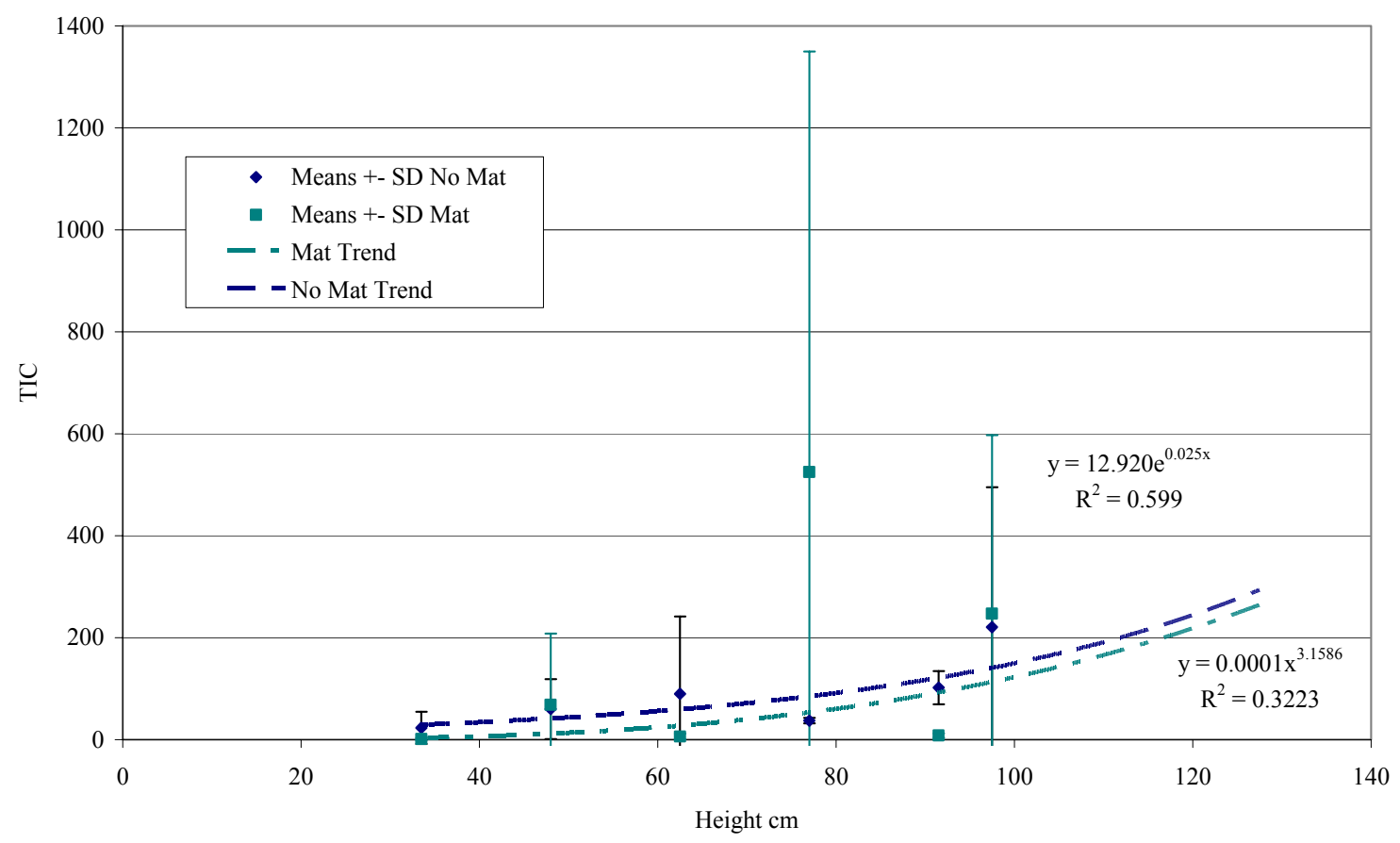

Figure 17: TIC values plotted with an estimated trend line during head first falls.

\section{Accelerations measured at the pelvis}

During the head first falls, impact deceleration was also measured at the pelvis.

When measured without a mat, the pelvic impact deceleration ranged from $11.46 \pm 7.54 \mathrm{~g}$ to $20.74 \pm 3.85 \mathrm{~g}$. The pelvic impact deceleration measured with a mat ranged from 8.48 $\pm 4.03 \mathrm{~g}$ to $20.52 \pm 10.99 \mathrm{~g}$. Table 9 includes means and standard deviations for all test configurations, and Figure 18 illustrates these values. The mean impact decelerations were significantly higher with an increase in height $(\mathrm{p}=.0397)$. Likewise, the use of the mat significantly lowered the mean impact decelerations $p=.0224$ ). However, the effectiveness of the mat did not change with a change in height. 
Table 9: Pelvic mean impact decelerations measured with and without a mat during head first falls and calculated values based on trend line equations.

\begin{tabular}{|l|c|c|}
\hline \multicolumn{1}{|c|}{ Height cm } & $\begin{array}{c}\text { Pelvis g: No Mat } \\
(\text { Mean } \pm \text { SD) }\end{array}$ & $\begin{array}{c}\text { Pelvis g: Mat } \\
\text { (Mean } \pm \text { SD) }\end{array}$ \\
\hline 33.5 & $14.29 \pm 8.25$ & $8.48 \pm 4.03$ \\
\hline 48.0 & $11.46 \pm 7.54$ & $13.97 \pm 7.45$ \\
\hline 62.5 & $20.74 \pm 3.85$ & $11.31 \pm 6.82$ \\
\hline 77.0 & $19.82 \pm 10.67$ & $12.44 \pm 4.16$ \\
\hline 91.5 & $18.06 \pm 5.91$ & $20.52 \pm 10.99$ \\
\hline 97.5 & $20.63 \pm 7.33$ & $16.32 \pm 9.94$ \\
\hline 112.5 & $21.31^{*}$ & $18.78^{* *}$ \\
\hline 115.0 & $21.45^{*}$ & $19.03^{* *}$ \\
\hline 117.5 & $21.60^{*}$ & $19.28^{* *}$ \\
\hline 120.0 & $21.74^{*}$ & $19.52^{* *}$ \\
\hline 122.5 & $21.88^{*}$ & $19.77^{* *}$ \\
\hline
\end{tabular}

*These values are calculated values based on the trend line equation Acceleration $=6.754 *$ Ln (Height) -10.592 .

**These values are calculated values based on the trend line equation Acceleration $=1.073 *\left(\right.$ Height $\left.^{0.606}\right)$. 


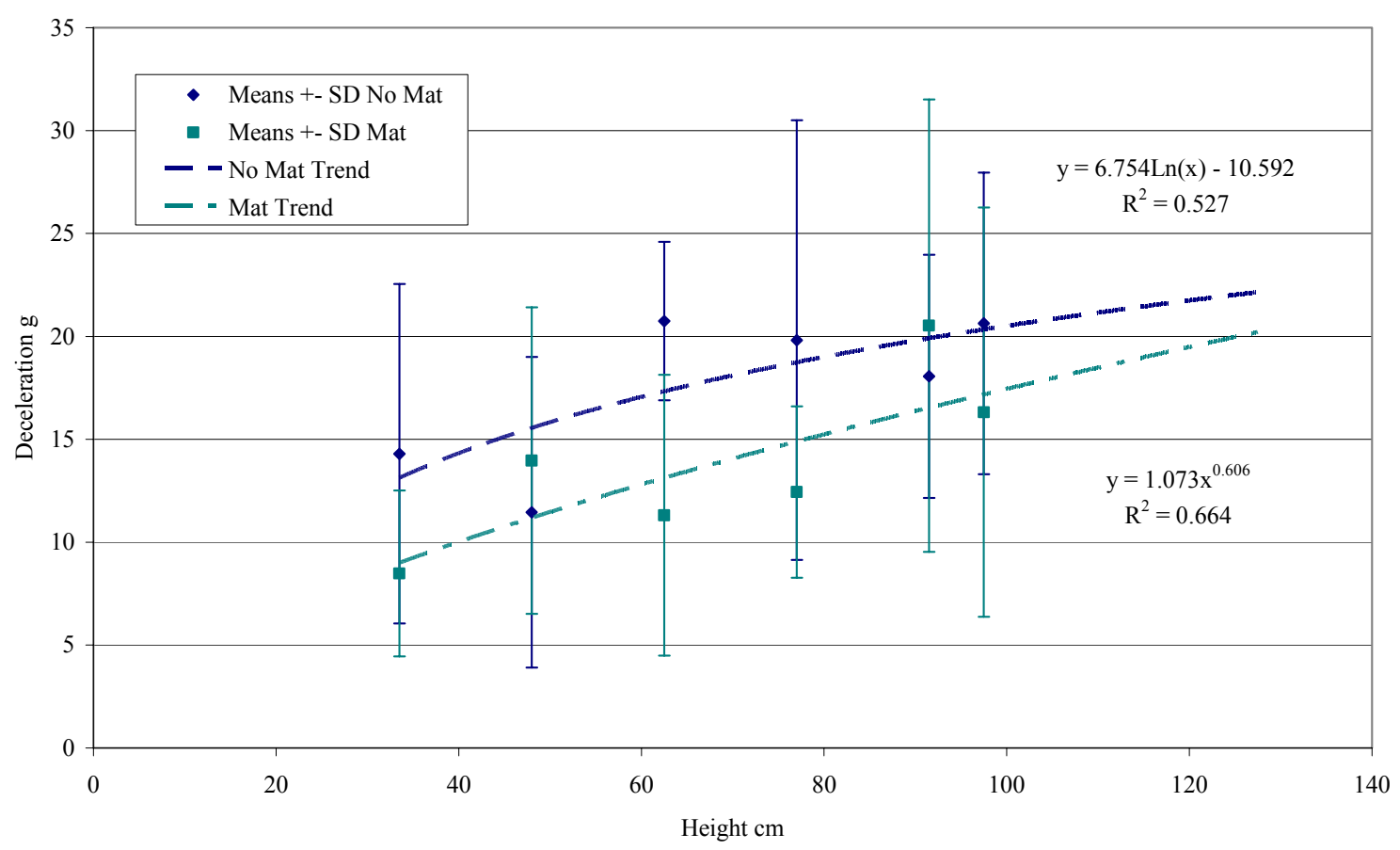

Figure 18: Pelvic mean impact decelerations plotted with an estimated trend line during head first falls.

Pelvic injury criteria (PIC) were also calculated for impact decelerations measured during head first falls. The PIC values calculated for impacts onto the tile surface ranged from $7.52 \pm 8.46$ to $21.69 \pm 13.78$, as shown in Table 10. The PIC values calculated for impacts onto the floor mat ranged from $2.14 \pm 1.74$ to $17.05 \pm 13.56$. Similar to the mean maximum values, the highest PIC value calculated did not correspond to the extreme trial condition of $97.5 \mathrm{~cm}$ with no floor mat, rather to $77 \mathrm{~cm}$ with no floor mat. As such, the PIC values did not significantly increase with an increase in height $(\mathrm{p}=.2245)$. Furthermore, impacts onto the floor mat did not result in significantly lower PIC values than those onto the tile floor $(\mathrm{p}=.0930)$. A maximum value of 21.25 was estimated for falls onto the tile surface from heights added by bedrails and 23.03 for falls onto the floor mat when a trend line was fitted to the measured data. Figure 19 graphically illustrates the PIC values calculated for head first falls. 
Table 10: Mean PIC values calculated for pelvic deceleration profiles measured during trials with and without a mat during head first falls.

\begin{tabular}{|l|c|c|}
\hline \multicolumn{1}{|c|}{ Height cm } & $\begin{array}{c}\text { PIC: No Mat } \\
(\text { Mean } \pm \text { SD) }\end{array}$ & $\begin{array}{c}\text { PIC: Mat } \\
(\text { Mean } \pm \text { SD) }\end{array}$ \\
\hline 33.5 & $11.21 \pm 14.41$ & $2.14 \pm 1.74$ \\
\hline 48.0 & $7.52 \pm 8.46$ & $10.98 \pm 15.07$ \\
\hline 62.5 & $17.10 \pm 10.22$ & $12.70 \pm 12.01$ \\
\hline 77.0 & $21.69 \pm 13.78$ & $9.08 \pm 5.76$ \\
\hline 91.5 & $16.76 \pm 12.48$ & $17.05 \pm 13.56$ \\
\hline 97.5 & $17.90 \pm 9.56$ & $11.92 \pm 16.58$ \\
\hline 112.5 & $20.48^{*}$ & $20.37^{* *}$ \\
\hline 115.0 & $20.68^{*}$ & $21.03^{* *}$ \\
\hline 117.5 & $20.88^{*}$ & $21.69^{* *}$ \\
\hline 120.0 & $21.07^{*}$ & $22.36^{* *}$ \\
\hline 122.5 & $21.25^{*}$ & $23.03^{* *}$ \\
\hline
\end{tabular}

*These values are calculated values based on the trend line equation PIC $=9.082 * \operatorname{Ln}($ Height $)-22.414$.

**These values are calculated values based on the trend line equation $\mathrm{PIC}=0.023 *\left(\right.$ Height $\left.^{1.440}\right)$. 


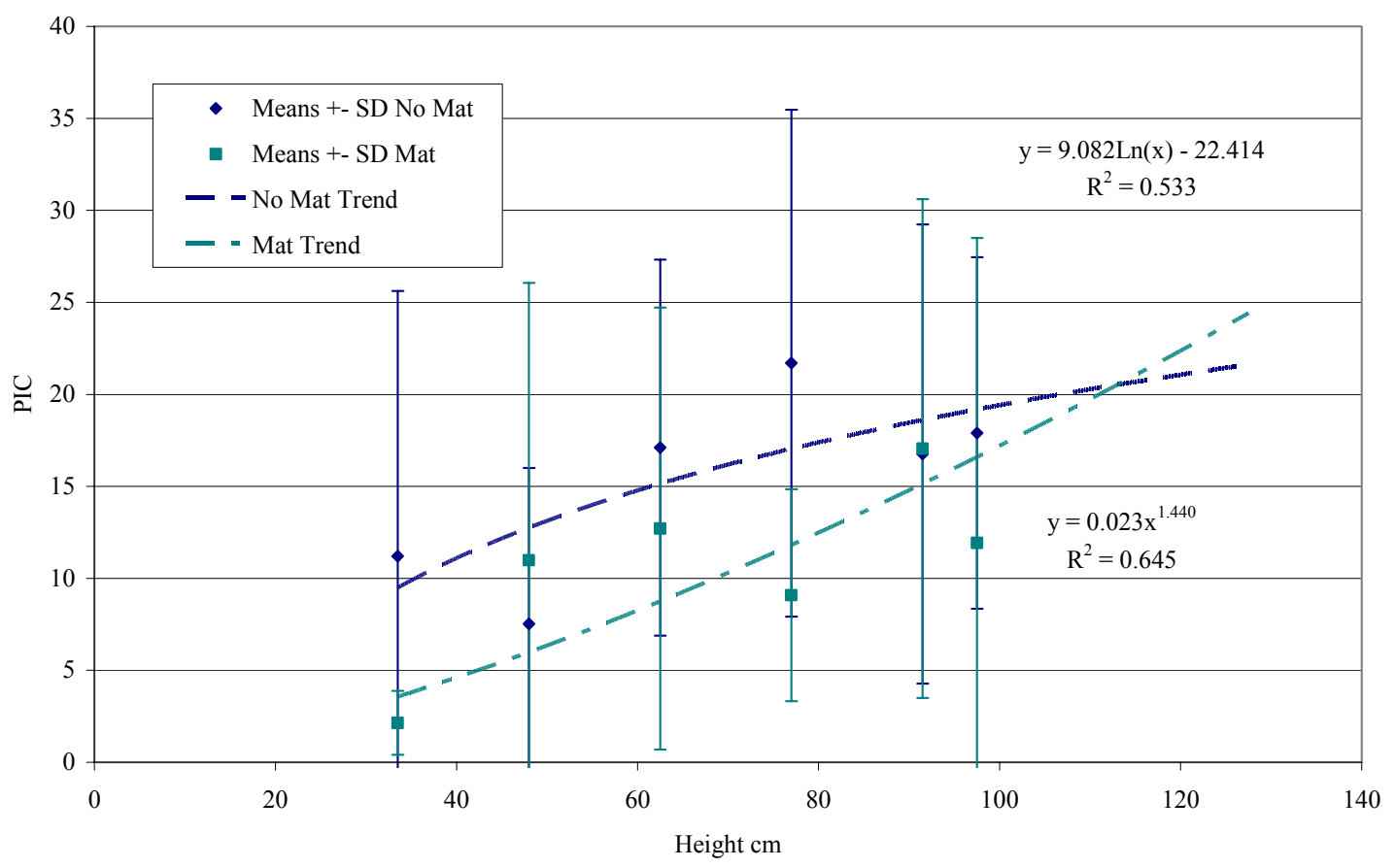

Figure 19: PIC values plotted with an estimated trend line during head first falls.

\section{Feet first falls}

As the description indicates feet first falls were initiated with the feet sliding from the bed. At heights above $48 \mathrm{~cm}$, the lower limbs slide from the bed in a nearly straight position. However, the feet and knees initiated a "crumple" effect at lower heights as these areas were in contact with the floor for long periods of time before torso impact occurred. Similar to head first falls, rotation occurred about the longitudinal axis; however, the dummy completed 180 degrees of rotation before impacting the floor. Consequently, when the pelvis impacted the floor, impact occurred either laterally at the hip farther from the bedside where the fall initiated or on the entire posterior portion of the pelvis. The rotation continued as the impact events occurred, and the thorax impacted fully in the posterior position regardless of height. The fall terminated with the head impacting the floor in the posterior position. As such, the dummy landed in a supine position at the end of the fall event. Furthermore, the dummy was observed to come to rest at greater distances away from the bed as height increased. With an increase in 
height, the ATD's final position on the floor moved passed the top of the bed and laterally away from the side of the bed.

\section{Acceleration measured at the head}

Although 72 trials were conducted with the fall direction as feet first, impact deceleration at the head was only measured for 54 of those trials; accelerometer frequency limitations prevented data collection above heights of $62.5 \mathrm{~cm}$ when measured without a mat. Since the accelerometer had a defined frequency range, any frequency measured by the accelerometer exceeding that range caused the instrument to shut down to prevent damage to the electronics. The mechanical vibrations between the mounting block and accelerometer may have caused the excessive frequency readings.

Consequently, the impact decelerations measured without a mat ranged from $74.13 \pm$ $58.41 \mathrm{~g}$ to $152.47 \pm 46.12 \mathrm{~g}$. Those measured with a mat included all heights and ranged from $8.48 \pm 6.66 \mathrm{~g}$ to $91.58 \pm 47.24 \mathrm{~g}$. Table 11 displays all mean and standard deviation values for head impact deceleration measured during feet first falls. The data measured at heights $33.5,48$, and $62.5 \mathrm{~cm}$ were the only heights included in the ANOVA. Nonetheless, a change in height was shown to increase the impact deceleration significantly $(p=.0004)$. Furthermore, the mat significantly lowered the impact deceleration $(\mathrm{p}<.0001)$; however, this effect was not dependent upon a change in height, as shown in Figure 20. 
Table 11: Head mean impact decelerations measured with and without a mat during feet first falls and calculated values based on trend line equations.

\begin{tabular}{|l|c|c|}
\hline \multicolumn{1}{|c|}{ Height cm } & $\begin{array}{c}\text { Head g: No Mat } \\
\text { (Mean } \pm \text { SD) }\end{array}$ & $\begin{array}{c}\text { Head g: Mat } \\
(\text { Mean } \pm \text { SD) }\end{array}$ \\
\hline 33.5 & $74.13 \pm 58.41$ & $8.48 \pm 6.66$ \\
\hline 48.0 & $152.47 \pm 46.12$ & $41.51 \pm 22.40$ \\
\hline 62.5 & $131.81 \pm 31.07$ & $75.93 \pm 26.38$ \\
\hline 77.0 & $187.86^{*}$ & $91.58 \pm 47.24$ \\
\hline 91.5 & $222.71^{*}$ & $66.41 \pm 38.37$ \\
\hline 97.5 & $237.11^{*}$ & $54.52 \pm 27.73$ \\
\hline 112.5 & $273.06^{*}$ & $118.03^{* *}$ \\
\hline 115.0 & $279.04^{*}$ & $122.56^{* *}$ \\
\hline 117.5 & $285.02^{*}$ & $127.16^{* *}$ \\
\hline 120.0 & $291.00^{*}$ & $131.83^{* *}$ \\
\hline 122.5 & $296.98^{*}$ & $136.57^{* *}$ \\
\hline
\end{tabular}

*These values are calculated values based on the trend line equation Acceleration $=2.589 *\left(\right.$ Height $\left.^{0.986}\right)$.

$* *$ These values are calculated values based on the trend line equation Acceleration $=0.036^{*}\left(\right.$ Height $\left.{ }^{1.714}\right)$. 


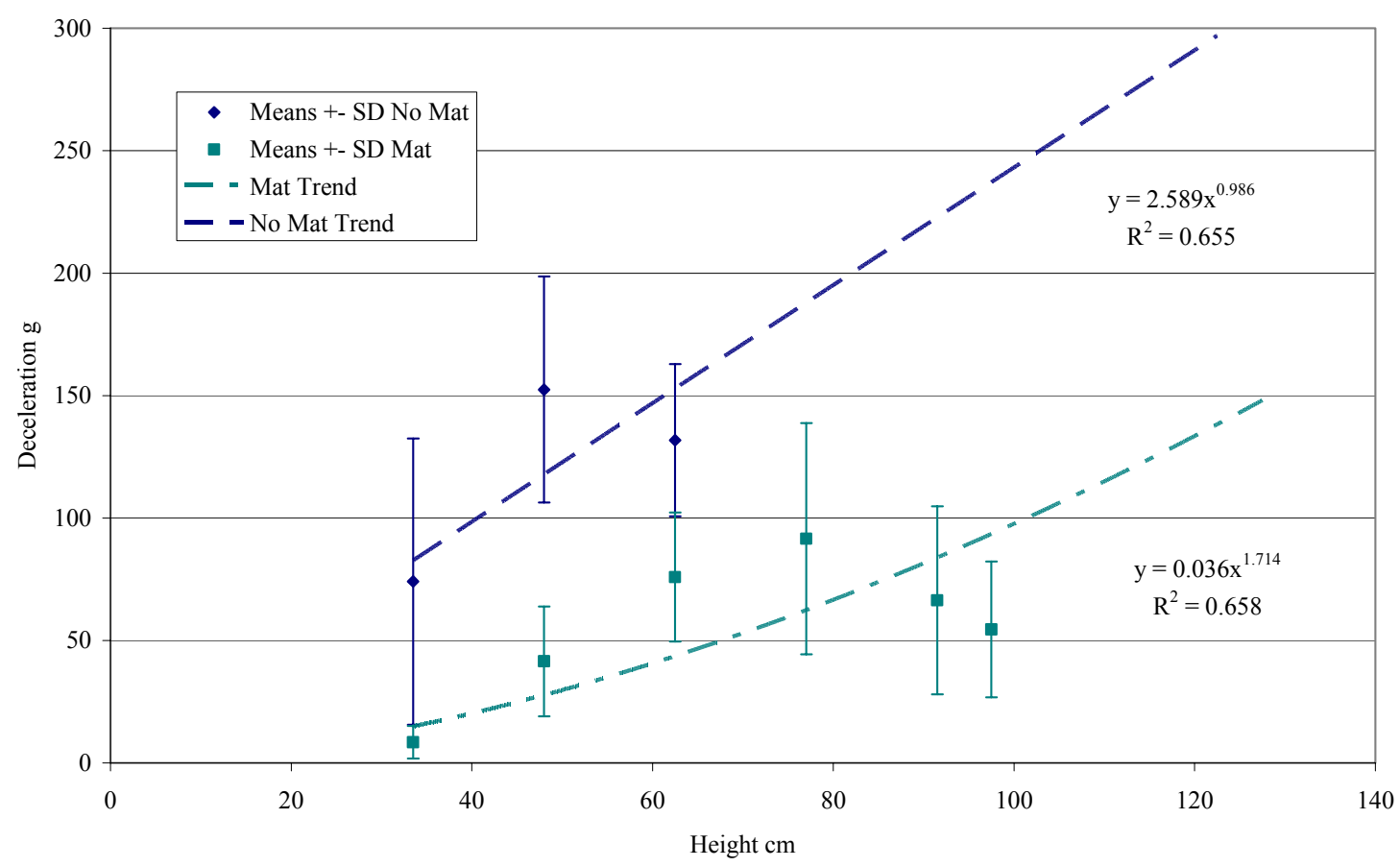

Figure 20: Head mean impact decelerations plotted with an estimated trend line during feet first falls.

Head injury criteria (HIC) were also calculated for feet first falls for the trials with available data. Mean HIC values calculated for trials conducted without a mat ranged from $486.51 \pm 880.08$ to $1234.63 \pm 945.72$. Trials conducted with a mat resulted in lower mean HIC values and ranged from $3.96 \pm 5.37$ to $374.35 \pm 389.04$. All means and standard deviations of calculated HIC values are presented in Table 12 and illustrated in Figure 21. ANOVA was also used to determine if changing the height or removing the mat had a significant effect upon HIC values. From this analysis, a change in height was determined to have no significant effect upon the HIC values $(p=.2136)$. However, removing the mat significantly increased the HIC values $(p=.0006)$. Trend line equations were used to estimate the HIC values for heights added by bedrails and resulted in a maximum value of 1468.59 for falls onto the tile surface and 737.35 for falls onto the floor mat. 
Table 12: Mean HIC values calculated for head deceleration profiles measured during trials with and without a mat during feet first falls.

\begin{tabular}{|l|c|c|}
\hline \multicolumn{1}{|c|}{ Height cm } & $\begin{array}{c}\text { HIC: No Mat } \\
\text { (Mean } \pm \text { SD) }\end{array}$ & $\begin{array}{c}\text { HIC: Mat } \\
(\text { Mean } \pm \text { SD) }\end{array}$ \\
\hline 33.5 & $486.51 \pm 880.08$ & $3.96 \pm 5.37$ \\
\hline 48.0 & $1234.63 \pm 945.72$ & $73.92 \pm 65.03$ \\
\hline 62.5 & $697.79 \pm 321.44$ & $212.26 \pm 151.19$ \\
\hline 77.0 & $1063.05^{*}$ & $374.35 \pm 389.04$ \\
\hline 91.5 & $1198.69^{*}$ & $196.82 \pm 204.70$ \\
\hline 97.5 & $1252.87^{*}$ & $133.75 \pm 100.85$ \\
\hline 112.5 & $1384.08^{*}$ & $557.23^{* *}$ \\
\hline 115.0 & $1405.41^{*}$ & $599.00^{* *}$ \\
\hline 117.5 & $1426.61^{*}$ & $642.91^{* *}$ \\
\hline 120.0 & $1447.66^{*}$ & $689.00^{* *}$ \\
\hline 122.5 & $1468.59^{*}$ & $737.35^{* *}$ \\
\hline
\end{tabular}

*These values are calculated values based on the trend line equation $\mathrm{HIC}=51.708 *\left(\right.$ Height $\left.^{0.696}\right)$.

**These values are calculated values based on the trend line equation $\mathrm{HIC}=0.0001 *\left(\right.$ Height $\left.^{3.289}\right)$. 


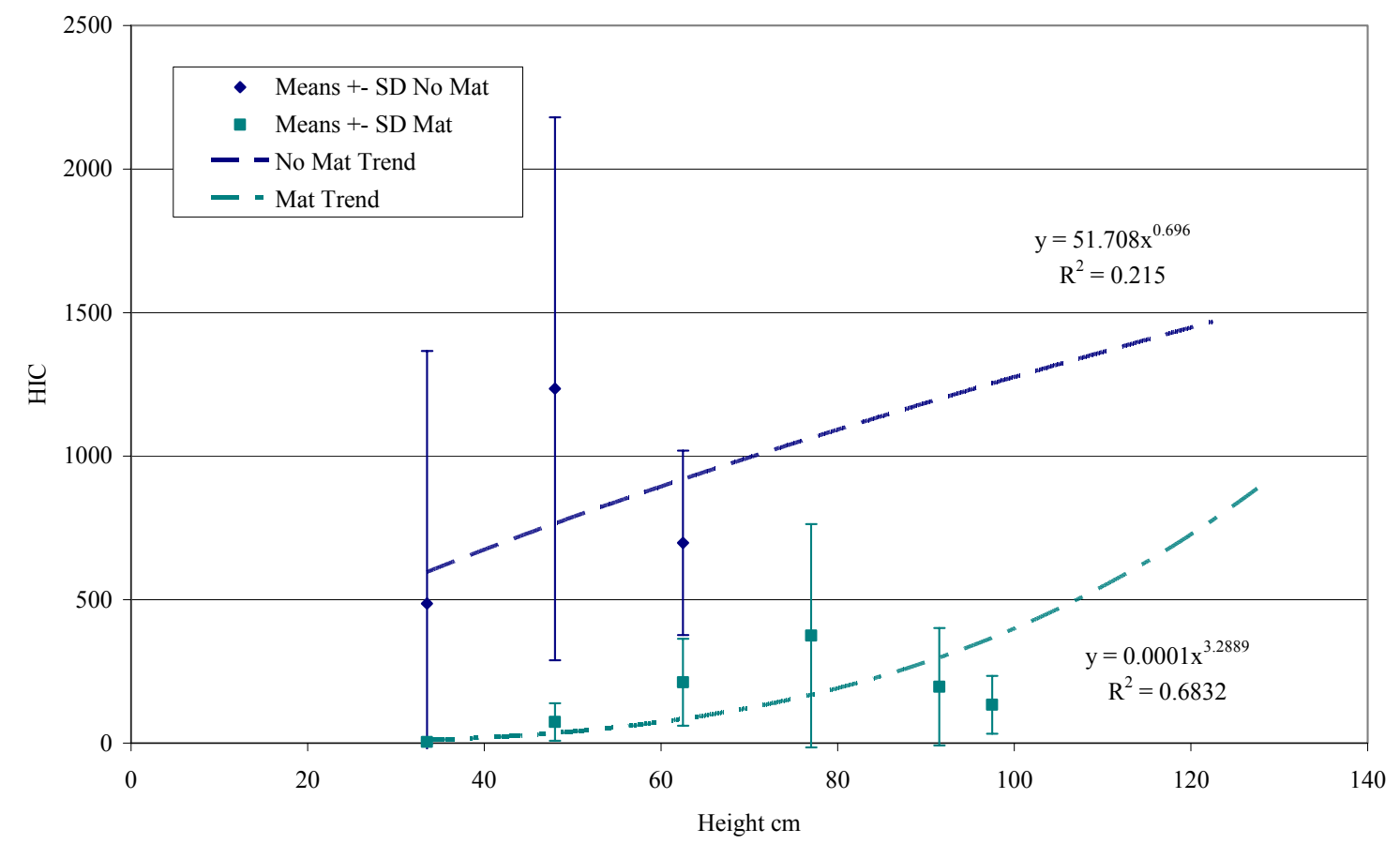

Figure 21: HIC values plotted with an estimated trend line during feet first falls.

\section{Acceleration measured at the thorax}

Due to accelerometer limitations, data was collected for all heights except 97.5

$\mathrm{cm}$. For the remaining heights, the mean impact decelerations measured at the thorax during feet first falls ranged from $8.47 \pm 5.16 \mathrm{~g}$ to $95.12 \pm 43.13 \mathrm{~g}$ without a mat and from $3.29 \pm 0.61 \mathrm{~g}$ to $58.25 \pm 46.01 \mathrm{~g}$ with a mat. All means and standard deviations are presented in Table 13 and graphically illustrated in Figure 22. Analysis of the available data showed a significant increase in impact deceleration with an increase in height $(\mathrm{p}<$ .0001). Also, mean impact decelerations significantly increased when the mat was not used $(\mathrm{p}<.0001)$. The mean impact decelerations measured during mat usage was influenced by a change in height, as an increase in height increased the effect of the mat $(\mathrm{p}=.0103)$. 
Table 13: Thoracic mean impact decelerations measured with and without a mat during feet first falls and calculated values based on trend line equations.

\begin{tabular}{|l|c|c|}
\hline \multicolumn{1}{|c|}{ Height cm } & $\begin{array}{c}\text { Thorax g: No Mat } \\
\text { (Mean } \pm \text { SD) }\end{array}$ & $\begin{array}{c}\text { Thorax g: Mat } \\
\text { (Mean } \pm \text { SD) }\end{array}$ \\
\hline 33.5 & $8.47 \pm 5.16$ & $3.29 \pm 0.61$ \\
\hline 48.0 & $17.80 \pm 6.04$ & $7.15 \pm 1.58$ \\
\hline 62.5 & $43.06 \pm 16.00$ & $20.26 \pm 10.17$ \\
\hline 77.0 & $50.23 \pm 13.64$ & $38.30 \pm 28.26$ \\
\hline 91.5 & $95.12 \pm 43.13$ & $38.06 \pm 16.24$ \\
\hline 97.5 & $105.54^{*}$ & $58.25 \pm 46.01$ \\
\hline 112.5 & $148.02^{*}$ & $99.54^{* *}$ \\
\hline 115.0 & $155.91^{*}$ & $105.61^{* *}$ \\
\hline 117.5 & $164.04^{*}$ & $111.90^{* *}$ \\
\hline 120.0 & $172.41^{*}$ & $118.43^{* *}$ \\
\hline 122.5 & $181.02^{*}$ & $125.18^{* *}$ \\
\hline
\end{tabular}

*These values are calculated values based on the trend line equation Acceleration $=\mathrm{y}=0.002 *\left(\right.$ Height $\left.^{2.364}\right)$.

**These values are calculated values based on the trend line equation Acceleration $=0.0003^{*}\left(\right.$ Height $\left.^{2.2916}\right)$. 
Thorax Deceleration during Feet First Falls

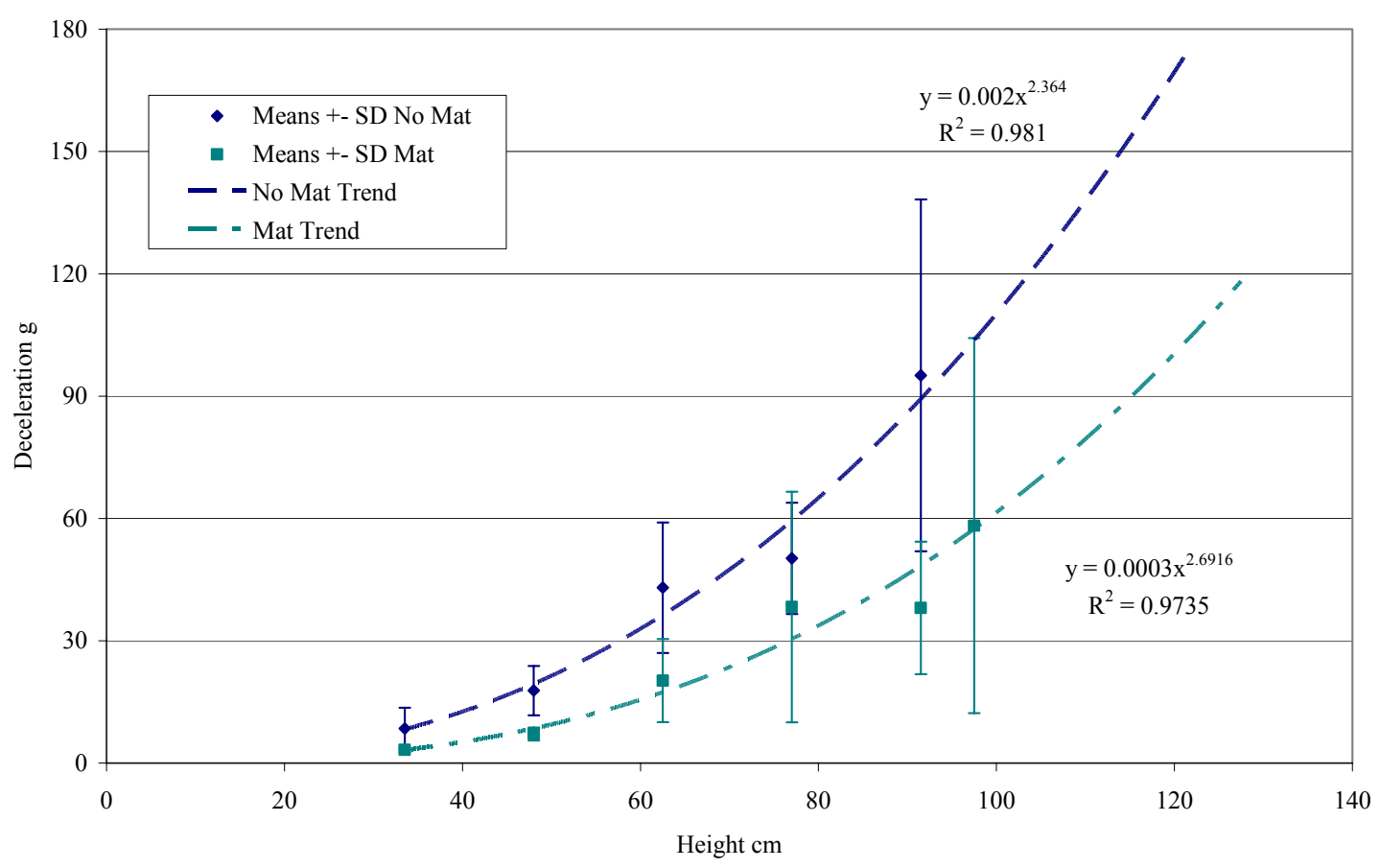

Figure 22: Thoracic mean impact decelerations plotted with an estimated trend line during feet first falls.

Injury criteria were calculated from the thoracic acceleration profiles measured for feet first falls. These values are shown for impacts with and without a floor mat in Table 14 and illustrated in Figure 23. The thoracic injury criteria (TIC) reached a maximum of $1103.40 \pm 733.32$ at a height of $91.5 \mathrm{~cm}$ and a minimum of $1.45 \pm 1.16$ when measured without a floor mat. The maximum TIC value calculated for impacts onto the floor mat was $379.02 \pm 456.90$ and a minimum of $0.17 \pm 0.05$. These values increased significantly with an increase in height $(\mathrm{p}<.0001)$ and decreased significantly with the use of a floor mat $(p=.0007)$. Furthermore, the mat more effectively decreased the TIC values at higher heights $(\mathrm{p}=.0002)$. Trend lines were also used to project TIC values that may result with the addition of bedrails. These values reached a maximum of 8053.09 without a floor mat and 1995.77 when a floor mat was utilized. 
Table 14: Mean TIC values calculated for thoracic deceleration profiles measured during trials with and without a mat during feet first falls.

\begin{tabular}{|l|c|c|}
\hline \multicolumn{1}{|c|}{ Height cm } & $\begin{array}{c}\text { TIC: No Mat } \\
(\text { Mean } \pm \text { SD) }\end{array}$ & $\begin{array}{c}\text { TIC: Mat } \\
(\text { Mean } \pm \text { SD })\end{array}$ \\
\hline 33.5 & $1.45 \pm 1.16$ & $0.17 \pm 0.05$ \\
\hline 48.0 & $13.69 \pm 8.84$ & $1.38 \pm 0.76$ \\
\hline 62.5 & $150.50 \pm 151.35$ & $39.54 \pm 30.86$ \\
\hline 77.0 & $298.17 \pm 368.83$ & $141.69 \pm 194.83$ \\
\hline 91.5 & $1103.40 \pm 733.32$ & $111.20 \pm 131.19$ \\
\hline 97.5 & $1776.46^{*}$ & $379.02 \pm 456.90$ \\
\hline 112.5 & $4582.18^{*}$ & $1082.58 * *$ \\
\hline 115.0 & $5300.02 *$ & $1267.72 * *$ \\
\hline 117.5 & $6111.12^{*}$ & $1479.49 * *$ \\
\hline 120.0 & $7025.33^{*}$ & $1721.03 * *$ \\
\hline 122.5 & $8053.09 *$ & $1995.77 * *$ \\
\hline
\end{tabular}

*These values are calculated values based on the trend line equation TIC $=1 \mathrm{E}-10 *\left(\right.$ Height $\left.^{6.6216}\right)$.

**These values are calculated values based on the trend line equation $\mathrm{TIC}=2 \mathrm{E}-12 *\left(\right.$ Height $\left.^{7.183}\right)$. 


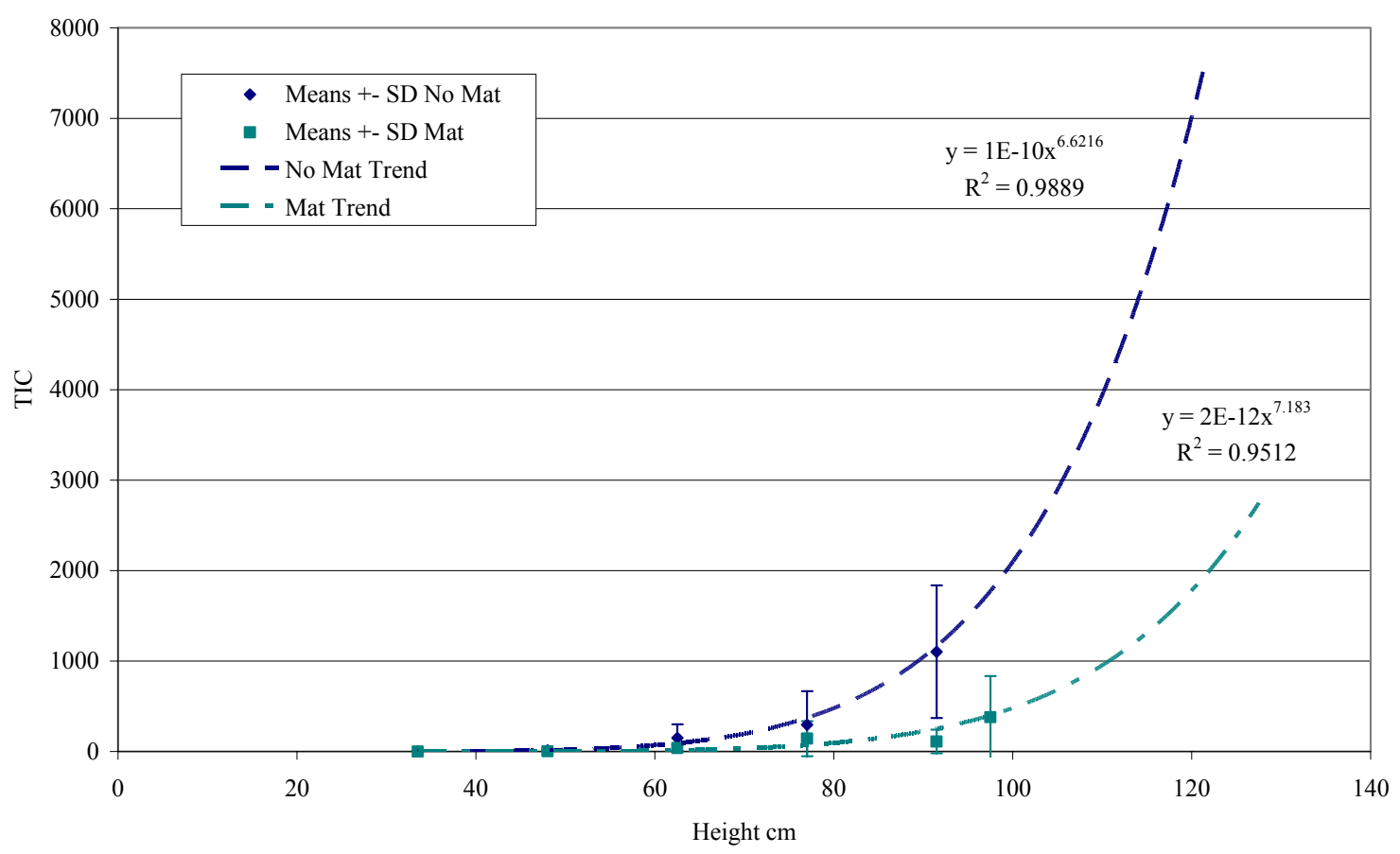

Figure 23: TIC values plotted with an estimated trend line during feet first falls.

\section{Acceleration measured at the pelvis}

Although data collected at the head and thorax was limited by the accelerometers, impact deceleration was measured at the pelvis for all heights. The mean impact decelerations measured without a mat ranged from $4.84 \pm 1.49 \mathrm{~g}$ to $36.97 \pm 21.52 \mathrm{~g}$, while those measured with a mat ranged from $5.13 \pm 3.13 \mathrm{~g}$ to $24.53 \pm 8.02 \mathrm{~g}$. Table 15 shows means and standard deviations measured for all trials conducted with and without a mat. Changing the height significantly increased the mean impact decelerations $(p<.0001)$; however, the presence of the mat had no significant effect on the mean impact decelerations $(\mathrm{p}=.0589)$, although Figure 24 shows the mean impact decelerations measured with a mat to be lower than those measured without a mat. 
Table 15: Pelvic mean impact decelerations measured with and without a mat during feet first falls and calculated values based on trend line equations.

\begin{tabular}{|l|c|c|}
\hline \multicolumn{1}{|c|}{ Height cm } & $\begin{array}{c}\text { Pelvis g: No Mat } \\
\text { (Mean } \pm \text { SD) }\end{array}$ & $\begin{array}{c}\text { Pelvis g: Mat } \\
\text { (Mean } \pm \text { SD) }\end{array}$ \\
\hline 33.5 & $4.84 \pm 1.49$ & $9.97 \pm 8.90$ \\
\hline 48.0 & $8.18 \pm 3.21$ & $5.13 \pm 3.13$ \\
\hline 62.5 & $8.88 \pm 3.55$ & $8.05 \pm 3.57$ \\
\hline 77.0 & $23.46 \pm 10.75$ & $18.17 \pm 7.41$ \\
\hline 91.5 & $32.28 \pm 23.19$ & $19.28 \pm 4.52$ \\
\hline 97.5 & $36.97 \pm 21.52$ & $24.53 \pm 8.02$ \\
\hline 112.5 & $62.72^{*}$ & $25.81^{* *}$ \\
\hline 115.0 & $68.09^{*}$ & $26.47^{* *}$ \\
\hline 117.5 & $73.93^{*}$ & $27.13^{* *}$ \\
\hline 120.0 & $80.27^{*}$ & $27.79^{* *}$ \\
\hline 122.5 & $87.15^{*}$ & $28.44^{* *}$ \\
\hline
\end{tabular}

*These values are calculated values based on the trend line equation Acceleration $=1.549 \mathrm{e}^{\left(0.033^{*} \text { Height }\right)}$.

$* *$ These values are calculated values based on the trend line equation Acceleration $=0.263 *$ Height -3.774 . 


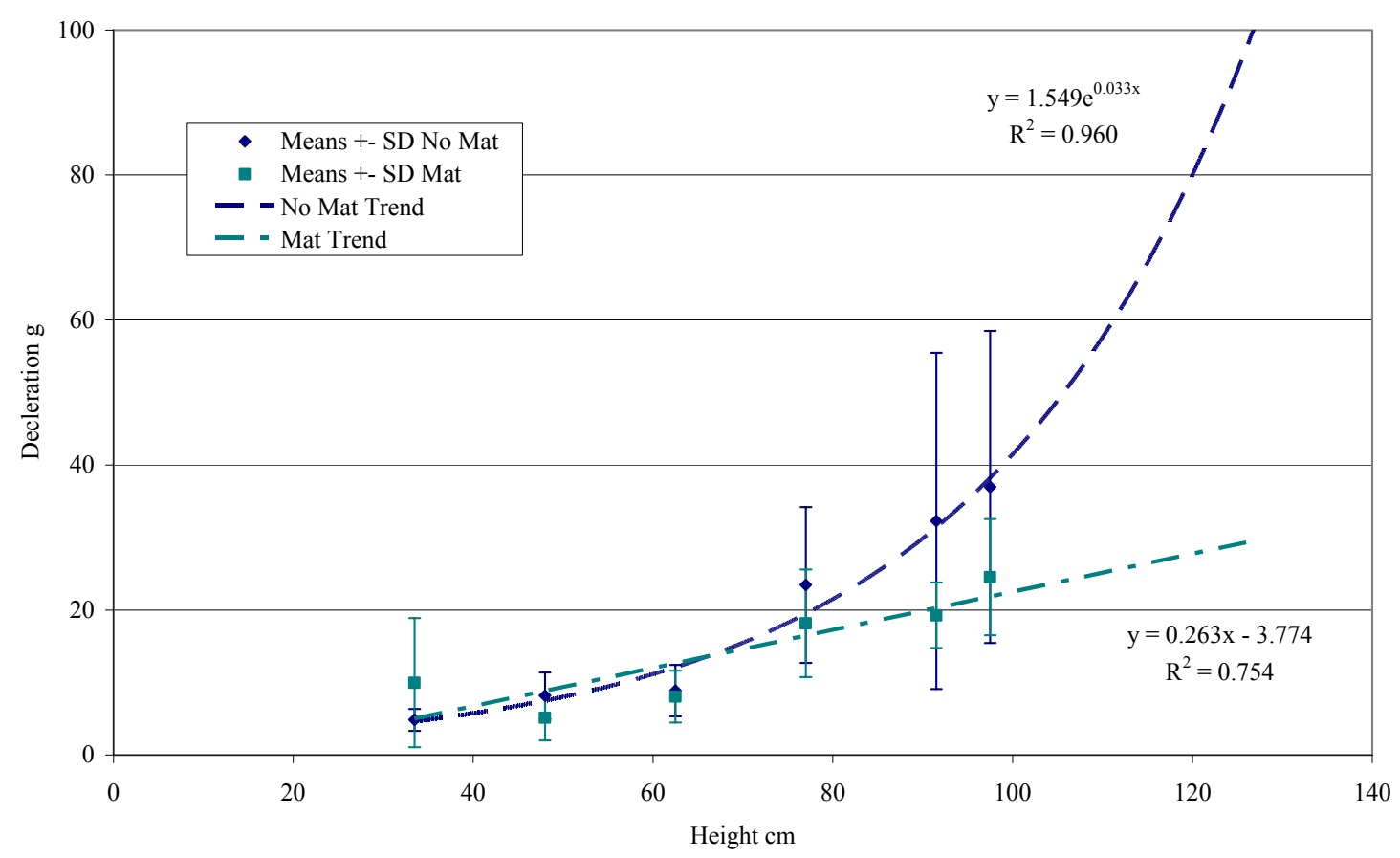

Figure 24: Pelvic mean impact decelerations plotted with an estimated trend line during feet first falls.

Pelvic injury criteria were calculated also from the measured acceleration profiles. The PIC values ranged from $0.43 \pm 0.24$ to $54.46 \pm 54.98$ when calculated for falls onto the tile surface and from $1.03 \pm 1.66$ to $24.30 \pm 12.38$ when calculated for falls onto the floor mat. Statistical analysis of these values showed the PIC values neither to decrease significantly with the use of a floor mat $(p=.0930)$ or increase significantly with an increase in height $(\mathrm{p}=.2245)$. Trend line equations were also used to estimate PIC values at heights added by bedrails. These values reached a maximum of 146.87 without a floor mat and 28.02 with a floor mat. A graphical representation of the PIC values calculated for impacts onto the tile surface and floor mat can be viewed in Figure 25. 
Table 16: Mean PIC values calculated for pelvic deceleration profiles measured during trials with and without a mat during feet first falls.

\begin{tabular}{|l|c|c|}
\hline \multicolumn{1}{|c|}{ Height cm } & $\begin{array}{c}\text { PIC: No Mat } \\
(\text { Mean } \pm \text { SD })\end{array}$ & $\begin{array}{c}\text { PIC: Mat } \\
\text { (Mean } \pm \text { SD) }\end{array}$ \\
\hline 33.5 & $0.43 \pm 0.24$ & $5.68 \pm 8.32$ \\
\hline 48.0 & $5.14 \pm 9.29$ & $1.03 \pm 1.66$ \\
\hline 62.5 & $2.74 \pm 2.52$ & $4.17 \pm 5.85$ \\
\hline 77.0 & $20.77 \pm 16.79$ & $16.65 \pm 22.00$ \\
\hline 91.5 & $53.77 \pm 40.98$ & $15.48 \pm 8.89$ \\
\hline 97.5 & $54.46 \pm 54.98$ & $24.30 \pm 12.38$ \\
\hline 112.5 & $100.97 *$ & $24.91 * *$ \\
\hline 115.0 & $111.22 *$ & $25.69 * *$ \\
\hline 117.5 & $122.26^{*}$ & $26.47 * *$ \\
\hline 120.0 & $134.13^{*}$ & $27.24 * *$ \\
\hline 122.5 & $146.87^{*}$ & $28.02^{* *}$ \\
\hline
\end{tabular}

*These values are calculated values based on the trend line equation $\mathrm{PIC}=1 \mathrm{E}-07 *\left(\right.$ Height $\left.{ }^{4.4007}\right)$.

**These values are calculated values based on the trend line equation $\mathrm{PIC}=(0.310 *$ Height $)-9.972$. 


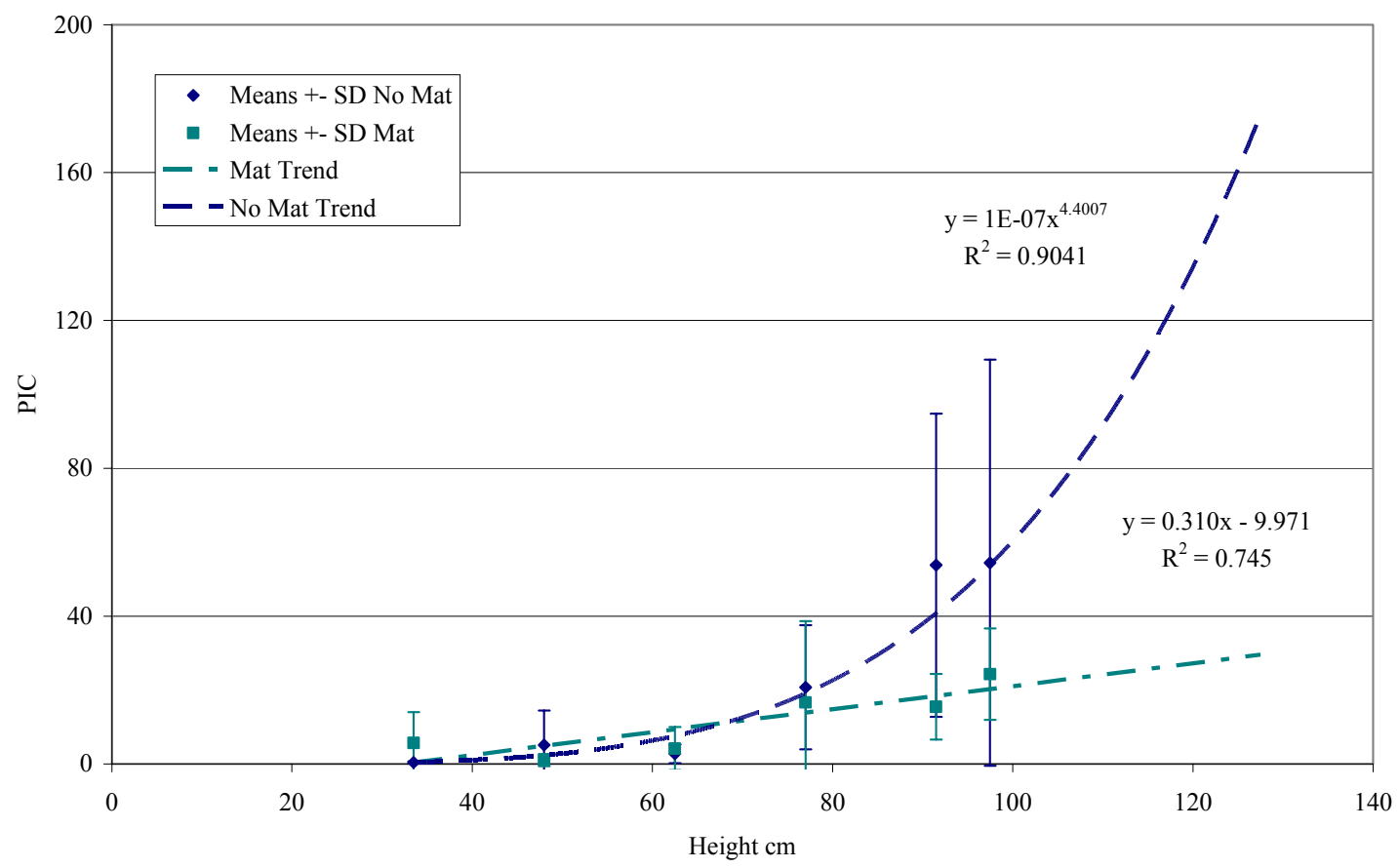

Figure 25: PIC values plotted with an estimated trend line during feet first falls.

During feet first falls, the pelvis impacted the surface before the thorax or head; therefore, force calculations were performed for the pelvis not the head. Equation 2 was used to calculate force based on the mean maximum accelerations measured for feet first falls at the pelvis and the total body weight minus the weight of the lower extremities. When calculated for impacts onto the tile surface, the maximum force was $1974.55 \mathrm{~N}$ at a height of $97.5 \mathrm{~cm}$, as shown in Table 17. The maximum force decreased to $1310.10 \mathrm{~N}$ at a height of $97.5 \mathrm{~cm}$ when the floor mat was used. As mentioned previously, no statistical analysis was performed on these calculations. See Figure 26 for a graphical representation for these calculations. A summary of all measured mean maximum values and calculated injury criteria for head and feet first falls is presented in Table 17. 
Table 17: Impact forces calculated at the pelvis for feet first falls with and without a floor mat.

\begin{tabular}{|l|c|c|}
\hline Height cm & Force N: No Mat & Force N: Mat \\
\hline 33.5 & 258.73 & 532.60 \\
\hline 48.0 & 437.06 & 273.73 \\
\hline 62.5 & 474.54 & 430.06 \\
\hline 77.0 & 1252.80 & 970.41 \\
\hline 91.5 & 1724.29 & 1029.64 \\
\hline 97.5 & 1974.55 & 1310.10 \\
\hline
\end{tabular}

Calculated Impact Force for Feet First Falls

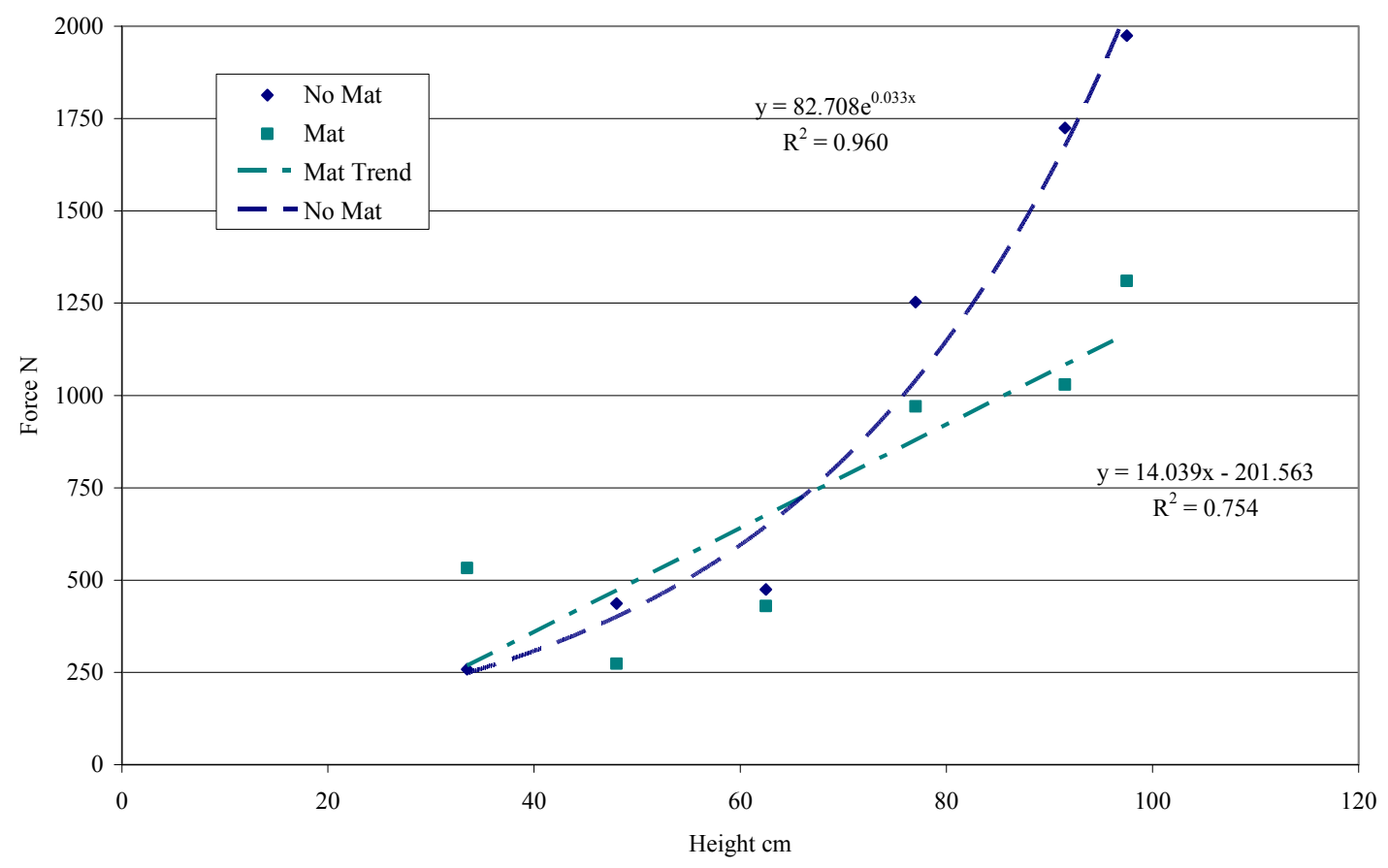

Figure 26: Impact forces plotted with an estimated trend line during feet first falls. 
Table 18: Summary of measured mean maximum values and calculated injury criteria.

\begin{tabular}{|c|c|c|c|c|}
\hline \multicolumn{5}{|c|}{ Head First Falls } \\
\hline Head & \multicolumn{2}{|c|}{ Means \pm SD $(\mathrm{g})$} & \multicolumn{2}{|c|}{ Injury Criteria } \\
\hline Height $(\mathrm{cm})$ & No Mat & Mat & No Mat & Mat \\
\hline 33.5 & $34.50 \pm 15.42$ & $9.22 \pm 5.56$ & $38.70 \pm 30.61$ & $3.35 \pm 4.11$ \\
\hline 48 & $47.69 \pm 25.65$ & $12.69 \pm 12.74$ & $116.59 \pm 141.19$ & $9.36 \pm 16.16$ \\
\hline 62.5 & $18.60 \pm 10.89$ & $6.90 \pm 1.41$ & $13.41 \pm 19.44$ & $1.33 \pm 0.48$ \\
\hline 77 & $44.19 \pm 15.80$ & $10.70 \pm 2.94$ & $84.92 \pm 76.48$ & $3.21 \pm 1.74$ \\
\hline 91.5 & $70.36 \pm 16.52$ & $12.26 \pm 4.19$ & $282.68 \pm 103.97$ & $3.82 \pm 2.08$ \\
\hline 97.5 & $64.02 \pm 25.33$ & $21.51 \pm 7.10$ & $260.49 \pm 264.30$ & $10.01 \pm 7.83$ \\
\hline Thorax & \multicolumn{2}{|c|}{ Means \pm SD $(g)$} & \multicolumn{2}{|c|}{ Injury Criteria } \\
\hline Height $(\mathrm{cm})$ & No Mat & Mat & No Mat & Mat \\
\hline 33.5 & $16.85 \pm 6.97$ & $6.61 \pm 3.98$ & $23.45 \pm 31.61$ & $1.58 \pm 2.04$ \\
\hline 48 & $28.55 \pm 15.79$ & $20.79 \pm 19.09$ & $60.24 \pm 58.58$ & $68.51 \pm 139.95$ \\
\hline 62.5 & $29.48 \pm 20.15$ & $13.48 \pm 3.94$ & $89.89 \pm 152.01$ & $6.37 \pm 5.92$ \\
\hline 77 & $30.82 \pm 8.63$ & $46.67 \pm 47.78$ & $37.49 \pm 5.26$ & $525.12 \pm 824.83$ \\
\hline 91.5 & $36.14 \pm 9.55$ & $13.87 \pm 2.80$ & $102.09 \pm 32.50$ & $8.23 \pm 4.26$ \\
\hline 97.5 & $48.50 \pm 25.54$ & $43.11 \pm 41.31$ & $220.85 \pm 274.74$ & $247.28 \pm 350.52$ \\
\hline Pelvis & \multicolumn{2}{|c|}{ Means \pm SD $(g)$} & \multicolumn{2}{|c|}{ Injury Criteria } \\
\hline Height $(\mathrm{cm})$ & No Mat & Mat & No Mat & Mat \\
\hline 33.5 & $14.29 \pm 8.25$ & $8.48 \pm 4.03$ & $11.21 \pm 14.41$ & $2.14 \pm 1.74$ \\
\hline 48 & $11.46 \pm 7.54$ & $13.97 \pm 7.45$ & $7.52 \pm 8.46$ & $10.98 \pm 15.07$ \\
\hline 62.5 & $20.74 \pm 3.85$ & $11.31 \pm 6.82$ & $17.10 \pm 10.22$ & $12.70 \pm 12.01$ \\
\hline 77 & $19.82 \pm 10.67$ & $12.44 \pm 4.16$ & $21.69 \pm 13.78$ & $9.08 \pm 5.76$ \\
\hline 91.5 & $18.06 \pm 5.91$ & $20.52 \pm 10.99$ & $16.76 \pm 12.48$ & $17.05 \pm 13.56$ \\
\hline 97.5 & $20.63 \pm 7.33$ & $16.32 \pm 9.94$ & $17.90 \pm 9.56$ & $11.92 \pm 16.58$ \\
\hline \multicolumn{5}{|c|}{ Feet First Falls } \\
\hline Head & \multicolumn{2}{|c|}{ Means \pm SD $(\mathrm{g})$} & \multicolumn{2}{|c|}{ Injury Criteria } \\
\hline Height $(\mathrm{cm})$ & No Mat & Mat & No Mat & Mat \\
\hline 33.5 & $74.13 \pm 58.41$ & $8.48 \pm 6.66$ & $486.51 \pm 880.08$ & $3.96 \pm 5.37$ \\
\hline 48 & $152.47 \pm 46.12$ & $41.51 \pm 22.40$ & $1234.63 \pm 945.72$ & $73.92 \pm 65.03$ \\
\hline 62.5 & $131.81 \pm 31.07$ & $75.93 \pm 26.38$ & $697.79 \pm 321.44$ & $212.26 \pm 151.19$ \\
\hline 77 & $\mathrm{~N} / \mathrm{A}$ & $91.58 \pm 47.24$ & $\mathrm{~N} / \mathrm{A}$ & $374.35 \pm 389.04$ \\
\hline 91.5 & $\mathrm{~N} / \mathrm{A}$ & $66.41 \pm 38.37$ & $\mathrm{~N} / \mathrm{A}$ & $196.82 \pm 204.70$ \\
\hline 97.5 & $\mathrm{~N} / \mathrm{A}$ & $54.52 \pm 27.73$ & N/A & $133.75 \pm 100.85$ \\
\hline Thorax & \multicolumn{2}{|c|}{ Means \pm SD $(g)$} & \multicolumn{2}{|c|}{ Injury Criteria } \\
\hline Height $(\mathrm{cm})$ & No Mat & Mat & No Mat & Mat \\
\hline 33.5 & $8.47 \pm 5.16$ & $3.29 \pm 0.61$ & $1.45 \pm 1.16$ & $0.17 \pm 0.05$ \\
\hline 48 & $17.80 \pm 6.04$ & $7.15 \pm 1.58$ & $13.69 \pm 8.84$ & $1.38 \pm 0.76$ \\
\hline 62.5 & $43.06 \pm 16.00$ & $20.26 \pm 10.17$ & $150.50 \pm 151.35$ & $39.54 \pm 30.86$ \\
\hline 77 & $50.23 \pm 13.64$ & $38.30 \pm 28.26$ & $298.17 \pm 368.83$ & $141.69 \pm 194.83$ \\
\hline 91.5 & $95.12 \pm 43.13$ & $38.06 \pm 16.24$ & $1103.40 \pm 733.32$ & $111.20 \pm 131.19$ \\
\hline 97.5 & N/A & $58.25 \pm 46.01$ & $\mathrm{~N} / \mathrm{A}$ & $379.02 \pm 456.90$ \\
\hline
\end{tabular}


Table 18: Continued

\begin{tabular}{|l|c|c|c|c|}
\hline \multicolumn{5}{|c|}{ Feet First Falls Continued } \\
\hline \multicolumn{1}{|c|}{ Pelvis } & \multicolumn{2}{c|}{ Means \pm SD $(\mathrm{g})$} & \multicolumn{2}{c|}{ Injury Criteria } \\
\hline Height $(\mathrm{cm})$ & No Mat & Mat & No Mat & Mat \\
\hline 33.5 & $4.84 \pm 1.49$ & $9.97 \pm 8.90$ & $0.43 \pm 0.24$ & $5.68 \pm 8.32$ \\
\hline 48 & $8.18 \pm 3.21$ & $5.13 \pm 3.13$ & $5.14 \pm 9.29$ & $1.03 \pm 1.66$ \\
\hline 62.5 & $8.88 \pm 3.55$ & $8.05 \pm 3.57$ & $2.74 \pm 2.52$ & $4.17 \pm 5.85$ \\
\hline 77 & $23.46 \pm 10.75$ & $18.17 \pm 7.41$ & $20.77 \pm 16.79$ & $16.65 \pm 22.00$ \\
\hline 91.5 & $32.28 \pm 23.19$ & $19.28 \pm 4.52$ & $53.77 \pm 40.98$ & $15.48 \pm 8.89$ \\
\hline 97.5 & $36.97 \pm 21.52$ & $24.53 \pm 8.02$ & $54.46 \pm 54.98$ & $24.30 \pm 12.38$ \\
\hline
\end{tabular}




\section{Discussion and Interpretation}

\section{Introduction}

During a fall from bed event investigated in this study, the resulting mean maximum values and injury criteria recorded at the head, thorax, and pelvis were dependent upon the height from which the fall occurred and the presence or absence of a floor mat. Statistically these factors affected each body region differently as the direction of impact changed from head first to feet first falls. The variations reported in the statistical results can be explained by the amount of bounce or rebound off the impact surface and the presence of bending between body regions.

\section{Head first falls}

The order of impact was observed visually to be head, thorax, and pelvis for head first falls and confirmed by the acceleration profiles recorded in LabView. The mean maximum values recorded at the head, thorax, and pelvis all increased significantly as height increased, as expected. However, the mat did not significantly decrease the mean maximum values at all body regions. As discussed previously, the ATD rotated about the longitudinal axis during a fall from bed event causing the thorax to impact the shoulder rather than the anterior or posterior portion of the region. The lateral impact of the thorax decreased the amount of surface area available to support the weight; therefore, the mat was unable to adequately cushion the fall and decrease the mean maximum values measured at the thorax. Furthermore, the tile surface deformed less during a fall event than did the mat; therefore, the ATD bounced or rebounded off the tile during a fall. By decreasing the amount of bounce, the mat increased the amount of time each body region was in contact with the surface to reduce significantly the mean maximum values recorded at the head and pelvis. 
The injury criteria calculated for the head, pelvis, and thorax were also dependent upon the amount of bounce and bend that occurred during a fall event. As the mean maximum values measured at the head were significantly affected by height and the presence of the mat, the HIC values were, likewise, expectedly affected by height and the presence of the mat. However, the thorax and pelvis did not produce similar results. The injury criteria calculated for the thorax or pelvis were not affected by height as were the mean maximum values. The TIC value is calculated based on the integral of acceleration with limits up to a $15 \mathrm{msec}$ time period. For the TIC values to remain unaffected by the significant increase in mean maximum values there must be a corresponding decrease in sustained acceleration. During impact the head and pelvis were allowed to pivot with respect to the thorax, thus pushing the thorax into the impact surface. As this occurred, the thorax experienced limited rebound off the surface; therefore, the thorax decelerated more quickly with the sustained contact with the surface. Likewise, the PIC values were not significantly increased as height increased for the same reason; the pelvis was allowed to pivot with respect to the thorax and remain in contact with the surface. The knees further pushed the pelvis into contact with the surface. The observed increase in mean maximum values measured at the pelvis was balanced by the corresponding decrease in sustained acceleration caused by the sustained surface contact; hence, no height effect was observed to increase significantly the PIC values. Furthermore, the presence of the mat did not significantly decrease the PIC values, because the mat allowed the pelvis to continue to accelerate into the surface thereby increasing the sustained acceleration.

The resulting mean maximum values and injury criteria recorded for head first falls were compared with injury prevention standards often used in the automotive industry. As discussed previously, the head injury criterion (HIC) was developed to provide a value to correlate acceleration with injury severity. According to these standards, HIC values must not exceed 700 when calculated over limits up to a $15 \mathrm{~ms}$ time period. The HIC values calculated for head first falls onto the tile surface reached a maximum of $282.68 \pm 103.97$ at $91.5 \mathrm{~cm}$. When the height increased to $122.5 \mathrm{~cm}$ to account for bedrails, the HIC value increased to 325.05. As shown in Figure 7, these HIC 
values correlated with a less than one percent chance of experiencing a serious injury as a result of falling out of bed, where serious is defined as an AIS score greater than or equal to 3. The use of a mat significantly reduced the HIC values; therefore, the risk of injury to the head was further reduced. Although Lyons and Oates (1993) and Macgregor (2000) reported head trauma to be specifically associated with falling from bed, these reports were documented incidences for children, not adults. As the ATD is designed to mimic a $50^{\text {th }}$ percentile male, direct application of these head trauma reports is not valid. Skull fractures have, however, been associated with falls in general but the specific circumstances causing those injuries are not reflected in the literature. The literature supports this finding as severe brain injury specifically resulting from falling out of bed has not been documented in adults, even though head trauma resulting from falling from bed was documented in children and skull fractures have been recorded as being associated with falls (Lyons and Oates, 1993; Sattin et al, 1990). However, the forces calculated during head first falls may indicate a risk of sustaining a skull fracture as the literature reports a range of values inclusive of the forces calculated in this study (Nahum, Gatts, Gadd, and Danforth, 1968; Schneider and Nahum, 1972). Sterling, O'Conner, and Bonadies (2001) further noted neck injuries to be associated with falls; however, neither the amount of bending nor acceleration was measured at the neck during this study, although both were visually observed to occur subsequent to head impact.

Currently, no injury criterion and industry standard exists specific to the thorax or pelvis. However, the automotive industry has set forth a limit of $60 \mathrm{~g}$ for chest (thoracic) acceleration. The mean maximum values measured at the thorax during head first falls reached a maximum of $48.50 \pm 25.54 \mathrm{~g}$ onto the tile surface and $46.67 \pm 47.78 \mathrm{~g}$ onto the floor mat. These values did not exceed the industry standard; however, no inference can be made with regard to injury severity either from these values or the calculated TIC values. Likewise, the pelvic injury criteria calculated in this study cannot, currently, infer injury severity, but as more research becomes available these values may prove useful in assessing injury severity associated with falling from bed. Although no inference can be made concerning thoracic or pelvic injury based upon measured or calculated values, visual observation of impact site may indicate a higher risk of injury. Nevitt et al (1993) 
concluded that fall direction affected the location of impact and injury to specific anatomical regions. During head first falls rotation occurred about the longitudinal axis and resulted in lateral impaction upon the shoulder and pelvis. As such, the risk of clavical or scapula and hip fractures may be increased as these areas have decreased soft tissue to cushion such an impact. Furthermore, dislocations have been documented to be associated with falls, hence the lateral impacts observed during head first falls may account for this association (Sattin et al 1990).

\section{Feet first falls}

Changing the fall direction from head first to feet first consequently changed the impact order to pelvis, thorax, and head which was observed visually and confirmed with the acceleration profiles recorded in LabView. As with head first falls, the mean maximum values were dependent upon the amount of bounce off the surface. The mean maximum values measured at the head, thorax, and pelvis were all significantly increased with increasing height as expected. However, the mat did not significantly reduce mean maximum values for all body regions or for the same body regions as head first falls. This apparent discrepancy resulted from the differing fall mechanics and orientations. During feet first falls, the ATD completed nearly 360 degrees of rotation about the longitudinal axis before impacting the surface. As such, the thorax impacted a greater percentage of the posterior surface than with the lateral impact observed in head first falls. This increase in impact surface area allowed the mat to support more of the thoracic weight directly; therefore, the mean maximum values were significantly decreased by the mat. Although the mean maximum values measured at the pelvis during head first falls were significantly decreased by the mat, the prior impact of the feet and legs during feet first falls absorbed much of the impact that would otherwise have been supported by the pelvis to create a "crumple" effect.

The dependence on height and mat of the thoracic injury criteria and dependence on the presence of the mat of the head injury criteria was expected as the mean maximum values were found to be similarly affected. However, the HIC values were not significantly increased with an increase in height because the head was able to bend and 
remain in contact with the impact surface. This sustained contact resulted in a corresponding decrease in sustained acceleration; therefore, the significant increase observed with the mean maximum values was balanced by the decrease in sustained acceleration. As with head first falls, the pelvis injury criteria calculated for feet first falls was not dependent upon height or mat even though the mean maximum values were found to be so. However, as discussed previously, the injury criteria can remain unaffected by a significant increase in mean maximum values by a corresponding decrease in sustained acceleration. The mat allowed the pelvis to continue to accelerate into the surface; therefore, the acceleration was sustained longer than that onto the tile surface. As a result, the mat did not significantly decrease the PIC values calculated for feet first falls.

Similar to head first falls, the mean maximum values and injury criteria calculated during feet first falls were compared to standards utilized by the automotive industry. The head injury criteria (HIC) calculated for feet first falls was limited by the inability to obtain acceleration profiles for heights greater than $62.5 \mathrm{~cm}$ when a floor mat was not in use. This limitation resulted in an incomplete data set for the higher heights. However, a trend line equation fitted to existing data was used to estimate HIC values at those heights. The HIC values calculated for acceleration profiles measured without a mat reached a maximum of $1234.63 \pm 945.72$ at a height of $48 \mathrm{~cm}$. As shown in Figure 7, this value results in approximately a 25 percent chance of experiencing an injury with an AIS score greater than or equal to 3 under these conditions. Furthermore, the projected data for bed heights up to $97.5 \mathrm{~cm}$ increased to 1252.87 , which indicates approximately a 25 percent chance of serious injury. With the inclusion of height added by bedrails, this risk increases to a 40 percent chance of a serious injury resulting from falling from bed and impacting a tile surface. On the other hand, the HIC values reached a maximum of $374.35 \pm 389.04$ at a height of $77.0 \mathrm{~cm}$ when the floor mat was in use. This value indicated a less than one percent chance of serious injury when compared to Figure 7. Moreover, the risk of injury does not increase with an increase in height added by bedrails, as the projected HIC values only increase to 250.70. This relatively high risk of serious injury associated with falling out of bed feet first without a mat is not supported 
by the literature as brain injury has not been specifically associated with falls from bed. However, these results may indicate that patients do not commonly fall from bed feet first.

Due to accelerometer limitation, acceleration profiles could not be measured at the thorax for a bed height of $97.5 \mathrm{~cm}$. As such, the injury criteria calculated for the acceleration profiles measured at the thorax for heights up to $91.5 \mathrm{~cm}$ resulted in a maximum TIC value of $1103.40 \pm 733.32$. Thoracic injury criteria for subsequent bed and bedrail heights were estimated by fitting a trend line to the existing data; the estimated TIC values increased to 8053.09. Although literature currently does not exist to correlate these values with injury severity, an exponential increase in TIC values is observed with an increase in height. Assuming the calculated TIC values follow a similar trend as the HIC value, this increase in TIC value would indicate an increase in risk of serious injury to the thorax. On the other hand, the impact during feet first falls occurred on the posterior portion of the thorax; therefore, a dislocation or fracture is not as likely as with the lateral impact observed in head first falls. Similar to head first falls, the mean maximum values measured at the thorax were compared to standards set forth by the automotive industry. The values measured during falls onto the tile surface reached a maximum of $95.12 \pm 43.13 \mathrm{~g}$ and $58.25 \pm 46.01 \mathrm{~g}$ during falls onto the floor mat. Clearly, these values exceed the automotive industry standard of a $60 \mathrm{~g}$ limit.

Although the PIC values calculated for feet first falls increased significantly with height to reach a maximum of $54.46 \pm 54.98$ when calculated for impacts onto the tile surface, a correlation with injury severity cannot be determined. Furthermore, the pelvis impacted the posterior portion during feet first falls; therefore, falling from bed feet first would probably not result in a hip fracture rather a wrist fracture according to Nevitt et al (1993). This is supported by the literature as the force required to fracture a hip is reported to be approximately $4340 \mathrm{~N}$, and the forces calculated in the current study were below this fracture threshold (Etheridge, Beason, Lopez, Alonso, McGwin, and Eberhardt, 2005). The literature has also documented fractures of the extremities to be specifically associated with falling and fractures to be generally associated with falling from bed (Sterling, O'Conner, and Bonadies, 2001; Innes and Turman, 1983). As the 
feet impact the surface first and dampen the acceleration measured at the pelvis, the incidence of extremity fractures may possibly be the result of just such a fall.

\section{General observations}

Throughout the data collection process, several observations were made with regard to fall mechanics and possible resulting injury. For instance, the material around the knee and shoulder impact sites became torn over time and may support the incidence of lacerations documented in the literature (Lyons and Oates, 1993; Macgregor, 2000). Furthermore, inspection of the mat revealed permanent deformation at the head and thorax impact sites. This information may be useful in determining mat placement and design. As discussed previously, the ATD fell from bed in a specific manner to impact particular body regions in a specific orientation. However, adding bedrails to a bedside may produce very different fall mechanisms as the bedrail may provide an additional pivot point about which the ATD can rotate. Particularly during feet first falls, the ATD may complete more degrees of rotation and impact the pelvis and thorax laterally rather than on the posterior portion as observed during this study. Additionally, the literature documents the incidence of bedrail entanglement; hence falling from bed with bedrails in place may increase the incidence of extremity fractures and dislocations by allowing entanglement to occur (FDA, CDRH, 1995; JCAHO, 2002).

There has been some discussion concerning the applicability of the measures determined in this study to human subjects as the ATD has different biomechanical properties with respect to the vinyl skin. The properties of the vinyl allowed the ATD to rebound off the impact surface. However, as the human body displays viscoelastic properties during applied forces, one can presume that some resilience is present in the human skin. Furthermore, the effect of rebound on the measured and calculated values would result in liberal estimates of these calculations; therefore, the calculations and measures reported in this study would apply to the more conservative results theoretically expected in human subjects. 


\section{Conclusions and Recommendations}

Even though the HIC values calculated in this study resulted in approximately a 40 percent chance of sustaining a serious brain injury as a consequence of falling from bed, the use of a mat significantly reduced this relatively high risk of injury.

Furthermore, the mat provided a protective effect for the pelvis during head first falls and for the thorax during feet first falls. As such, a floor mat should be used in the healthcare environment to prevent injuries associated with falling from bed. However, the floor mat used in this study did not provide appropriate floor coverage to ensure impact onto the mat rather than onto the tile surface. During data collection, the mat was repositioned several times as the pelvis of the ATD tended to impact farther past the foot of the bed with an increase in height during head first falls. Similarly, the head of the ATD tended to impact farther past the head of the bed during feet first falls. However, in a clinical situation the bed may be positioned against a wall; therefore, the length of the mat would not need to be lengthened in that direction. To increase the prevention potential of the floor mat, it should be lengthened approximately $30 \mathrm{~cm}$ to cover a total length of $213 \mathrm{~cm}$ to extend past the foot of the bed. The ATD also impacted the surface farther away from the bedside with an increase in height; therefore the mat was repositioned several times during both head first and feet first falls to account for this movement. For the best clinical performance, the width of the floor mat should also be increased by approximately $15 \mathrm{~cm}$ to increase to a total width of $111.5 \mathrm{~cm}$. However, clinicians have posed concerns regarding tripping hazards and sanitation methods associated with the use of floor mats. A floor mat with a beveled edge should be used in the clinical setting to reduce the risk of introducing a trip hazard, and a mat with a plastic or other easily cleaned surface should be used to reduce the risk of spreading infection. If the use of a floor mat is not a feasible option for a particular patient or facility, other protective devices are available such as hip protectors. However, patients often do not use them 
consistently as they have been reported to be uncomfortable to wear and are not aesthetically pleasing to the patient. As such, the use of a floor mat is the less invasive injury prevention device when compared to hip protectors.

Regardless of fall direction, the mean maximum values measured at the head, thorax, and pelvis were all determined to increase significantly with increasing height. To prevent the most injuries resulting from falling from bed, the bed should be positioned to the lowest height available while the patient is left unattended. The literature supports repositioning the bed to a height comfortable for caregivers to reduce the risk of low back injuries experienced by the caregiver (DeLooze et al, 1994; Caboor et al, 2000). By utilizing an adjustable bed in the clinical environment, injuries can be prevented for both the patient and the caregiver.

Bedrails were not physically implemented in this study; however, mean maximum values and injury criteria were extrapolated from estimated trend lines of the data collected during this study. These values reflected a consistent increase in mean maximum values and injury criteria for all test conditions and body regions. When the entrapment and entanglement issues presented in the literature are taken into account, the removal of bedrails from the clinical environment should be solemnly considered.

Furthermore, the literature has documented falls from bed even when the bedrails were in place; therefore, the benefit of utilizing bedrails must come into question. The results of this study clearly support removing bedrails simply based on the effect the increase in height has on the mean maximum values and injury criteria.

In conclusion, the results of this study have important clinical applications as injury prevention is paramount to maintaining a quality healthcare environment. According to the results of this study, the ideal environment for preventing injuries resulting from falling out of bed include positioning the bed to the lowest available height, placing a floor mat beside the bed, and removing bedrails. Historically, injury prevention devices, such as bedrails or physical restraints, were implemented in part to show an active participation in injury prevention to the legal system. By implementing the aforementioned changes in the clinical environment, the patient and caregiver could 
be assured that the highest quality care is being provided as each are easily documented and pose little negative impact on the daily function of providing care to patients. 


\section{References}

Backaitis, S.H, \& Mertz, H.J. (1994), Hybrid III: The first human-like crash test dummy. Warrendale, Pennsylvania: Society of Automotive Engineers, Inc.

Barbee, G.C. (1957). More about bedrails and the nurse. The American Journal of Nursing, 57, 1441-1442.

Baum, T., Capezuti, E., \& Driscoll, G.(2002). Falls. In Cotter, V.T. \& Strumpf, N.E. (Eds.), Advanced Practice Nursing with Older Adults: Clinical Guidelines. (pp.245-259). New York: McGraw Hill.

Bertocci, G.E., Pierce, M.C., Deemer, E., Aguel, F., Janosky, J.E., \& Vogeley, E. (2003).Using test dummy experiments to investigate pediatric injury risk in simulated short-distance falls. Archives of Pediatrics and Adolescent Medicine, 157, 480-486.

Bones and Skeletal Tissues. In E. N. Marieb (Ed.), Human Anatomy \& Physiology (pp. 172-197). New York: Benjamin Cummings.

Bradham, D.D., MacClellan, L.R., South, B., Tate, M., Powell-Cope, G., Luther, S., et al.(2003). Hospital bed-related adverse events, Part II: Direct costs to a VHA healthcare network. Journal of Healthcare Safety, 1(3), 24-30.

Braun, J., \& Capezuit, E. (2000). Siderail use and legal liability in Illinois nursing homes. Illinois Bar Journal, vol(), pp-pp.

Caboor, D.E., Verlinden, M.O., Zinzen, E., van Roy, P., van Riel, M.P., \& Clarys, J.P. (2000). Implications of an adjustable bed height during standard nursing tasks on spinal motion, perceived exertion and muscular activity. Ergonomics, 43 (10), 1771-1780.

Capezuit, E., Talerico, K.A., Cochran, I., Becker, H., Strumpf, N., \& Evans, L.(1999). Individualized interventions to prevent bed-related falls and reduce siderail use. Journal of Geronotological Nursing, vol, 26-34.

Casalena, J.A., Badre-Alam, A., Ovaert, T.C., Cavanagh, P.R., \& Streit, D.A. (1998). The Penn State safety floor: Part II-Reduction of fall-related peak impact forces on the femur. Journal of Biomechanical Enigneering, 120, 527-532. 
Champion, H.R., Copes, W.S., Buyer, D. Flanagan, M.E., Bain, L., \& Sacco, W.J. (1989). Major trauma in geriatric patients. American Journal of Public Health, 79, 1278-1282.

Copes, W.S., Sacco, W.J., Champion, H.R., \& Bain, L.W. (n.d.). Progress in characterizing anatomic injury. In Proceedings of the $33^{\text {rd }}$ Annual Meeting of the Association for the Advancement of Automotive Medicine, USA, 205-218. Retrieved November 29, 2004, from http://www.trauma.org/scores/ais.html

de Looze, M.P., Zinzen, E., Caboor, D., Heyblom, P., van Bree, E., van Roy, P., et al. (1994). Effect of individually chosen bed-height adjustments on the low-back stress of nurses. Scandinavian Journal of Environmental Health, 20, 427-434.

Donius, M., \& Rader, J. (1994). Use of siderails: Rethinking a standard of practice. Journal of Gerontological Nursing, vol(), 23-27.

Eppinger, R., Sun, E., Kuppa, S., \& Saul, R. Reports to National Highway Safety Administration. (2000). Supplement: Development of improved injury criteria for the assessment of advanced automotive restraint systems-II. Retrieved March 23, 2005 from http://www-nrd.nhsta.dot.gov/pdf/nrd-11/airbags/finalrule_all.pdf

Etheridge, B.S, Beason, D.P., Lopez, R.R., Alonso, J.E., McGwin, G., \& Eberhardt, A.W. (2005). Effects of trochanteric soft tissues and bone density on fracture of the female pelvis in experimental side impacts. Annals of Biomedical Engineering, $33,248-254$.

Feinsod, F.M., Moore, M., \& Levenson, S.A. (1997). Eliminating full-length bed side rails from long-term care facilities. Nursing Home Medicine, 5(8), 257-263.

French, D.D., Campbell, R., Spehar, A., \& Angaran, D.M. (2004). Benzodiazepines and injury: A risk adjusted model. Pharmacoepidemiology and Drug Safety.

Gaebler, S. (1993). Predicting which patient will fall again....and again. Journal of Advanced Nursing, 18, 1895-1902.

Gurwitz, J.H., Sanchez-Cross, M.T., Eckler, M.A., \& Matulis, J. (1994). The epidemiology of adverse and unexpected events in the long-term care setting. The Journal of the American Geriatrics Society, 42, 33-38.

Hanger, H.C., Ball, M.C., \&Wood, L.A. (1999). An analysis of falls in the hospital: Can we do without bedrails? The Journal of the American Geriatrics Society, $47,539-531$. 
Hoffman, S.B., Powell-Cope, G., MacClellan, L., \& Bero, K. (2003). BEDSAFE: A bed safety project for frail older adults. Journal of Gerontological Nursing, vol, 34-42.

Hospital Bed Safety Workgroup. (2000, October). A guide to bed safety. Retrieved July 9,2004, from http: //www.fda.gov/cdrh/beds/

Innes, E.M., \& Turman, W.G. (1983). Evaluation of patient falls. QRB, vol, 30-35.

Janken, J.K., Reynolds, B.A., Swiech, K. (1988). Patient falls in the acute care setting: Identifying risk factors. Nursing Research, 35(4), 216-219.

Joint Commission on Accreditation of Healthcare Organizations. (2002, September 6). Sentinel Event Alert. Retrieved May 14, 2004, from http://www.jcaho.org/ about+us/news+letters/sentinel+event+alert/print/sea_27.htm

Lyons, T.J., \& Oates, R.K. (1993). Falling out of bed: A relatively benign occurrence. Pediatrics, 92, 125-127.

Macgregor, D.M. (2000). Injuries associated with falls from beds. Injury Prevention, 6, 291-292.

Mendelson, W.B. (1996). The use of sedative/hypnotic medication and its correlation with falling down in the hospital. Sleep, 19(9), 698-701.

Mertz, H. (1994). Anthropomorphic test devices. In Backaitis, S.H.\& Mertz, H. (Eds.), Hybrid III: The first human-like crash test dummy (pp387-405). Warrendale, PA: Society of Automotive Engineers, Inc.

Nahum, A.M., Gatts, J.D., Gadd, C.W., \& Danforth, J.P. (1968). Impact tolerance of the skull and face, Proceedings of the $12^{\text {th }}$ STAPP Conference, SAE 680785.

National Center for Injury Prevention and Control. (n.d.). Falls and hip fractures among older adults. Retrieved April 13, 2004, from http://www.cdc.gov/ncipc/factsheets/falls.htm

Nevitt, M.C., Cummings, S.R., \& Study of Osteoporotic Fractures Research Group. (1993). Type of fall and risk of hip and wrist fractures: The study of osteoporotic fractures. The Journal of the American Geriatrics Society, 41, 1226-1234.

Nordin, M. \& Frankel, V.H. (2001). Basic Biomechanics of the Musculoskeletal System $\left(3^{\text {rd }}\right.$ ed.). New York: Lippincott Williams \& Wilkins. 
O’Loughlin, J.L., Robitaille, Y., Boivin, J., \& Suissa, S. (1993). Incidence of and risk factors for falls and injurious falls among the community-dwelling elderly. American Journal of Epidemiology, 137, 342-354.

Parker, K., \& Miles, S.H. (1997). Deaths caused by bedrails. The Journal of the American Geriatrics Society, 45, 797-802.

Santora, T.A., Schinco, M.A, \& Trooskin, S.Z. (1994). Management of trauma in the elderly patient. Surgical Clinics of North America, 74, 163-186.

Sattin R.W. et al. (1990). The incidence of fall injury events among the elderly in a defined population. American Journal of Epidemiology, 131(6), 1028-1037.

Schneider, D.C., \& Nahum, A.M. (1972). Impact studies of facial bones and skull, Proceedings of the $16^{\text {th }}$ STAPP Conference, SAE 720965.

Si M., Neufeld, R.R., \& Dunbar, J. (1999). Removal of bedrails on a short-term nursing home rehabilitation unit. The Gerontologist, 39(5), 611-614.

Simpson, A.H.R.W., Lamb, S., Roberts, P.J., Gardner, T.N., \& Grimley Evans, J. (2004). Does the type of flooring affect the risk of hip fracture? Age and Ageing, 33, 242-246.

Sterling, D.A., O’Connor, J.A., and Bonadies, J. (2001). Geriatric falls: Injury severity is high and disproportionate to mechanism. The Journal of TRAUMA ${ }^{\circledR}$ Injury, Infection, and Critical Care, 50, 116-119.

Tinetti, M.E., Speechley, M., Ginter, S.F. 1988. Risk factors for falls among elderly persons living in the community. New England Journal of Medicine, 319, 1701-1707.

Todd, J.F., Ruhl, C., \& Gross, T.P. (1997). Injury and death associated with hospital bedside-rails: Reports to the US Food and Drug Administration from 1985 to 1995. The American Journal of Public Health, 87 (10), 1675-1677.

Trauma.Org (n.d.). Abbreviated injury scale. Retrieved November 29, 2004 from http://www.trauma.org/scores/ais.html

U.S. Food and Drug Administration. ( 1995, August 23). FDA Safety alert:

Entrapment hazards with hospital bed side rails. Retrieved July 9, 2004, from http://www.fda.gov/cdrh/bedrails.html

Versace, J. (1972). A review of the severity index, Proceedings of the $15^{\text {th }}$ Stapp Car Crash Conference, SAE 710881, Society of Automotive Engineers. 771-796. 
Walshe, A. \& Rosen, H. (1979). A study of patient falls from bed. Journal of Nusing Adminstration. 
Appendices 


\section{Appendix A: MatLab Code}

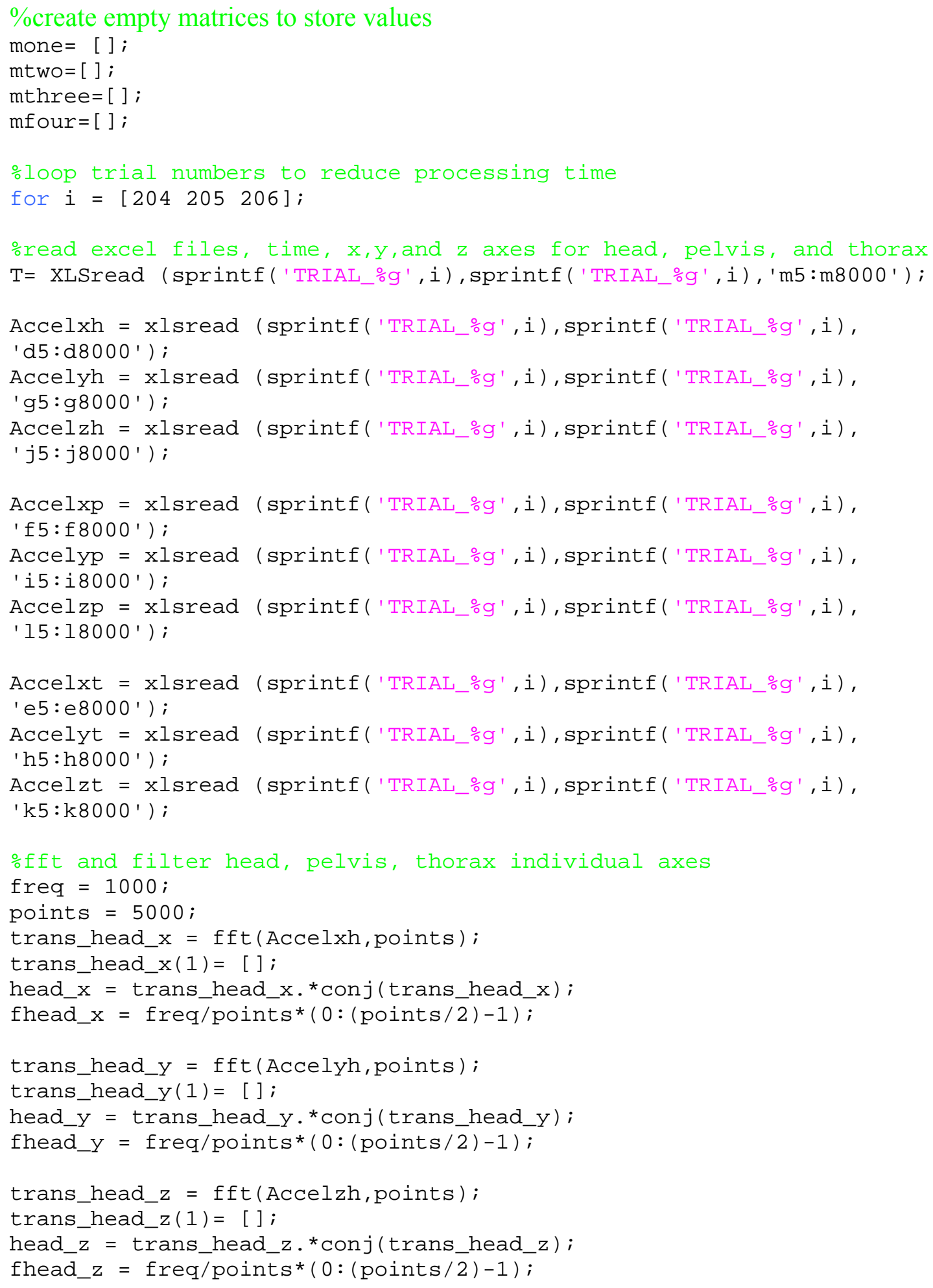




\section{Appendix A: Continued}

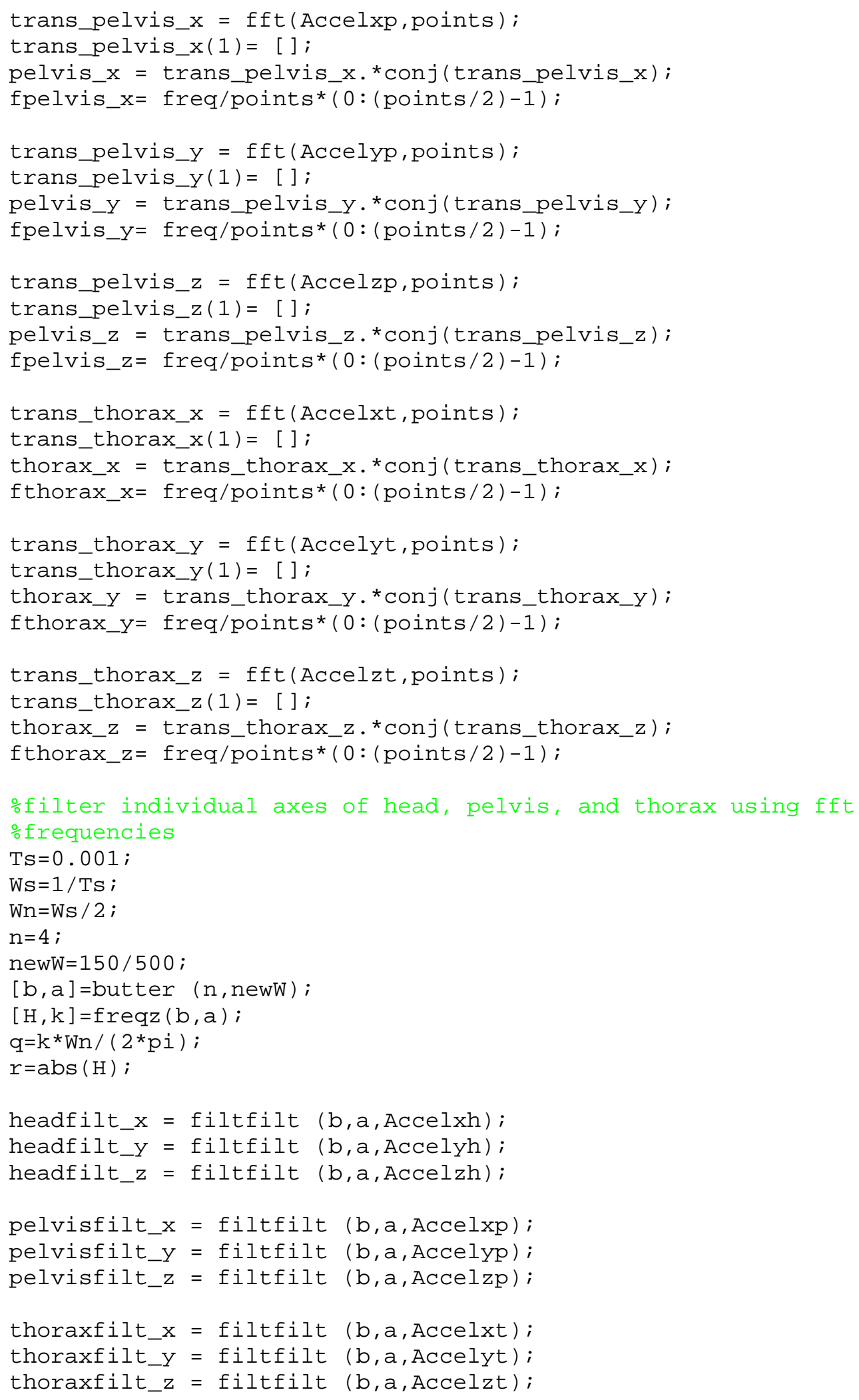




\section{Appendix A: Continued}

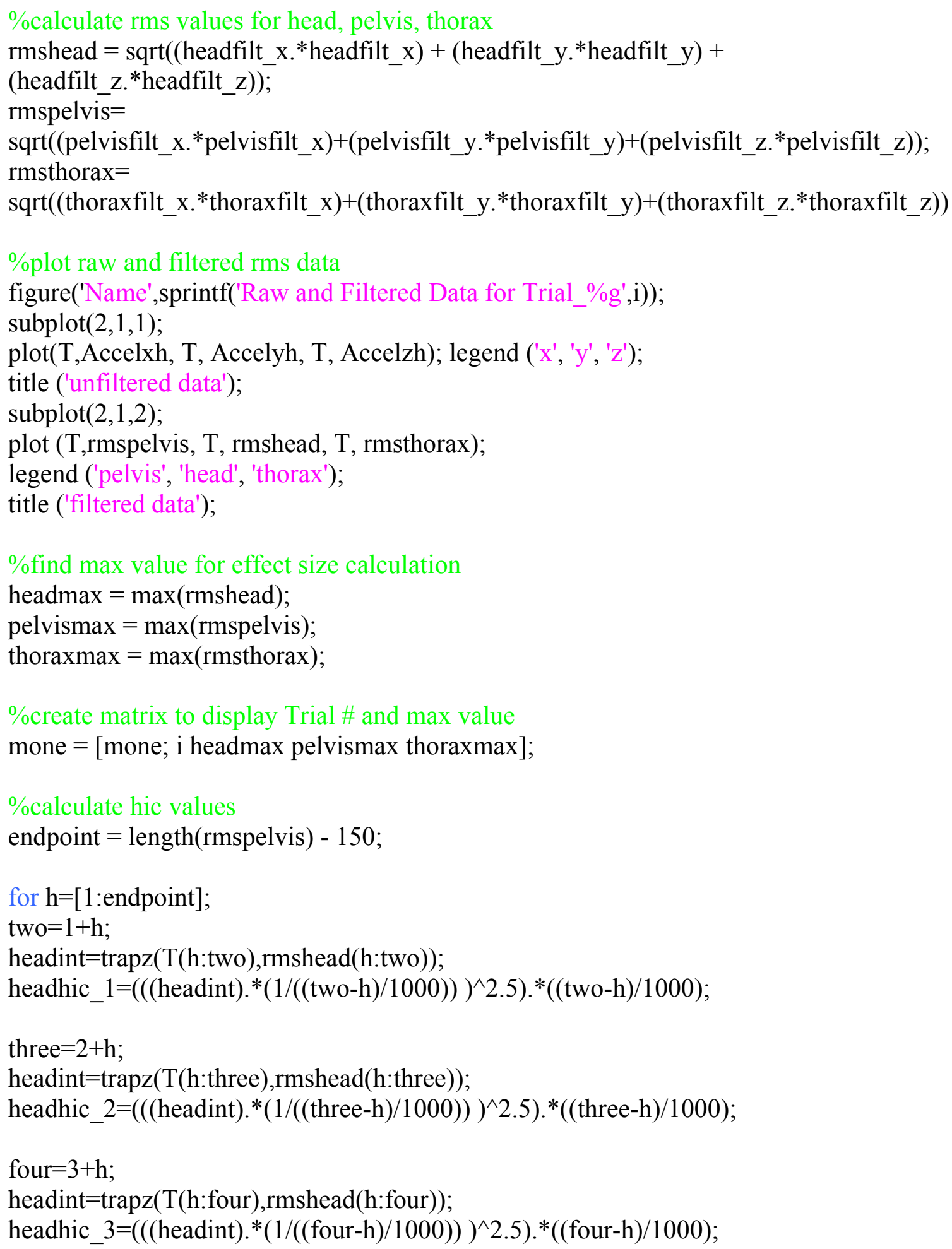




\section{Appendix A: Continued}

five $=4+h$;

headint $=\operatorname{trapz}(\mathrm{T}$ (h:five), $\operatorname{rmshead}(\mathrm{h}:$ five $)$ );

headhic_4=(((headint).*(1/((five-h)/1000)) $\left.)^{\wedge} 2.5\right) *(($ five-h $) / 1000)$;

$\operatorname{six}=5+h$;

headint $=\operatorname{trapz}(\mathrm{T}(\mathrm{h}: \mathrm{six}), \mathrm{rmshead}(\mathrm{h}: \mathrm{six}))$;

headhic_5=(((headint).*(1/((six-h)/1000)) $\left.)^{\wedge} 2.5\right) . *(($ six-h $) / 1000)$;

seven $=6+h$;

headint $=\operatorname{trapz}(\mathrm{T}(\mathrm{h}:$ seven $), \mathrm{rmshead}(\mathrm{h}:$ seven $))$;

headhic_6=(((headint).* $(1 /(($ seven-h $\left.) / 1000)))^{\wedge} 2.5\right) . *(($ seven-h $) / 1000)$;

eight $=7+h$;

headint $=\operatorname{trapz}(\mathrm{T}(\mathrm{h}$ :eight $), \operatorname{rmshead}(\mathrm{h}$ :eight $))$;

headhic_ $7=((($ headint $) . *(1 /(($ eight-h $) / 1000))) \wedge 2.5) . *(($ eight-h $) / 1000)$;

nine $=8+\mathrm{h}$;

headint $=\operatorname{trapz}(\mathrm{T}(\mathrm{h}:$ nine $), \operatorname{rmshead}(\mathrm{h}:$ nine $))$;

headhic_8 $\left.=(((\text { headint }) . *(1 /((\text { nine-h }) / 1000))))^{\wedge} 2.5\right) . *(($ nine-h $) / 1000)$;

ten $=9+h$;

headint $=\operatorname{trapz}(\mathrm{T}(\mathrm{h}:$ ten $), \operatorname{rmshead}(\mathrm{h}:$ ten $))$;

headhic_9 $\left.=(((\text { headint }) . *(1 /((\text { ten-h }) / 1000))))^{\wedge} 2.5\right) . *(($ ten-h $) / 1000)$;

eleven $=10+\mathrm{h}$;

headint $=\operatorname{trapz}(\mathrm{T}(\mathrm{h}:$ eleven $), \operatorname{rmshead}(\mathrm{h}:$ eleven $))$;

headhic_10=(((headint).* $(1 /(($ eleven-h $\left.) / 1000))))^{\wedge} 2.5\right) . *(($ eleven-h $) / 1000)$;

twelve $=11+\mathrm{h}$;

headint $=\operatorname{trapz}(\mathrm{T}(\mathrm{h}:$ twelve $), \mathrm{rmshead}(\mathrm{h}:$ twelve $))$;

headhic_11=(((headint).* $(1 /(($ twelve-h $\left.) / 1000))))^{\wedge} .5\right) *(($ twelve-h $) / 1000)$;

thirteen $=12+\mathrm{h}$;

headint $=\operatorname{trapz}(\mathrm{T}(\mathrm{h}:$ thirteen $), \mathrm{rmshead}(\mathrm{h}:$ thirteen $))$;

headhic_12=(((headint).*(1/((thirteen-h)/1000) $\left.))^{\wedge} 2.5\right) . *(($ thirteen-h $) / 1000)$;

fourteen $=13+\mathrm{h}$;

headint=trapz $(\mathrm{T}(\mathrm{h}$ :fourteen $), \operatorname{rmshead}(\mathrm{h}:$ fourteen $))$;

headhic_13=(((headint).* $(1 /(($ fourteen-h $\left.) / 1000))))^{\wedge} 2.5\right) . *(($ fourteen-h $) / 1000)$;

fifteen $=14+\mathrm{h}$;

headint $=\operatorname{trapz}(\mathrm{T}(\mathrm{h}:$ fifteen $), \operatorname{rmshead}(\mathrm{h}:$ fifteen $))$;

headhic_14=(((headint).*(1/((fifteen-h)/1000)) $) \wedge 2.5) *(($ fifteen-h $) / 1000)$; 


\section{Appendix A: Continued}

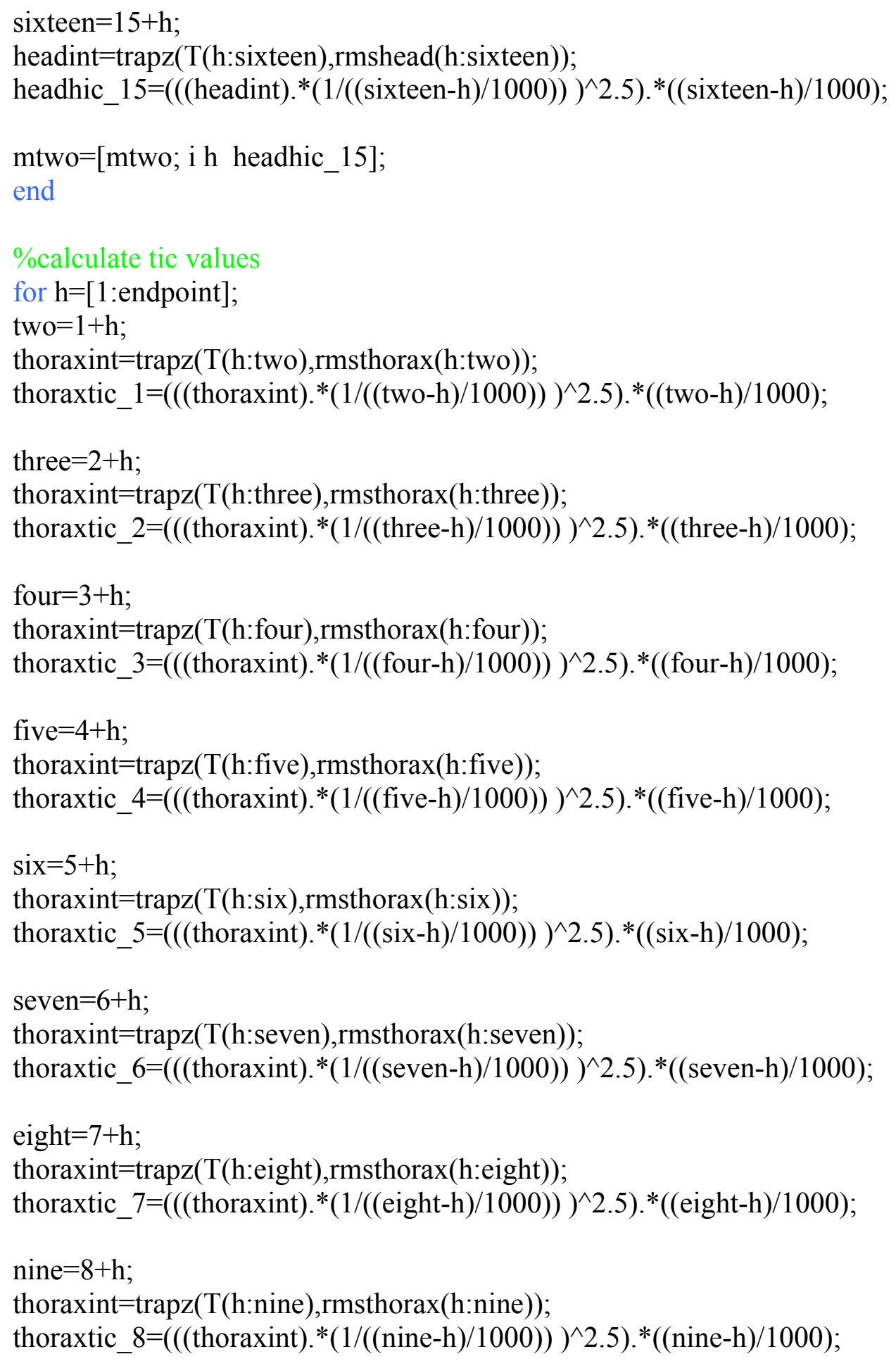




\section{Appendix A: Continued}

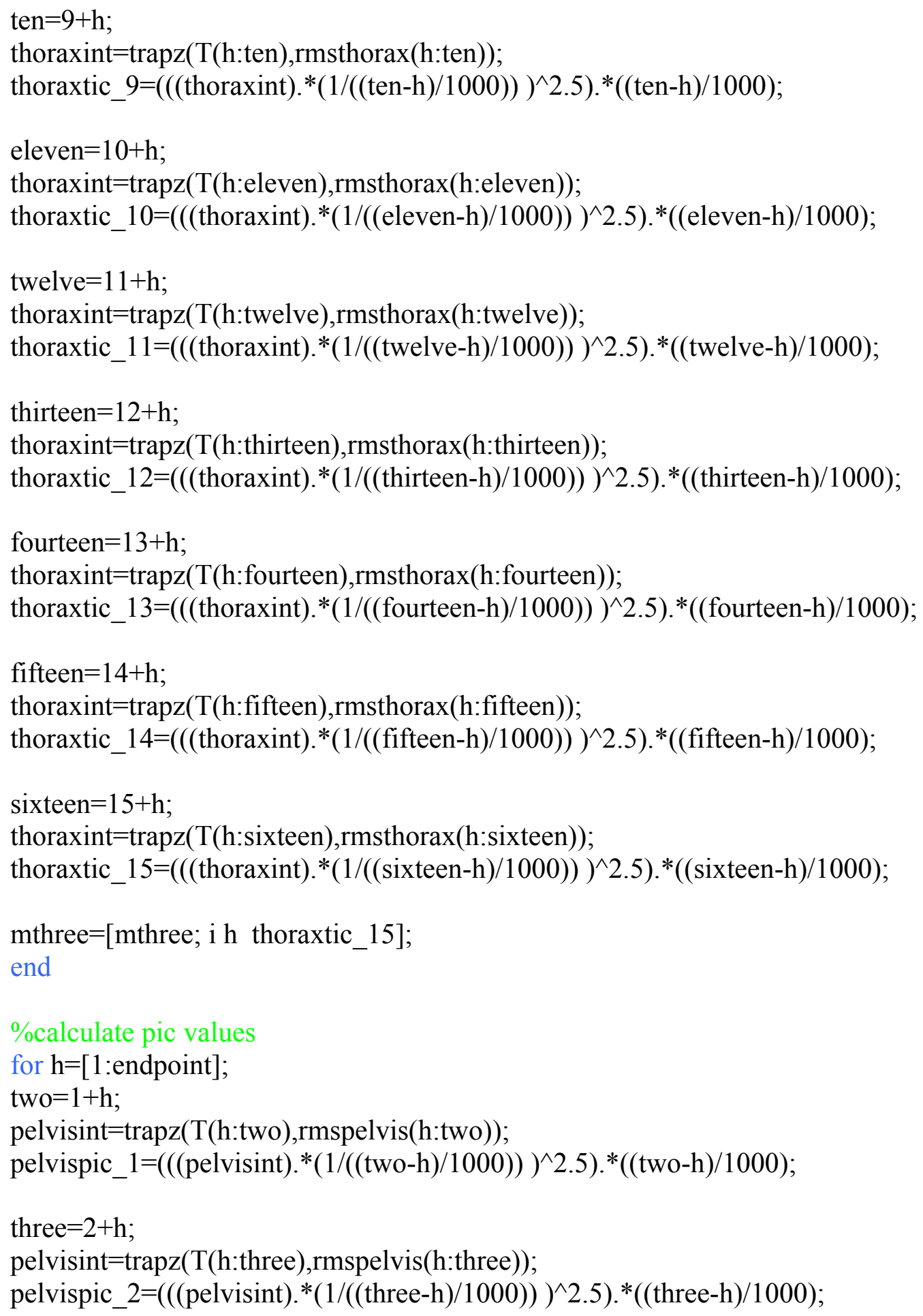




\section{Appendix A: Continued}

four $=3+h$;

pelvisint=trapz(T(h:four),rmspelvis(h:four $)$;

pelvispic_3 $\left.=(((\text { pelvisint }) . *(1 /((\text { four-h }) / 1000))))^{\wedge} 2.5\right) . *(($ four-h $) / 1000)$;

five $=4+h$;

pelvisint $=\operatorname{trapz}(\mathrm{T}(\mathrm{h}:$ five $)$, rmspelvis(h:five $)$;

pelvispic_4=(((pelvisint).*(1/((five-h)/1000)) $\left.)^{\wedge} 2.5\right) . *(($ five-h $) / 1000)$;

$\operatorname{six}=5+\mathrm{h}$

pelvisint $=\operatorname{trapz}(\mathrm{T}(\mathrm{h}: \mathrm{six}), \mathrm{rmspelvis}(\mathrm{h}: \mathrm{six}))$;

pelvispic_5 $\left.=(((\text { pelvisint }) . *(1 /((\text { six-h }) / 1000))))^{\wedge} 2.5\right) . *(($ six-h $) / 1000)$;

seven $=6+h$;

pelvisint $=\operatorname{trapz}(\mathrm{T}(\mathrm{h}$ :seven $)$, rmspelvis(h:seven $))$;

pelvispic $6=\left(((\text { pelvisint }) . *(1 /((\text { seven}-h) / 1000)))^{\wedge} 2.5\right) . *(($ seven$-h) / 1000)$;

eight $=7+\mathrm{h}$;

pelvisint $=\operatorname{trapz}(\mathrm{T}(\mathrm{h}$ :eight $)$, rmspelvis(h:eight $))$;

pelvispic $\left.7=(((\text { pelvisint }) . *(1 /((\text { eight-h }) / 1000))))^{\wedge} 2.5\right) . *(($ eight-h $) / 1000)$;

nine $=8+\mathrm{h}$;

pelvisint $=\operatorname{trapz}(\mathrm{T}(\mathrm{h}:$ nine $)$, rmspelvis(h:nine $))$;

pelvispic_8 $\left.=(((\text { pelvisint }) . *(1 /((\text { nine-h }) / 1000))))^{\wedge} 2.5\right) . *(($ nine-h $) / 1000)$;

ten $=9+\mathrm{h}$;

pelvisint $=\operatorname{trapz}(\mathrm{T}(\mathrm{h}:$ ten $)$, rmspelvis(h:ten $))$;

pelvispic_9= $\left(((\text { pelvisint }) . *(1 /((\text { ten-h }) / 1000)))^{\wedge} 2.5\right) . *(($ ten-h $) / 1000)$;

eleven $=10+\mathrm{h}$;

pelvisint $=\operatorname{trapz}(\mathrm{T}(\mathrm{h}$ :eleven $)$, rmspelvis(h:eleven $))$;

pelvispic_10= $\left(\left((\text { pelvisint }) .{ }^{*}(1 /((\text { eleven-h }) / 1000))\right)^{\wedge} 2.5\right) .{ }^{*}(($ eleven-h $) / 1000)$;

twelve $=11+\mathrm{h}$;

pelvisint $=\operatorname{trapz}(\mathrm{T}(\mathrm{h}:$ twelve $)$, rmspelvis(h:twelve $))$;

pelvispic_11=(((pelvisint).*(1/((twelve-h)/1000)) $\left.)^{\wedge} 2.5\right) . *(($ twelve-h $) / 1000)$;

thirteen $=12+\mathrm{h}$;

pelvisint $=\operatorname{trapz}(\mathrm{T}(\mathrm{h}:$ thirteen $)$, rmspelvis(h:thirteen $))$;

pelvispic_12=(((pelvisint $). *(1 /(($ thirteen-h $\left.) / 1000)))^{\wedge} 2.5\right) .{ }^{*}(($ thirteen-h $) / 1000)$;

fourteen $=13+\mathrm{h}$;

pelvisint $=\operatorname{trapz}(\mathrm{T}(\mathrm{h}$ :fourteen $), \mathrm{rmspelvis}(\mathrm{h}:$ fourteen $))$;

pelvispic_13 $\left.=(((\text { pelvisint }) . *(1 /((\text { fourteen-h }) / 1000))))^{\wedge} 2.5\right) . *(($ fourteen $-h) / 1000)$; 


\section{Appendix A: Continued}

fifteen $=14+\mathrm{h}$;

pelvisint $=\operatorname{trapz}(\mathrm{T}(\mathrm{h}:$ fifteen $), \mathrm{rmspelvis}(\mathrm{h}:$ fifteen $))$;

pelvispic_14=(((pelvisint).* $(1 /(($ fifteen-h $\left.) / 1000)))^{\wedge} 2.5\right){ }^{*}(($ fifteen-h $) / 1000)$;

sixteen $=15+h$;

pelvisint $=\operatorname{trapz}(\mathrm{T}(\mathrm{h}:$ sixteen $)$, rmspelvis(h:sixteen $))$;

pelvispic_15 $\left.=(((\text { pelvisint }) . *(1 /((\text { sixteen }-\mathrm{h}) / 1000))))^{\wedge} 2.5\right) . *(($ sixteen-h $) / 1000)$;

mfour $=[$ mfour; i h pelvispic_15];

end

end

csvwrite ('maxvalue.csv',mone);

csvwrite ('hicvalue.csv',mtwo);

csvwrite('ticvalue.csv',mthree);

csvwrite('picvalue.csv',mfour); 


\section{Appendix B: Protocol}

1. Turn on computer

2. Open LabView VI: "FP + Load Cells"

a. Set max cutoff frequency to $500 \mathrm{~Hz}$

b. Set min cutoff frequency to $1 \mathrm{~Hz}$

c. Set sample frequency to $1000 \mathrm{~Hz}$

d. Set filter to None

3. Turn on SCUXI

4. Turn power to on position for accelerometer power supply $1,2,3$

5. Connect each cable to correct position on project box for accelerometer 1,2,3

a. Head accelerometer-Accelerometer 1 (SN 35568)

b. Thorax accelerometer-Accelerometer 2 (SN 37400)

c. Pelvis accelerometer-Accelerometer 3 (SN 37401)

6. Position bed to correct height (measured in $\mathrm{cm}$ from mattress top with no ATD on surface)

7. Lock bed brakes

8. Position sling on bed according to marks indicated on mattress for feet or head first drop

9. Position ATD on the sling according to marks indicated for feet or head first drop

10. Position video camera to view impact surface

11. Record Trial number with video camera

12. Raise sling using ceiling lift and coordinate data acquisition with height of sling relative to the bed height.

13. Export impact event to file

14. Repeat steps 8-13 until all trials are complete, stopping periodically to detangle accelerometer cables 
libname look 'e:';run;

\section{Appendix C: SAS ${ }^{\circledR}$ Code}

$* * * * * * * * * * * * * * * * * * * * * * * * * * * * * * * * * * * * * * * * * * * * * * * * * * * * * * * * * * * * * * * * * * * * * *$

Head first analysis

*******************************************************************;

proc glm data = headfirst_max;

class height mat;

model head = height mat height*mat;

title 'Fixed ANOVA for Head First Head Acceleration';

run;

proc glm data $=$ headfirst_max;

class height mat;

model pelvis = height mat;

title 'Fixed ANOVA for Head First Pelvis Acceleration';

run;

proc glm data $=$ headfirst_max;

class height mat;

model thorax = height mat;

title 'Fixed ANOVA for Head First Thorax Acceleration';

run;

$* * * * * * * * * * * * * * * * * * * * * * * * * * * * * * * * * * * * * * * * * * * * * * * * * * * * * * * * * * * * * * * * * * * * * *$

Feet first analysis

********************************************************************;

data feetfirst_max2;

set feetfirst_max;

if height $=\overline{3} 3.5$ then h $2=1$;

else if height $=48$ then $\mathrm{h} \_2=2$;

else if height $=62.5$ then $h \_2=3$;

else $\mathrm{h} \_2=$;

if head $=$. then delete;

run;

proc glm data $=$ feetfirst_max 2 ;

class h_2 mat;

model head $=$ h_2 mat;

title 'Fixed ANOVA for Feet First Head Acceleration';

run;

proc glm data = feetfirst_max;

class height mat;

model pelvis = height mat;

title 'Fixed ANOVA for Feet First Pelvis Acceleration';

run; 


\section{Appendix C: Continued}

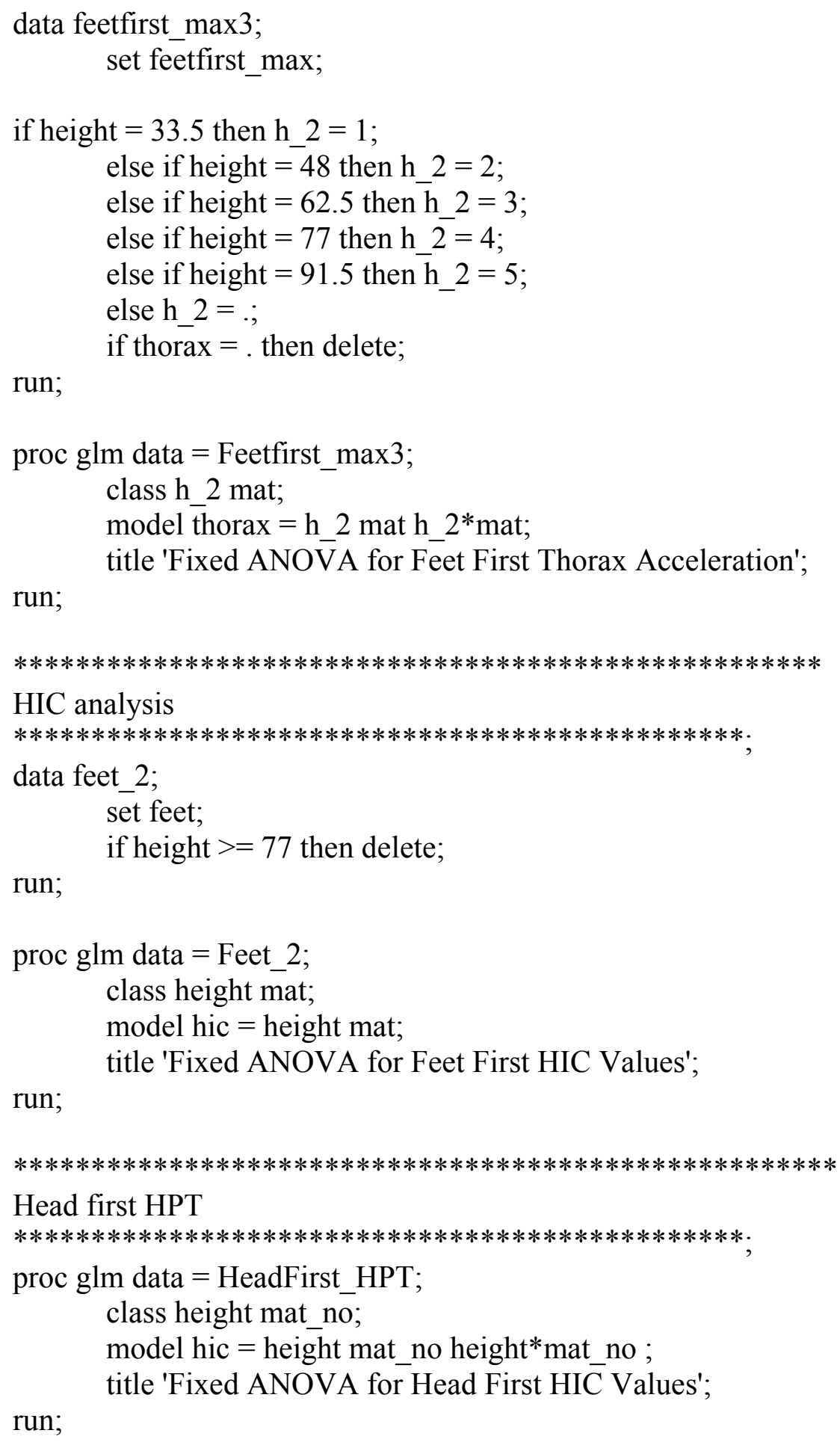




\section{Appendix C: Continued}

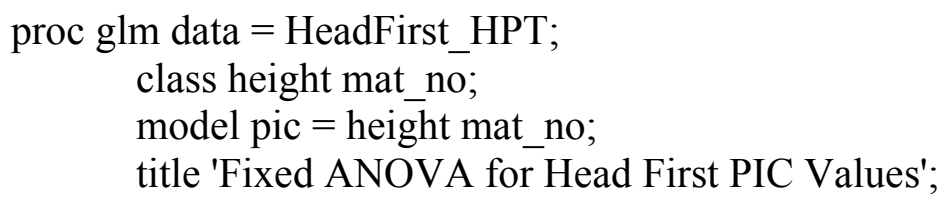

